\title{
The potential importance of frost flowers, recycling on snow, and open leads for ozone depletion events
}

\author{
M. Piot ${ }^{1}$ and R. von Glasow ${ }^{1,2}$ \\ ${ }^{1}$ Institute of Environmental Physics, University of Heidelberg, Germany \\ ${ }^{2}$ now at: School of Environmental Sciences, University of East Anglia, Norwich, UK
}

Received: 5 March 2007 - Published in Atmos. Chem. Phys. Discuss.: 2 April 2007

Revised: 29 January 2008 - Accepted: 18 April 2008 - Published: 7 May 2008

\begin{abstract}
.
We present model studies with the one-dimensional model MISTRA to investigate the potential role of frost flowers, recycling on snow, and open leads in the depletion of tropospheric ozone in the Arctic spring. In our model, we assumed frost flower aerosols to be the major source of bromine. We show that a major ozone depletion event can be satisfactorily reproduced only if the recycling on snow of deposited bromine into gas phase bromine is assumed. In the model, this cycling is more efficient than the bromine explosion process and maintains sufficiently high levels of bromine to deplete ozone down to few nmol mol ${ }^{-1}$ within four days. We assessed the influence of different surface combinations (open lead/frost flowers) on the chemistry in the model. Results showed noticeable modifications affecting the composition of aerosols and the deposition velocities. A model run with a series of coupled frost flower fields and open leads, separated by large areas of snow, showed results comparable with field observations. In addition, we studied the effects of modified temperature of either the frost flower field or the ambient airmass. A warmer frost flower field increases the relative humidity and the aerosol deposition rate. The deposition/re-emission process gains in importance, inducing more reactive bromine in the gas phase, and a stronger ozone depletion. A decrease of $1 \mathrm{~K}$ in airmass temperature shows in our model that the aerosol uptake capacities of all gas phase species substantially increases, leading to enhanced uptake of acids from the gas phase. Consequently, the so-called bromine explosion accelerated and $\mathrm{O}_{3}$ mixing ratios decreased. In our model representation, variations in wind speed affected the aerosol source function and influenced the amount of bromine in the atmosphere and thus the ozone depletion strength. Recent studies have suggested
\end{abstract}

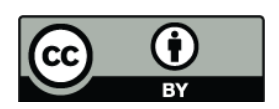

Correspondence to: M. Piot (matthias.piot@iup.uni-heidelberg.de) the important role of the precipitation of calcium carbonate $\left(\mathrm{CaCO}_{3}\right)$ out of the brine layer for the possible acidification of the liquid phase by acid uptake. Our investigation showed that this precipitation is a crucial process for the timing of the bromine explosion in aerosols. Nevertheless, model runs with either $50 \%$ precipitation or complete precipitation displayed a relatively weak difference in ozone mixing ratios after four simulated days. By considering conditions typical for "Arctic Haze" pollution events at the start of the run we obtained a low $\mathrm{pH}$ in frost flower aerosols due to a greater mixing ratio of $\mathrm{SO}_{2}$, and a strong recycling efficiency via large aerosol number concentration. The aerosol acidification during a haze event most likely intensifies the ozone depletion strength and occurrence. The comparison between our modeled deposition on snow and sampled snow at Barrow (Alaska) shows that approximately $75 \%$ of deposited bromine may be re-emitted into the gas phase as $\mathrm{Br}_{2} / \mathrm{BrCl}$. Among several non-halogen fluxes from the snow, model simulations showed that only HONO affects the chemistry. Finally, we investigated the release of $\mathrm{Br}_{2}$ potentially produced by heterogeneous reactions directly on frost flowers. In this case, we obtained unrealistic results of aerosol compositions and deposition rates on snow compared to observations in the Arctic.

\section{Introduction}

In the mid 1980s, events with extremely low ozone concentrations in the troposphere have been observed at several sites in the Arctic. It was first observed at Barrow, Alaska (Oltmans, 1981; Oltmans and Komhyr, 1986), later at Alert, Canada (Bottenheim et al., 1986; Barrie et al., 1988; Mickle et al., 1989) and at other stations in the Arctic (Thule, Greenland; Ny-Ålesund, Spitsbergen). Similar observations were also reported in the Antarctic (Kreher et al., 1997; Roscoe et al., 2001; Tarasick and Bottenheim,

Published by Copernicus Publications on behalf of the European Geosciences Union. 
2002). However, a reanalysis of surface ozone measurements undertaken during the International Geophysical Year (IGY) (MacDowall, 1960) in 1957-1958 at Halley Bay, Antarctic, showed the presence of periodic ozone depletions already then (Roscoe and Roscoe, 2006). According to current knowledge, these so-called Ozone Depletion Events (ODEs) occur regularly in polar boundary layers (PBL) in spring, both in the Arctic and Antarctic. The near-total depletions of ozone last several hours to several days. This might impact the global tropospheric ozone budget (Hollwedel, 2005; Simpson et al., 2007b). The absence of ODEs in summer or fall might be linked to seasonal changes affecting the boundary layer stability (see Lehrer et al., 2004).

Measurements made by Barrie et al. $(1988,1989)$ and Bottenheim et al. (1990) suggested that tropospheric ozone depletions might be related to $\mathrm{Br}$ atom chain reactions. Their collections of aerosol samples by cellulose filters have highlighted a striking correlation between high concentrations of filterable bromine and a corresponding ozone destruction (see also Lehrer et al., 1997; Langendörfer et al., 1999). Subsequently $\mathrm{BrO}$ has been measured by Hausmann and Platt (1994) by the use of long-path Differential Optical Absorption (DOAS) instruments. Lehrer et al. (1997) showed a clear positive correlation between filterable bromine in aerosols and $\mathrm{BrO}$. More recently, measurements of column $\mathrm{BrO}$ from the GOME satellite instrument showed that significant concentrations were observable over large scale areas in Arctic spring (Wagner and Platt, 1998; Richter et al., 1998; Wagner et al., 2001; Hollwedel et al., 2004). Later on, substantial molecular halogen concentrations of $\mathrm{Br}_{2}$ and $\mathrm{BrCl}$ were measured at Alert, Canada (Foster et al., 2001; Spicer et al., 2002). They varied from values close to the detection limit $(\sim 0.2 \mathrm{ppt})$ to $30-35 \mathrm{ppt}$ in a range of hours during periods of ODEs, while $\mathrm{Cl}_{2}$ was not observed above its detection limit of about 2 ppt.

It is now widely accepted that the bromine catalytic reaction cycles in the gas phase are responsible for the ozone destruction via three main cycles. Under high $\mathrm{BrO}$ concentrations, the self reaction of $\mathrm{BrO}$ is dominant:

Cycle I:

$$
\begin{aligned}
2\left(\mathrm{O}_{3}+\mathrm{Br}\right. & \left.\longrightarrow \mathrm{BrO}+\mathrm{O}_{2}\right) \\
\mathrm{BrO}+\mathrm{BrO} & \longrightarrow 2 \mathrm{Br}+\mathrm{O}_{2} \\
& \longrightarrow \mathrm{Br}_{2}+\mathrm{O}_{2} \\
\mathrm{Br}_{2} & \stackrel{h v}{\longrightarrow} 2 \mathrm{Br}
\end{aligned}
$$

Net: $2 \mathrm{O}_{3} \longrightarrow 3 \mathrm{O}_{2}$

If enough chlorine is present, the interhalogen reaction between $\mathrm{BrO}$ and $\mathrm{ClO}$ might become a relevant pathway for recycling the halogen oxides (Le Bras and Platt, 1995).
Cycle II:

$$
\begin{aligned}
\mathrm{BrO}+\mathrm{ClO} & \longrightarrow \mathrm{Br}+\mathrm{Cl}+\mathrm{O}_{2} \\
& \longrightarrow \mathrm{BrCl}+\mathrm{O}_{2} \\
& \longrightarrow \mathrm{Br}+\mathrm{OClO}
\end{aligned}
$$

Net: $2 \mathrm{O}_{3} \longrightarrow 3 \mathrm{O}_{2}$

At smaller $\mathrm{BrO}$ levels, its reaction with $\mathrm{HO}_{2}$ becomes relatively important:

Cycle III:

$$
\begin{gathered}
\mathrm{BrO}+\mathrm{HO}_{2} \longrightarrow \mathrm{HOBr}+\mathrm{O}_{2} \\
\mathrm{HOBr} \stackrel{h v}{\longrightarrow} \mathrm{OH}+\mathrm{Br} \\
\mathrm{CO}+\mathrm{OH} \stackrel{\mathrm{O}_{2}}{\longrightarrow} \mathrm{HO}_{2}+\mathrm{CO}_{2}
\end{gathered}
$$

Net: $\mathrm{O}_{3}+\mathrm{CO} \longrightarrow \mathrm{O}_{2}+\mathrm{CO}_{2}$

In order to release and sustain a significant amount of halogens in the gas phase, additional mechanisms involving the liquid and solid phases (aerosols, quasi-liquid layers (QLL) on snow, ice crystals/snow), activating halides, and recycling non-reactive gas phase halogens are necessary. In the early 1990s Fan and Jacob (1992) and McConnell et al. (1992) suggested the following important heterogeneous reaction path $(\mathrm{X}=\mathrm{Br}, \mathrm{Cl})$ for the liberation of $\mathrm{Br}_{2}$ and $\mathrm{BrCl}$ from sea salt (based on data from Eigen and Kustin, 1962), involving $\mathrm{HOBr}$ found in reaction (10):

$$
\mathrm{HOBr}_{\mathrm{aq}}+\mathrm{X}_{\text {sea salt }}^{-}+\mathrm{H}^{+} \longrightarrow \mathrm{BrX}_{\mathrm{aq}}+\mathrm{H}_{2} \mathrm{O}
$$

The activation of $\mathrm{Br}_{2}$ compared to $\mathrm{BrCl}$ has been studied in detail by Fickert et al. (1999). $\mathrm{H}^{+}$ions may be supplied by strong acids, such as $\mathrm{HNO}_{3}$ and $\mathrm{H}_{2} \mathrm{SO}_{4}$ mostly originating from man-made emissions (see also Mozurkewich, 1995; Tang and McConnell, 1996; Vogt et al., 1996). The release of two bromine atoms out of the liquid phase from one gaseous $\mathrm{Br}(\mathrm{X}=\mathrm{Br}$ in $\mathrm{Eq} .14)$ atom is called "Bromine explosion" (Platt and Lehrer, 1996). Later, these reaction cycles were studied in detail by numerical models (Sander et al., 1997; Michalowski et al., 2000; Evans et al., 2003; Lehrer et al., 2004).

With sufficient $\mathrm{NO}_{\mathrm{x}}$ levels, the formation of halogen nitrates can substantially modify the availability of reactive bromine:

$$
\begin{aligned}
\mathrm{XO}+\mathrm{NO}_{2} & \stackrel{M}{\longrightarrow} \mathrm{XONO}_{2} \\
\mathrm{X}+\mathrm{NO}_{2} & \longrightarrow \mathrm{XNO}_{2}
\end{aligned}
$$

After its formation, $\mathrm{XONO}_{2}$ can either photolyse, decompose back to $\mathrm{XO}$ and $\mathrm{NO}_{2}$, or hydrolyse in water surfaces via:

$$
\mathrm{XONO}_{2} \stackrel{\mathrm{H}_{2} \mathrm{O}}{\longrightarrow} \mathrm{HOX}+\mathrm{HNO}_{3}
$$


Also, Sander et al. (1999) suggested that $\mathrm{XONO}_{2}$ can heterogeneously react on the surface of aerosols without the need for acidity to convert halides into photolysable compounds:

$\mathrm{XONO}_{2}+\mathrm{X}_{\mathrm{aq}}^{-} \longrightarrow \mathrm{X}_{2, \mathrm{aq}}+\mathrm{NO}_{3, \mathrm{aq}}^{-} \longrightarrow \mathrm{X}_{2}$

$\mathrm{XONO}_{2}+\mathrm{Y}_{\mathrm{aq}}^{-} \longrightarrow \mathrm{XY}_{\mathrm{aq}}+\mathrm{NO}_{3, \mathrm{aq}}^{-} \longrightarrow \mathrm{XY}$

but the reaction rate of these activation pathways remains small (about 100 times less efficient than Reaction (14) under Arctic conditions).

These heterogeneous reactions activating bromide ions $\left(\mathrm{Br}^{-}\right)$are needed to sustain the autocatalytic destruction of ozone. Indeed, both laboratory and modeling studies showed that observations can only be explained if both gas phase and heterogeneous reactions are taken into account (McConnell et al., 1992; Sander et al., 1997; Kirchner et al., 1997; Fickert et al., 1999; Michalowski et al., 2000). However, it can be easily demonstrated that sea salt aerosols are a minor contributor to gas phase bromine (see Sander et al., 1997; Michalowski et al., 2000; Lehrer et al., 2004).

The dominant source for bromine remains a matter of debate. Several sources for bromine were suggested in the literature. The presence of high concentrations of biological bromoform in April (spring bloom) was proposed to be linked to the destruction of ozone (Barrie et al., 1988; Sturges et al., 1992). But the $\mathrm{CHBr}_{3}$ mixing ratio is too small and its photodissociation is too slow $\left(\mathrm{J}_{\mathrm{CHBr}_{3}} \sim 10^{-6} \mathrm{~s}^{-1}\right.$, Moortgat et al., 1993). Growing evidence from observations highlighted the importance of the snowpack and models satisfactorily underlined its role for the heterogeneous halogen chemistry (Tang and McConnell, 1996; Michalowski et al., 2000; Lehrer et al., 2004), but the geographical occurrence of ODEs cannot be fully explained with the simple presence of snow and aerosols. Studies on first-year sea ice highlighted its potential importance in providing adequate halogen-enriched surfaces with a likely role of frost flowers (FF) as they are promising candidates for supplying bromine compounds into the air. Comparisons between model calculations and measurements made by Frieß et al. (2004) showed good agreement between enhanced levels of $\mathrm{BrO}$ and air that may have been in contact with sea salt surfaces. Also, the study from Kaleschke et al. (2004) using backtrajectories associated with a thermodynamic model to simulate areas potentially covered by frost flowers (PFF) revealed a strong correlation between PFF-impacted air and GOME $\mathrm{BrO}$ maps. This would suggest that frost flowers could be implicated in the generation of $\mathrm{BrO}$ (also see Jacobi et al., 2006). However, very recently, Simpson et al. (2007a) measured that high levels of $\mathrm{BrO}$ were more correlated to firstyear sea ice than to PFF.

Rankin et al. (2000) calculated that frost flower aerosol production in a sea-ice zone dominates the sea salt aerosol production, which originates from the bubble bursting mechanism (e.g. Pruppacher and Klett, 1997). In a further study, they mentioned a large FF total surface area which enhances exchange and heterogeneous chemical reactions with the ambient air (Rankin et al., 2002). In contrast, Dominé et al. (2005) showed by use of a volumetric method and $\mathrm{CH}_{4}$ adsorption (see Legagneux et al., 2002) that FFs are unlikely to provide additional surface area relative to the ice surface. Thus, the uncertainties regarding the role of FFs remain large.

Frost flowers consist of multiple crystal needles and naturally grow on freshly-formed (sea) ice under very cold and calm weather conditions by addition of water vapor from the ambient air. They start their growth in the vicinity of open cracks $(T \simeq 271 \mathrm{~K})$ over ocean or fresh water when the forming ice reaches a thickness of 5-8 mm (Martin et al., 1995). During sea ice formation, the thermodynamical upward transport of sea salt from the ice interior toward the surface, called "brine rejection", leads to the accumulation of a brine layer on top of the new sea ice (Richardson and Keller, 1966) on which frost flowers can grow (see Martin et al., 1995). This brine layer has been observed to persist at temperatures as low as the required temperature of -10 to $-20^{\circ} \mathrm{C}$ for the FF formation (Cho et al., 2002). However, ionic fractionation occurs at such temperature (Richardson and Keller, 1966). Ions contained in the brine migrate toward the crystal branches of the frost flowers through the quasi-liquid layer due to concentration gradients and probably via mechanisms similar to the thermo-migration called Ludwig-Soret effect (Kempers, 1989; Hafskjold et al., 1993; Zhang et al., 1996). FF salinities have been measured at up to $115 \mathrm{~g} / \mathrm{kg}$ in the Arctic (Perovitch and Richter-Menge, 1994; Rankin et al., 2002) compared to an average of $35 \mathrm{~g} / \mathrm{kg}$ for sea water.

There is growing evidence from field measurements that the processes related to the formation of FFs could provide adequate surfaces for the liberation of particles from the quasi-liquid layers under wind stress. Wagenbach et al. (1998) observed low concentrations of sulfate in airborne particles at Neumayer. By comparing the ratio $\left[\mathrm{SO}_{4}^{2-}\right]:\left[\mathrm{Na}^{+}\right]$ in aerosols and in sea water, they found that the aerosols originated from sea ice surfaces where mirabilite $\left(\mathrm{Na}_{2} \mathrm{SO}_{4}\right)$ had to be precipitated. Daily aerosol samples commonly showed deficits in $\mathrm{SO}_{4}^{2-}$ of about $60-80 \%$ during cold seasons. Laboratory experiments confirmed this fractionation on the ice pack and emphasized its rise with decreasing temperature (Koop et al., 2000). Similarly, Rankin et al. (2000) collected frost flowers and observed analogous depletions in sulfate and sodium relative to sea water concentrations. These results suggest that particles observed by Wagenbach et al. (1998) are likely to originate from the brine (including FF). Simpson et al. (2005) found that frost flowers provide limited enhancements in direct heterogeneous exchange compared to other Arctic surfaces. Also, they found that bromide release rather develops subsequent to production of aerosols from FFs. Similarly, Kalnajs and Avallone (2006) showed that bromide is unlikely to be released directly from FFs. These studies underline the obvious need to better understand the 


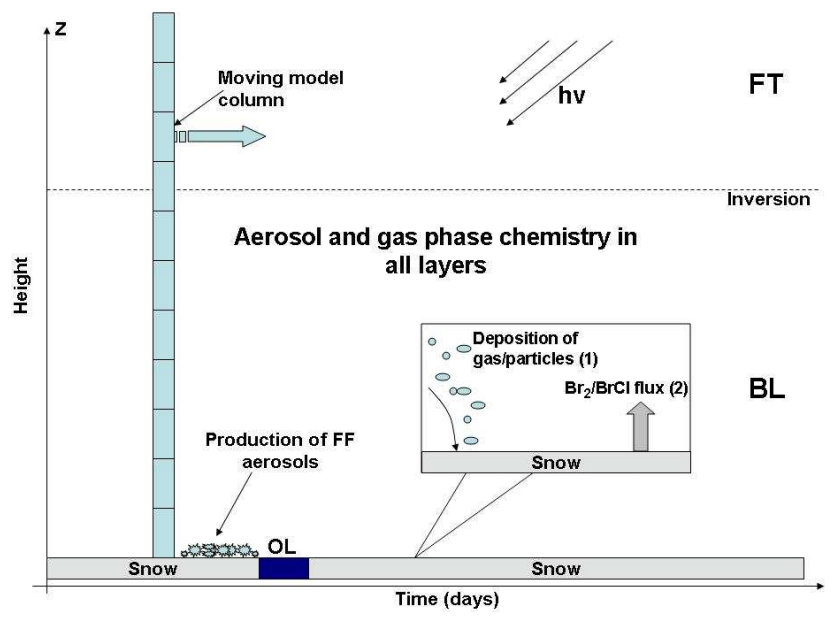

Fig. 1. Schematic depiction of the most important processes included in the 1-D Arctic version of MISTRA. The boundary layer is denoted as BL, open lead as OL, and the free troposphere as FT. Aerosol and gas phase chemistry are calculated in all layers. (1): Deposition process discussed in Sect. 3.1; (2): $\mathrm{Br}_{2} / \mathrm{BrCl}$ reemission described in Sect. 2.3.

complete mechanisms releasing such particles.

In Sect. 2 we describe the model setup and sensitivity runs. In Sect. 3 we assess the potential influence of FF aerosols by detailed model studies under different chemical and meteorological conditions. In particular, we studied the impact of different surface sequences of open lead and FF, meteorological parameters, the role of halogen recycling from snow as well as the influence of emissions that have been measured from snow. Direct heterogeneous reactions on frost flowers themselves are also discussed. A summary and some concluding remarks are given in the last section of this paper.

\section{Model description and setup}

We have used the one-dimensional model MISTRA (von Glasow et al., 2002a,b; von Glasow and Crutzen, 2004) which was initially developed as a model of the marine boundary layer (MBL) and modified it to reproduce Arctic conditions. MISTRA describes microphysical processes and focuses on the interaction of gas phase and particulate phase (sea salt and sulfate aerosol) chemistry. The chemical mechanism contains the most important reactions of $\mathrm{O}$, $\mathrm{H}, \mathrm{C}, \mathrm{N}, \mathrm{S}, \mathrm{Cl}$, and $\mathrm{Br}$ both in the gas and particulate phase, with a focus on halogen species. The initial gas phase mixing ratios $(\xi)$ are based on observational data at Arctic sites, during spring (Table 1). The gas phase chemistry mechanism has been updated from von Glasow and Crutzen (2004) and extended by reactions including alkyl nitrate $\left(\mathrm{RONO}_{2}\right)$ and biogenic alkyl bromide $\left(\mathrm{CHBr}_{3}, \mathrm{CH}_{3} \mathrm{Br}\right)$, based on the IUPAC compilation (Febtuary 2006, available from http: //www.iupac-kinetic.ch.cam.ac.uk/). The complete mech- anism consists of 169 gas phase reactions and 150 aqueous phase reactions, 60 phase exchange reactions, 13 heterogeneous reactions and 21 equilibria for both sulfate and sea salt aerosols. It is available as electronic attachment to this paper http://www.atmos-chem-phys.net/8/2437/2008/ acp-8-2437-2008-supplement.pdf.

We used MISTRA in a "Lagrangian mode" where a column of $2000 \mathrm{~m}$ height moves across a pre-defined sequence of surfaces: snow, FF, and open lead (see Fig. 1). In the remainder of this paper we only discuss the evolution of the chemistry in the lowest $1000 \mathrm{~m}$, subdivided into 100 equidistant layers. All presented model runs last 4 days which are preceded by a 2-day spin-up of the meteorology; temperature, relative humidity, particle size distribution, and inversion height are explicitly calculated. All runs start at midnight where the chemistry is initialized with the values given in Table 1. In order to calculate the photolysis frequencies we chose the site of Alert $\left(82^{\circ} \mathrm{N}\right)$ with a declination of the Sun of $+7^{\circ}$ (corresponding to the first week of April). Under these conditions, the model simulates the presence of the Sun from 03:25 to 20:35, local time. The initial boundary layer height is $300 \mathrm{~m}$ as often observed in the Arctic at this period of the year (Hopper and Hart, 1994; Hopper et al., 1998; Ridley et al., 2003).

Based on King and Turner (1997) we chose an albedo of 0.8 corresponding to a typical snow-covered area of the Arctic spring. Photolysis rates are calculated online with the model of Landgraf and Crutzen (1998).

We prescribe a fixed temperature of $245 \mathrm{~K}$ for the snow surface which is typical for the Arctic in early spring (Jobson et al., 1994; Hopper et al., 1994, 1998; Ridley et al., 2003). The resulting temperatures in the boundary layer remain above $240 \mathrm{~K}$. Koop et al. (2000) showed experimentally that sea salt aerosols stay aqueous down to about $240 \mathrm{~K}$. Therefore, we assume the aerosol particles to be liquid in all layers of our model. All particles above their deliquescence humidity $(70 \%$ and $75 \%$ of relative humidity for sulfate and sea salt aerosols, respectively) are treated as aqueous solutions. The same holds for particles that had been activated or have been released as droplets above their crystallisation humidity ( $40 \%$ and $42 \%$, respectively). For a detailed description of the aerosol characteristics, see von Glasow et al. (2002b). In a sensitivity study we investigated the importance of pollution levels (gas and aerosol particles) as observed under "Arctic Haze" conditions (Mitchell, 1957; Saw, 1984; Barrie et al., 1989). The initial size distribution of the haze particles is given in Table 2. The haze aerosol composition is based on the molar fraction from Hoff et al. (1983), calculated for a mean particle diameter of $0.22 \mu \mathrm{m}$. Gas phase mixing ratios are modified according to ground-based measurements during a haze event (Table 1). 
Table 1. Initial mixing ratios ( $\xi$ in nmol mol ${ }^{-1}$ ) for gas phase species under "background" and "Arctic Haze" conditions. Values given only when different than "background" conditions.

\begin{tabular}{|c|c|c|c|c|}
\hline Species & $\xi$ "background" & Reference & $\xi$ "hazy" & Reference \\
\hline $\mathrm{SO}_{2}$ & 0.01 & Barrie and Hoff (1984), Bottenheim et al. (1990) & 0.3 & Barrie et al. (1989) \\
\hline $\mathrm{O}_{3}$ & 40.0 & Bottenheim et al. (1986), Anlauf et al. (1994) & & \\
\hline $\mathrm{NO}_{2}$ & 0.02 & Beine et al. (1997) & & \\
\hline $\mathrm{HNO}_{3}$ & 0.05 & Ridley et al. (2003), Leaitch et al. (1994) & & \\
\hline HONO & 0.01 & Li (1994), Zhou et al. (2001) & & \\
\hline $\mathrm{RONO}_{2}$ & 0.14 & Sander et al. (1997) & & \\
\hline PAN & 0.3 & Ridley et al. (2003), Stroud et al. (2003) & 0.5 & Barrie et al. (1989) \\
\hline $\mathrm{CO}$ & 150.0 & Ramacher et al. (1999) & 154.0 & Khalil and Rasmussen (1984) \\
\hline Methane & 1800.0 & Worthy et al. (1994) & 1840.0 & Khalil and Rasmussen (1984) \\
\hline Ethane & 2.0 & Jobson et al. (1994), Hopper et al. (1994) & 2.6 & Khalil and Rasmussen (1984) \\
\hline Ethene & 0.08 & Bottenheim et al. (2002a) & 0.12 & Khalil and Rasmussen (1984) \\
\hline $\mathrm{HCHO}$ & 0.1 & Barrie et al. (1994), Sumner and Shepson (1999) & & \\
\hline $\mathrm{H}_{2} \mathrm{O}_{2}$ & 0.3 & de Serves (1994), Snow et al. (2002) & & \\
\hline $\mathrm{CH}_{3} \mathrm{Br}$ & 0.012 & Cicerone et al. (1988) & 0.009 & Khalil and Rasmussen (1984) \\
\hline $\mathrm{CHBr}_{3}$ & 0.006 & Cicerone et al. (1988) & & \\
\hline
\end{tabular}

Table 2. Initial size distribution of Arctic Haze aerosols. $N_{i}$ is the mean aerosol number concentration for each mode, and $\sigma_{i}$ the standard deviation. The data is after Covert and Heintzenberg (1993) and adapted to a moderate haze event $\left(N_{\text {total }}=300 \mathrm{~cm}^{-3}\right.$, see Kieser et al., 1993; Staebler et al., 1994). Note the bimodal distribution (fine mode: $i=1$; accumulation mode: $i=2$ ), also observed by Saw (1984).

\begin{tabular}{llll}
\hline mode $i$ & $N_{i}\left(\mathrm{~cm}^{-3}\right)$ & $R_{N, i}(\mu \mathrm{m})$ & $\sigma_{i}$ \\
\hline 1 & 50 & 0.025 & 1.6 \\
2 & 250 & 0.11 & 1.4 \\
\hline
\end{tabular}

The particle size distribution is then calculated according to the function:

$$
\frac{d N(r)}{d \lg r}=\sum_{i=1}^{2} \frac{N_{i}}{\lg \sigma_{i} \sqrt{2 \pi}} \times \exp \left(-\frac{\left(\lg r-\lg R_{(N, i)}\right)^{2}}{2\left(\lg \sigma_{i}\right)^{2}}\right) \cdot \lg x=\log _{10} x
$$

\subsection{Frost flowers}

We assume that the particles released from the quasiliquid layers present on the FF branches constitute our "FF aerosols". A particularly critical need is a parameterization for the FF aerosol production which so far is not available. As a rough approximation we used the expression from Monahan et al. (1986) that was developed for the production of sea salt aerosols. We adjusted it with a scaling factor $\mu$ to reproduce typical measured Arctic atmospheric bromine loadings.

The structure of FFs depends on the wind strength. At a wind speed of about $6-7 \mathrm{~m} \mathrm{~s}^{-1}$, saltation of snow grains is initiated (King and Turner, 1997). One might think that FFs are fragile bodies and that they break apart at such wind speeds. However, according to observations on Spitzbergen (Norway) made by F. Dominé (personal communication), the major body of FFs can withstand moderate storms without radical modification of its structure. Therefore, when saltation occurs, snow might start accumulating on the FF crystals, altering their structure, composition or total surface area.

As evident from Reaction (14) the autocatalytic release of bromine from salt particles depends on the acidity of the particles. Ocean water, which is the source of sea salt particles and the brine layer on top of new sea ice, is strongly buffered with $\mathrm{HCO}_{3}^{-}$to a $\mathrm{pH}$ of about 8.1. Sander et al. (2006) suggested that the precipitation of $\mathrm{CaCO}_{3}$ out of the brine (nearly complete at temperatures below $265 \mathrm{~K}$ ) would reduce this buffer in the brine which would facilitate the release of bromine according to Reaction (14) under clean conditions with little available acidity. Papadimitriou et al. (2003) experimentally showed that calcium carbonate precipitates during new sea ice formation. $\mathrm{CaCO}_{3}$ starts to precipitate at a temperature of $-2.2^{\circ} \mathrm{C}$ (Anderson and Jones, 1985; Marion, 2001). Below $-6.7^{\circ} \mathrm{C}$, phosphate, known as inhibitor of the nucleation of calcium carbonate, prevents $\mathrm{CaCO}_{3}$ precipitation (see Bischoff et al., 1993). We included this process in the model by adjusting the initial $\mathrm{HCO}_{3}^{-}$concentration in $\mathrm{FF}$ aerosols from $0 \%$ to $100 \%$ of its concentration in sea water. After depletion of the alkalinity, subsequent uptake of gaseous acids such as $\mathrm{HNO}_{3}, \mathrm{H}_{2} \mathrm{SO}_{4}$ or $\mathrm{HCl}$ then causes an earlier start of the acidification of the particles and thus the bromine explosion. The temperature of the FFs is subject to vertical as well as horizontal temperature gradients between open water and air. Its mean is estimated at the fixed temperature of $255 \mathrm{~K}$ (see Rankin et al., 2002). Based on aerosol composition measurements from Wagenbach et al. (1998) and FF composition results from Rankin et al. (2000), 
we consider the FF aerosols and the QLL to be sulfate free for such a low prescribed temperature. Since there is very little information about the accurate multi-dimensional FF composition, we assumed an homogeneous concentration of halogen ions on FFs, three times higher than in standard sea water (Drinkwater and Crocker, 1988; Perovitch and RichterMenge, 1994; Simpson et al., 2005).

In order to study the effect of FF aerosols specifically, all runs are initialized with aged sulfate particles only (i.e. no salt aerosols present at the start of the runs). The only sources for salt aerosols in the model are the release of FF aerosols and sea salt aerosols from the open lead. Note, also, that no initial concentration of halide is prescribed in snow. Therefore, under these conditions snow itself does not represent an initial reservoir of halides and is not a real source of halogens. For all presented runs, FF aerosols are released for a total period of two hours which corresponds in the Lagragian perspective to a FF field of 36-km extension (the typical horizontal wind speed is $5 \mathrm{~m} \mathrm{~s}^{-1}$ in the model). It is important to stress that even though we talk about aerosols produced from FFs throughout the paper, all effects would be the same if the source of salt aerosols were a different, brine-related source.

\subsection{Open leads}

Spring is a common period for the observation of open leads (OL) due to ocean currents or wind stress on ice sheets. Leads and polynyas can occupy up to $12 \%$ of the Arctic ice area (Gloersen and Campbell, 1991) and provide a source region for sea salt aerosols. Water vapor over those leads exerts a major control on the regional energy budget through cloud formation and radiative effects (Dethleff, 1994; Leaitch et al., 1994; Strunin et al., 1997; Morales Maqueda et al., 2004). Moisture fluxes over sea water induce significant growth of aerosol particles, changing the particle composition and the gas-particulate partitioning. We compared sensible and latent heat fluxes as well as the turbulent kinetic energy flux in our model with values from field data (Strunin et al., 1997; Hartmann et al., 1999; Georgiadis et al., 2000; Argentini et al., 2003). The comparison showed satisfactory agreements (in MISTRA $\overline{\omega^{\prime} T^{\prime}} \mathrm{OL} \simeq 300 \mathrm{~W} \mathrm{~m}^{-2}$ and $\overline{\omega^{\prime} q^{\prime}} \mathrm{OL} \simeq 45 \mathrm{~W} \mathrm{~m}^{-2}$; data from Hartmann et al. (1999): $\overline{\omega^{\prime} T^{\prime}}$ open water $\simeq 300-$ $350 \mathrm{~W} \mathrm{~m}^{-2}$ and $\overline{\omega^{\prime} q^{\prime}}$ open water $\simeq 60-75 \mathrm{~W} \mathrm{~m}^{-2}$ ). These values highlight the importance of the vertical mixing over open cracks due to temperature and humidity differences between packed ice and open water. We prescribe a temperature of $271 \mathrm{~K}$ for the open water. This high surface temperature, compared to an air surface temperature of $245 \mathrm{~K}$, induces a strong convection in the boundary layer. Due to increased evaporation, the specific humidity above such an open lead is about an order of magnitude higher than over snow $\left(2.5 \times 10^{-3}\right.$ compared to $\left.2.2 \times 10^{-4} \mathrm{~kg}_{\mathrm{aq}} \mathrm{kg}_{\mathrm{air}}^{-1}\right)$. A noticeable feature of open leads is that they are also a source for marine gases such as DMS and $\mathrm{NH}_{3}$. As FF occurrence is closely related to the presence of leads we investigated their importance on the chemistry and the aerosol composition (see Sect. 3.2).

We performed a sensitivity study on the open lead extension from $5 \min \left(1.5 \mathrm{~km}\right.$ with a wind speed of $\left.5 \mathrm{~m} \mathrm{~s}^{-1}\right)$ to $1 \mathrm{~h}(18 \mathrm{~km})$. For low aerosol liquid water contents $\left(\mathrm{LWC}_{a}\right)$, the particle radius and mass and therefore the deposition are low. If $\mathrm{LWC}_{a}$ increases, aerosol deposition on the ground increases as well. This is in accordance with aerosol loss over open sea and cracked ice estimated by Strunin et al. (1997). When extending the size of the lead, the maximum $\mathrm{LWC}_{a}$ increases and can lead to cloud droplet formation. When a cloud forms, the change in uptake capacity of the aerosols and droplets greatly modifies the atmospheric chemical composition. This effect will be discussed in detail later. For an OL duration not exceeding $10 \mathrm{~min}, \mathrm{LWC}_{a}$ in the boundary layer increases but no cloud forms in the model. For an OL of $15 \mathrm{~min}(4.5 \mathrm{~km})$, the humidity flux is sufficient to result in the formation of a thin cloud on the top of the BL. The maximum LWC reaches up to $5 \times 10^{-3} \mathrm{~g} \mathrm{~m}^{-3}$ but decreases after $30 \mathrm{~min}$ due to the decrease in relative humidity. The cloud droplets also evaporate within $30 \mathrm{~min}$. Greater open lead extensions induce stronger growth of the cloud thickness and longer persistence of the activated particles. For most of our model runs, we chose an OL duration of 10 min leading to a large $\mathrm{LWC}_{a}$ (and thus deposition) but no cloud formation.

\subsection{Fluxes of gases from the snow}

Observations in the Arctic have shown that with increasing availability of sunlight after the polar sunrise, the snowpack produces a series of reactive species in the gas phase, including HCHO (Fuhrer et al., 1996; Hutterli et al., 1999), HONO (Honrath et al., 1999; Ridley et al., 2000; Zhou et al., 2001; Jacobi et al., 2004), and $\mathrm{H}_{2} \mathrm{O}_{2}$ (Sumner and Shepson, 1999; Hutterli et al., 2001). We include the reported values of surface fluxes in our model (see Table 3), adjusted with a diurnal variation for observed light-dependent species (all but ethene). Fluxes are switched off when the solar zenith angle is greater than $88^{\circ}$.

When no literature value is available for the Arctic spring, emission rates are estimated by comparing photolysis rates $(J)$ between the period of measurements and springtime. Temperature differences are also taken into account in the comparison of the two periods. For $\mathrm{NO}$ and $\mathrm{NO}_{2}$ we used $J_{\mathrm{NO}_{3}-}$ as $\mathrm{NO}_{3}^{-}$is the precursor for $\mathrm{NO}_{\mathrm{x}}$ production in snow interstitial air (Honrath et al., 1999, 2000a,b; Wolff et al., 2002). $J_{\mathrm{H}_{2} \mathrm{O}_{2}}$ and $J_{\mathrm{HCHO}}$ are used to obtain spring values for hydrogen peroxide and formaldehyde fluxes. All prescribed fluxes from snow are included in all model simulations except for those discussed in Sect. 3.7.

Measurements made in the Arctic above the snowpack have shown the production of $\mathrm{Br}_{2}$ and $\mathrm{BrCl}$ (Foster et al., 2001; Spicer et al., 2002). Independently, Peterson and Honrath (2001) speculated that recycling of bromine species in interstitial air is a rather fast process. The availability of 
Table 3. Prescribed emission rates from the snow $\left(\right.$ molec $\left.\mathrm{cm}^{-2} \mathrm{~s}^{-1}\right)$.

\begin{tabular}{lll}
\hline Species & Emission rates & References \\
\hline $\mathrm{NO}$ & $1.6 \times 10^{7}$ & Estimated from Jones et al. (2000), Jones et al. (2001) \\
$\mathrm{NO}_{2}$ & $1.6 \times 10^{7}$ & Estimated from Jones et al. (2000), Jones et al. (2001) \\
$\mathrm{HONO}$ & $5.0 \times 10^{8}$ & Zhou et al. (2001) \\
$\mathrm{H}_{2} \mathrm{O}_{2}$ & $1.0 \times 10^{8}$ & Estimated from Jacobi et al. (2002) \\
$\mathrm{HCHO}$ & $6.0 \times 10^{7}$ & Estimated from Jacobi et al. (2002) \\
$\mathrm{C}_{2} \mathrm{H}_{4}$ & $1.3 \times 10^{8}$ & Swanson et al. (2002) \\
\hline
\end{tabular}

acidity in snow (see Kalnajs and Avallone, 2006) may importantly increase the reaction rate of reaction 14 . However, Adams et al. (2002) also showed that $\mathrm{Br}_{2} / \mathrm{BrCl}$ are released from frozen surfaces in the presence of $\mathrm{HOBr}$ with no significant influence of the $\mathrm{pH}$. In order to investigate the importance of this release from snow, we performed model runs where deposited bromine compounds (both gas and particulate phases) are re-released to the gas phase. A detailed investigation of reactions on the snow surface or in the snow interstitial air, however, is beyond the scope of this study. The amount of bromine in snow is the limiting factor in the liberation of both $\mathrm{Br}_{2}$ or $\mathrm{BrCl}$ as the availability of $\mathrm{Cl}$ atoms is considered unlimited. We assume the deposited bromine to be stochiometrically converted in the snowpack to $\mathrm{Br}_{2} / \mathrm{BrCl}$ with a 40/60 branching ratio (Kirchner et al., 1997). The fraction of re-emitted bromine, $v_{\text {snow }}$, is varied between 0 (no recycling) and $100 \%$ (complete recycling), and stays constant during a whole run.

Note that the re-emission of gaseous $\mathrm{Br}_{2} / \mathrm{BrCl}$ from the ground leads to a "leap-frogging" process, consisting of series of deposition/re-emission of bromine as the air moves away from the source of bromine. This process is in accordance with observations from Simpson et al. (2005). Also notice that compounds deposited on sea water (OL) are not re-released.

\subsection{Model sensitivity studies}

The model runs discussed in this paper are summarized in Table 4. In all runs (except for the assessment of FFs during night) the model column traverses the FF field four hours after the model start (day 0, 04:00 local time), approximately $30 \mathrm{~min}$ after sunrise in order to start the production of FF aerosols at daytime. All parameters in the sensitivity studies have the same values as in the base model run unless stated explicitly otherwise.

In run 1 (base run) we chose the most realistic values for all parameters. As we compare all other runs to this one, we discuss it in greatest detail (Sect. 3.1). Runs 2 to 7 are discussed to assess the impact of the recycling on snow and the presence of a lead in the model. In order to evaluate the effect of FF aerosols during nighttime, the FF field is crossed by the model column on day 0, 00:00 local time (runs 8 and 9). Meteorological parameters were also investigated: the frost flower and ambient air temperatures were varied by $5 \mathrm{~K}$ and $1 \mathrm{~K}$, respectively (runs 10 and 11). We evaluated the impact of a change in wind speed in run 12 . The precipitation of bicarbonate from the brine layer was suggested to be a key process for the acceleration of the bromine explosion (see Sander et al., 2006). We investigated the importance of this by assuming that only $50 \%$ or $0 \%$ is precipitated (run 13 and 14) as opposed to $100 \%$ in the base run. The characteristics of an Arctic Haze event were also investigated (run 15). We assessed the impact of the potential recycling efficiency from snow with the parameter $v_{\text {snow }}$ which controls the fraction of deposited bromine re-emitted from the snow as $\mathrm{Br}_{2} / \mathrm{BrCl}$. Our study comprises values for $\nu_{\text {snow }}$ of $0 \%$ (run 3), $25 \%$ (run 16), 50\% (run 17) and $75 \%$ (run 1). The impact of non-halogen gases released from the snow shown in Table 3 has also been investigated. Only the role of the HONO flux in the bromine explosion is discussed (run 18). Finally, we will discuss the differences between the FF aerosols as the source of bromine and a direct release of gaseous $\mathrm{Br}_{2}$ from that field of FFs (run 19). Further details to the model sensitivity studies are given in the respective result sections.

To facilitate the discussion in this paper, we used the classification of Ridley et al. (2003) to define the ODE types depending on ozone mixing ratios: partial ODE as $4<\xi_{\text {Ozone }} \leq 20 \mathrm{nmol} \mathrm{mol}^{-1}$ (PODE) and major ODE as $\xi_{\text {Ozone }} \leq 4 \mathrm{nmol} \mathrm{mol}^{-1}$ (MODE). To distinguish ODEs developing within one day from ODEs developing in four days, we used the abbreviation MODE1/MODE4 and PODE1/PODE4.

To better show the partitioning of bromine between the different phases we define the following variables: TCg: 1000 m model column (renamed "Total Column") concentration of gas phase species containing $\mathrm{Br}$ atoms, TCa: same for sea salt and sulfate aerosols, TCd same for cloud droplets, $\mathrm{ID}_{\mathrm{Br}}$ : the accumulated irreversible deposition of bromine atoms or ions integrated over time, and $\mathrm{TC}_{\mathrm{Br}}$ : the sum of 
Table 4. List of runs performed. Deposited bromine is re-emitted from snow as $\mathrm{Br}_{2} / \mathrm{BrCl}$ with a ratio $v_{\text {snow }}$ "OL duration" is the period over which the surface has the characteristics of open water. "Flux from snow" represents the prescribed fluxes out of the snow; if standard, all fluxes listed in Table 3 are used. "Characteristics" refers to additional run properties.

\begin{tabular}{|c|c|c|c|c|c|}
\hline Name & Run\# & $v_{\text {snow }}$ & OL duration & flux from snow & Characteristics \\
\hline Base case (or Ratio $=75$ ) & 1 & $75 \%$ & $10 \min$ & standard & - \\
\hline NOL-noR & 2 & $0 \%$ & none & standard & - \\
\hline OL-10 min-noR (or Ratio=0) & 3 & $0 \%$ & $10 \min$ & standard & - \\
\hline OL-1 h-noR & 4 & $0 \%$ & 1 hour & standard & - \\
\hline OL-1 h & 5 & $75 \%$ & 1 hour & standard & - \\
\hline OL.FF.S & 6 & $75 \%$ & $10 \min$ & standard & OL prior to FF \\
\hline separated-FF & 7 & $75 \%$ & $10 \times 1 \mathrm{~min}$ & standard & $10 \times 12$ min FF field \\
\hline FF-nightR & 8 & $75 \%$ & $10 \mathrm{~min}$ & standard & recycl. at night \\
\hline FF-nightnoR & 9 & $75 \%$ & $10 \mathrm{~min}$ & standard & no recycl. at night \\
\hline $\mathrm{T}_{\mathrm{FF}}=260 \mathrm{~K}$ & 10 & $75 \%$ & $10 \min$ & standard & FF temp. $=260 \mathrm{~K}$ \\
\hline $1 \mathrm{~K}$-colder airmass & 11 & $75 \%$ & $10 \min$ & standard & airmass temp. $1 \mathrm{~K}$ colder \\
\hline Wind $=7 \mathrm{~m} \mathrm{~s}^{-1}$ & 12 & $75 \%$ & $10 \mathrm{~min}$ & standard & $\mu=45$ \\
\hline halfHCO ${ }_{3}^{-}$ & 13 & $75 \%$ & $10 \mathrm{~min}$ & standard & $50 \% \mathrm{HCO}_{3}^{-}$precip. \\
\hline full $\mathrm{HCO}_{3}^{-}$ & 14 & $75 \%$ & $10 \mathrm{~min}$ & standard & no $\mathrm{HCO}_{3}^{-}$precip. \\
\hline Arctic Haze & 15 & $75 \%$ & $10 \mathrm{~min}$ & standard & hazy airmass composition \\
\hline Ratio $=25$ & 16 & $25 \%$ & $10 \min$ & standard & - \\
\hline Ratio $=50$ & 17 & $50 \%$ & $10 \mathrm{~min}$ & standard & - \\
\hline no-HONO & 18 & $75 \%$ & $10 \min$ & no HONO & - \\
\hline $\mathrm{Br}_{2}$-flux & 19 & $75 \%$ & $10 \mathrm{~min}$ & standard & direct $\mathrm{Br}_{2}$ flux from $\mathrm{FF}$ \\
\hline
\end{tabular}

the four previous parameters. These parameters will be displayed in $\mathrm{mol} \mathrm{m} \mathrm{m}^{-2}$.

\section{Results and discussions}

The discussion of the results is subdivided into eight parts. In Sect. 3.1 we discuss the base run to reproduce an ODE with the frost flower aerosols being the source for bromine. (see Fig. 1 for a schematic depiction of the model runs). Different sequences of FF fields and open leads as surfaces are examined (Sect. 3.2) as well as the impact of temperature and wind speed on the production of FF aerosols (Sect. 3.3). In Sect. 3.4 we examine the impact of 50 or $100 \%$ of $\mathrm{HCO}_{3}^{-}$ remaining in aerosols. Also, the effects of Arctic Haze are discussed (Sect. 3.5). In Sect. 3.6, we present results on the importance of gaseous halogen re-emission from the snow of both particulate and gas phase bromine depositions. This is followed by a sensitivity study on the impact of non-halogen outgassing from the snow (Sect. 3.7). Finally, in Sect. 3.8, we discuss differences between the production of FF aerosols and a direct release of $\mathrm{Br}_{2}$ from FFs that could help differentiate among direct or indirect release of reactive bromine from FFs.

\subsection{Base case}

In this model run (starting on day 0 , after the two-day spinup), the model column begins to cross a field of FFs at 04:00 local time. Aerosols, with no bicarbonate, are released from the FFs. These constitute the major source of bromine in the model. The field of FFs is with $36 \mathrm{~km}$ (corresponding to two hours where the model column moves with a wind speed of $5 \mathrm{~m} \mathrm{~s}^{-1}$ ) rather large. In order to release enough bromine for a major ODE to develop within four days (MODE4), the scaling factor for the FF aerosol emission (see Sect. 2.1) was chosen as $\mu=90$ (PODE4 is reached with $\mu=60$ ). The FF field is followed by an open lead of 10 min duration (equivalent to $3 \mathrm{~km}$ ). After the open lead the model column moves over snow from which deposited gas and particulate bromine is re-emitted as gas phase $\mathrm{Br}_{2}$ and $\mathrm{BrCl}$ (see Sect. 2.3). The efficiency for the recycling of bromine is assumed to be $v_{\text {snow }}=75 \%$, based on model-field data comparisons (see Sect. 3.6). Furthermore, the release of non-halogen species from the snowpack is included (see Table 3). In the following we provide a detailed interpretation of the base model run and will analyse the importance of the various assumptions in the next sections.

Some important features of the base run are shown in Fig. 2. The strong temperature difference between the open water $(271 \mathrm{~K})$ and the overlying air $(245 \mathrm{~K})$ leads to convection that penetrates the temperature inversion at around $300 \mathrm{~m}$ and leads to an extension of the mixed layer up to $400 \mathrm{~m}$ (Fig. 2-H to J). The relative humidity displays highest values at the top of the BL due to the decrease of temperature with height. FF aerosols are well mixed throughout the BL due to vertical air motion caused by the increase of the 

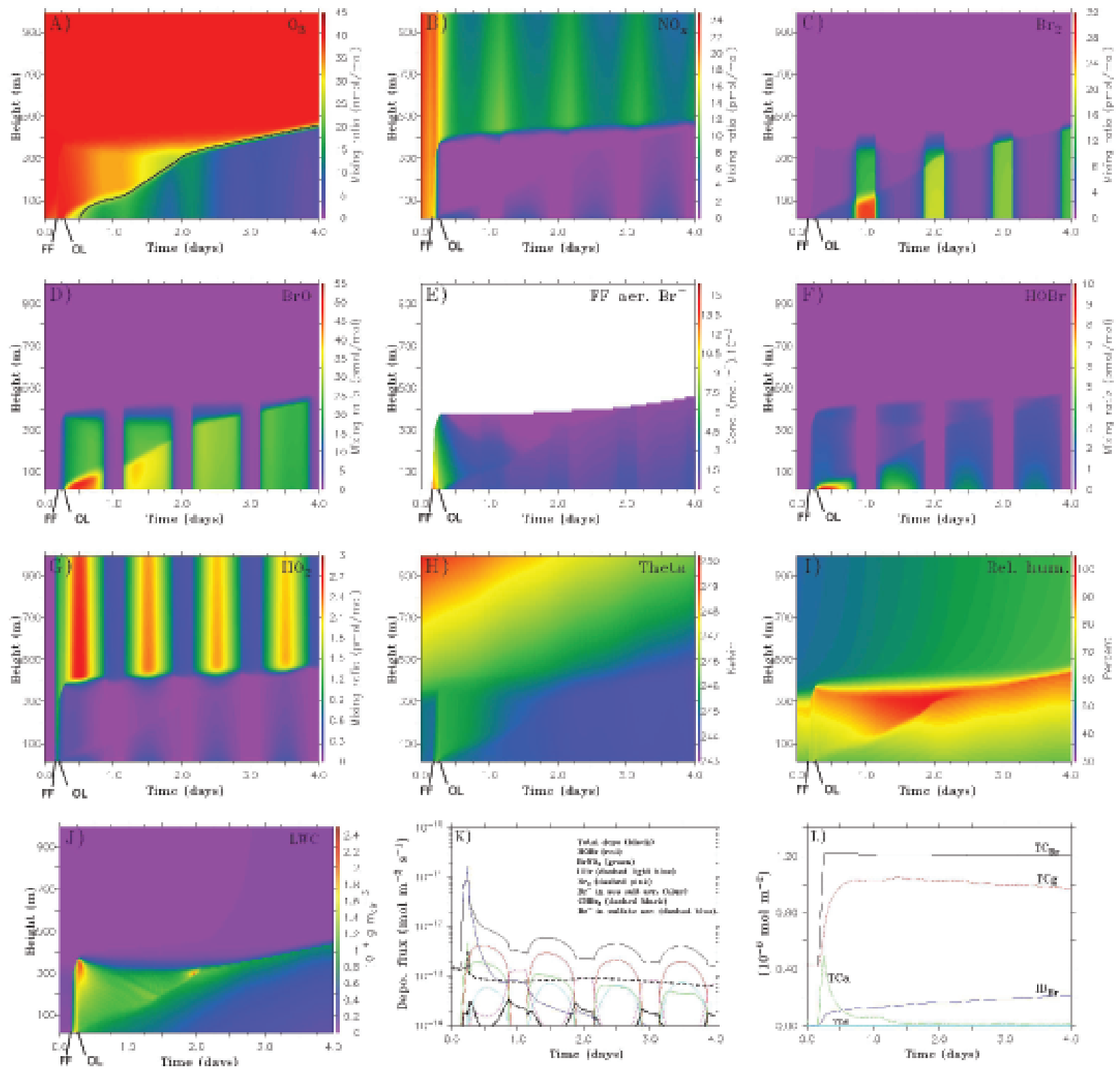

Fig. 2. "Base case" run. (A) $\mathrm{O}_{3}$ : isopleth $25 \mathrm{nmol} \mathrm{mol}^{-1}$ represents the separation between two ozone regions within the BL until day 2, (B) $\mathrm{NO}_{\mathrm{X}}\left(\mathrm{NO}+\mathrm{NO}_{2}\right),(\mathbf{C}) \mathrm{Br}_{2}$, (D) $\mathrm{BrO},(\mathbf{E}) \mathrm{FF}$ aerosol $\mathrm{Br}^{-},(\mathbf{F}) \mathrm{HOBr},(\mathbf{G}) \mathrm{HO}_{2}$, (H) potential temperature $\theta$, (I) relative humidity, (J) aerosol LWC, $(\mathbf{K})$ deposition flux of the most relevant bromine species $\left(\mathrm{mol} \mathrm{m}^{-2} \mathrm{~s}^{-1}\right)$. Black: total deposition, red: $\mathrm{HOBr}$, green: $\mathrm{BrONO}_{2}$, dashed light blue: $\mathrm{HBr}$, dashed pink: $\mathrm{Br}_{2}$, dash-dotted black: $\mathrm{BrCl}$, dashed black: $\mathrm{CHBr}_{3}$, blue: $\mathrm{Br}^{-}$in $\mathrm{FF}$ aerosols, dashed blue: $\mathrm{Br}^{-}$in sulfate aerosols (in this case, not visible on this scale). $(\mathbf{L}) \mathrm{Black}=\mathrm{TC}_{B r}$, red=TCg, green=TCa, light blue $=\mathrm{TCd}, \mathrm{blue}=\mathrm{ID}_{\mathrm{Br}}\left(\mathrm{all}\right.$ in $\mathrm{mol} \mathrm{m}^{-2}$ ). Model run starts at midnight.

surface temperature over the FF field and the OL (see potential temperature in Fig. 2-H).

Liberation of $\mathrm{Br}_{2} / \mathrm{BrCl}$ from the $\mathrm{FF}$ aerosols starts subsequent to uptake of acids in particles and is more efficient at the top of the boundary layer due to smaller particle $\mathrm{pH}$ values at the top of the BL (see von Glasow and Sander, 2001). However, this release is slow and ozone is weakly depleted by this process only, as will become clear in the next paragraphs.
The five parameters $\mathrm{TCg}, \mathrm{TCa}, \mathrm{TCd}, \mathrm{ID}_{\mathrm{Br}}$ and $\mathrm{TC}_{\mathrm{Br}}$ introduced in Sect. 2.4 are displayed in Fig. 2-L. TCg has a positive starting value due to the presence of bromoform and methyl bromide in the atmosphere. $\mathrm{ID}_{\mathrm{Br}}$ shows a monotonically increasing behavior as it represents the accumulated deposition over time. In our model runs, deposited aerosol bromide is instantaneously re-emitted as gas phase bromine. This particulate-to-gas-phase conversion is therefore, with $v_{\text {snow }}=75 \%$, faster than the bromide liberation 
via the bromine explosion cycle from particles. Thus, the way that halogen re-emission from the snow is treated in the model is clearly more efficient than the release from aerosols in terms of bromide liberation: $\mathrm{TCg}$ is closely correlated to the aerosol deposition on snow. When the $\mathrm{LWC}_{a}$ and the deposition increase, the re-emission from the ground and $\mathrm{TCg}$ increase as well (under cloud-free conditions, as explained in Sect. 2.2). Note that the correlation between deposited bromine and its re-emission is directly related to the way our model was set up. The possible delay between deposition and recycling that can occur in/on snow at the field does not affect, in our model representation, the values given to $v_{\text {snow }}$. Note that the contribution of snowfall to the deposition of bromide on snow is not taken into account in our model.

In Fig. 2-A we distinguish two regions of ozone in the BL before day 2: we used the ozone mixing ratio isopleth of $25 \mathrm{nmol} \mathrm{mol}^{-1}$ as an approximate separation of these two regions (see black curve, which will be displayed in all other $\mathrm{O}_{3}$ plots as well). The difference between the regions comes from the influence of the re-emission of bromine from the snow. Note that the natural deposition of ozone on the ground also contributes (by 13\% after four days of simulation) to the removal of $\mathrm{O}_{3}$ molecules near the surface. On day 0 , the lowest layers of the BL (up to $100 \mathrm{~m}$ ) are greatly disturbed by the re-emission of halogens from the ground. Ozone is quickly depleted: over the first 12 simulated hours, the deposition/re-emission of bromine is strongest and leads to a maximum value of the ozone destruction rate of $2.15 \mathrm{nmol} \mathrm{mol}^{-1} \mathrm{~h}^{-1}$. This destruction rate agrees well with the rate $2.4 \mathrm{nmol} \mathrm{mol}^{-1} \mathrm{~h}^{-1}$ calculated by Platt (1997) based on measurements. Notably, substantial ozone depletion is found only several tens of kilometers downwind of the FF field (Fig. 2-A). The ozone destruction on the first day can be classified as a PODE and occurs within $10 \mathrm{~h}$. In the upper layers, the much smaller ozone destruction is a consequence of the bromine explosion cycle in aerosols. The strength of this cycle for gas phase bromine concentrations is weak compared to the re-emission of bromine from the ground: a substantial amount of bromide in layers above $100 \mathrm{~m}$ remains in FF aerosols up to day 1, 12:00 (see dashdotted green line in Fig. 2-L) whereas bromide in the lowest layers is entirely liberated after $9 \mathrm{~h}$.

Figure 2-K shows that aerosol bromide accounts for 9599\% of the modeled deposition flux between 04:00 and 06:00 on day 0 (later, gaseous $\mathrm{HOBr}$ accounts for approximately half of the deposition during daytime: the major components depositing at night are $\mathrm{Br}_{2}$ and $\mathrm{CHBr}_{3}$ ). As the deposition flux (mostly composed of bromide) is strongest near the region of particulate halogen production from the FF field, re-emissions of $\mathrm{Br}_{2}$ and $\mathrm{BrCl}$ from the snow reach maxima of $3.2 \times 10^{8}$ and $9.5 \times 10^{8}$ molec $\mathrm{cm}^{-2} \mathrm{~s}^{-1}$, respectively, shortly after moving across the OL. At this time, halogen re-emission from the snow rapidly initiates the bromine explosion in the lowest $100 \mathrm{~m}$ of the BL. After photodissociation of $\mathrm{Br}_{2}$, free $\mathrm{Br}$ radicals destroy ozone via the cy- cles mentioned before. The reaction product $\mathrm{BrO}$ exhibits a maximum of $48 \mathrm{pmol} \mathrm{mol}^{-1}$ in the lowest layers on the first day (Fig. 2-D). This maximum is a consequence of two different processes: the re-emission of $\mathrm{Br}_{2} / \mathrm{BrCl}$ from the snow followed by photolysis and reaction with available $\mathrm{O}_{3}$, and the induced bromine explosion acceleration which liberates bromine from the aerosol phase. After day $0, \mathrm{BrO}$ mixing ratio decreases to values similar to field data (up to $30 \mathrm{pmol} \mathrm{mol}^{-1}$, see Hausmann and Platt, 1994; Tuckermann et al., 1997; Martinez et al., 1999; Hönninger and Platt, 2002; Hönninger et al., 2004). Vertical transport within the BL extends the presence of high bromine mixing ratios $\left(\mathrm{Br}_{\mathrm{x}}\right)$ over the simulated days in the whole BL. In the first night (i.e. night between day 0 and 1), gas phase $\mathrm{Br}_{2}$ and $\mathrm{BrCl}$ are replenished by several mechanisms in the absence of photolysis and display mixing ratios of about 28 and $6 \mathrm{pmol} \mathrm{mol}^{-1}$ in the first $100 \mathrm{~m}$ of the BL (Fig. 2-C). Such concentrations are in the range measured by Foster et al. (2001) and Spicer et al. (2002).

On day 1 at 22:00 local time, $\mathrm{LWC}_{a}$ shows a maximum of $2.1 \times 10^{-4} \mathrm{~g} \mathrm{~m}^{-3}$. No cloud forms under these conditions but perturbations in the radiative and heat fluxes induce a weak turbulent mixing resulting in downward $\mathrm{O}_{3}$ transport. As a consequence, ozone is temporarily replenished down to the surface from day 1, 23:00 to day 2, 05:00 (Fig. 2-A). After day 2, bromine is well mixed in the BL and until the end of day 3 , ozone decreases to about $3 \mathrm{nmol} \mathrm{mol}^{-1}$ (equivalent to MODE4) in the lowest $400 \mathrm{~m}$.

These model results suggest that the deposition/reemission of halogens on the snowpack, with characteristics as described in this paper, is a key process for the ozone depletion. Open leads modify the particle deposition velocities, so that the whole chemical mechanisms are influenced by the presence of open leads. These open leads increase the aerosol sedimentation and thus the re-emission of halogens from the ground. Systematic and comprehensive measurements of snow composition in the vicinity of open leads in association with air mass composition are needed to verify this finding. Detailed studies on the influence of open leads are presented in the following section.

\subsection{Surface influence}

We performed a model run, where the model column traverses a field of FFs only (fluxes from Table 3 also prescribed), to investigate the impact of FF aerosols only, and no open water; recycling of deposited bromine on snow is also ignored (called NOL-noR for No Open Lead - no Recycling from snow; run 2 in Table 4). All deposited bromine is definitely lost on snow. Such a case might occur if recycling processes in/on the snow are not important. In this run, the other parameters remain the same as in the base run.

In this sensitivity run, a similar plume of aerosols is generated from the field of FFs as in our base run. Aerosols spread within the boundary layer (Fig. 3-C) due to the convection 

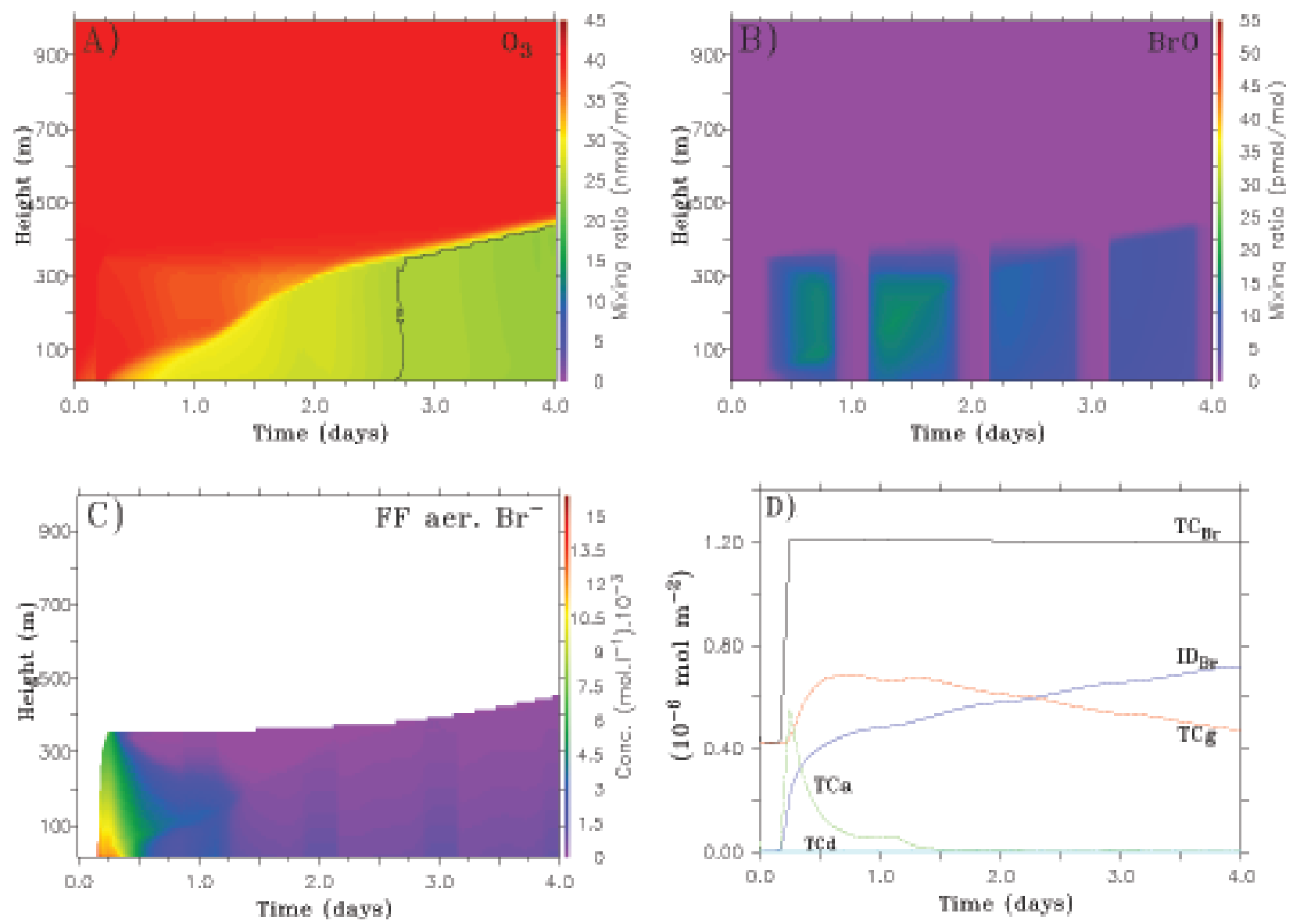

Fig. 3. Run NOL-noR with the FF field only; neither OL nor recycling on snow considered. (A) $\mathrm{O}_{3}$, (B) $\mathrm{BrO},(\mathbf{C}) \mathrm{FF}_{\text {aerosol }} \mathrm{Br}^{-}$, (D) total bromine budget.

generated by the temperature difference between the FF field and the overlying air. As no halogen re-emission takes place from the snow after sedimentation, gaseous $\xi_{\mathrm{HOBr}}$ is reduced to maximum values of $4.5 \mathrm{pmol} \mathrm{mol}{ }^{-1}$ compared to $9.7 \mathrm{pmol} \mathrm{mol}^{-1}$ for the base run (in both cases, mostly confined to the lowest layers of the model due to highest concentrations of oxidants near the surface). As a consequence, the liberation of aerosol bromide via the bromine explosion mechanism (see Reaction 14) between the surface and the altitude of $100 \mathrm{~m}$ on day 0 is delayed by two hours compared to the base run. Nevertheless, all aerosols that remain suspended in air still undergo a debromination which is nearly completed after 32 hours.

In this case, daytime deposition during the first day is mainly composed of aerosol bromide and $\mathrm{HOBr}$ (not shown) and is, during the rest of the simulation, dominated by $\mathrm{HOBr}$ and $\mathrm{BrONO}_{2}$. Under the conditions of this run, a large amount of aerosol bromide (which is the only relevant source of bromine) deposits on snow before it can be activated to gas phase $\mathrm{Br}$, i.e., it does not affect the atmospheric composition.

We calculate a ratio of 1.3 between $\mathrm{ID}_{\mathrm{Br}}$ and $\mathrm{TCg}$ after the four simulated days (Fig. 3-D) compared to 0.2 for the base run. Due to these high values of $\mathrm{ID}_{\mathrm{Br}}, \mathrm{TCg}$ undergoes a severe reduction: the absence of re-emission from the snow substantially diminishes the presence of bromine radicals near the surface.

The ozone loss rate is small, with a minimum mixing ratio of $23.5 \mathrm{nmol} \mathrm{mol}^{-1}$, and cannot even be categorized as a PODE after four days of simulation (Fig. 3-A). We calculated that the ozone decrease in this case is only $40 \%$ attributed to chemical reactions; $60 \%$ of the total ozone removal is a consequence of its deposition on snow, with modeled ozone deposition velocity similar to the velocity determined by Strunin et al. (1997). As a consequence, the $\mathrm{O}_{3}$ profile does not correlate with the $\mathrm{BrO}$ profile. The maximum mixing ratio of $\mathrm{BrO}$ is with $17 \mathrm{pmol} \mathrm{mol}^{-1}$ rather small compared to the base case (Fig. 3-B), and $\mathrm{BrO}$ develops down from the top of the BL. Under conditions of no recycling of bromine from the snow, the liberation of bromide from FF aerosols is too slow, and a large amount of bromide is deposited on snow; the strong bromine loss onto the ground is the main characteristic of this run.

A similar model run (not shown), with the inclusion of a $3-\mathrm{km}$ open lead $(10 \mathrm{~min})$ but still without recycling of 

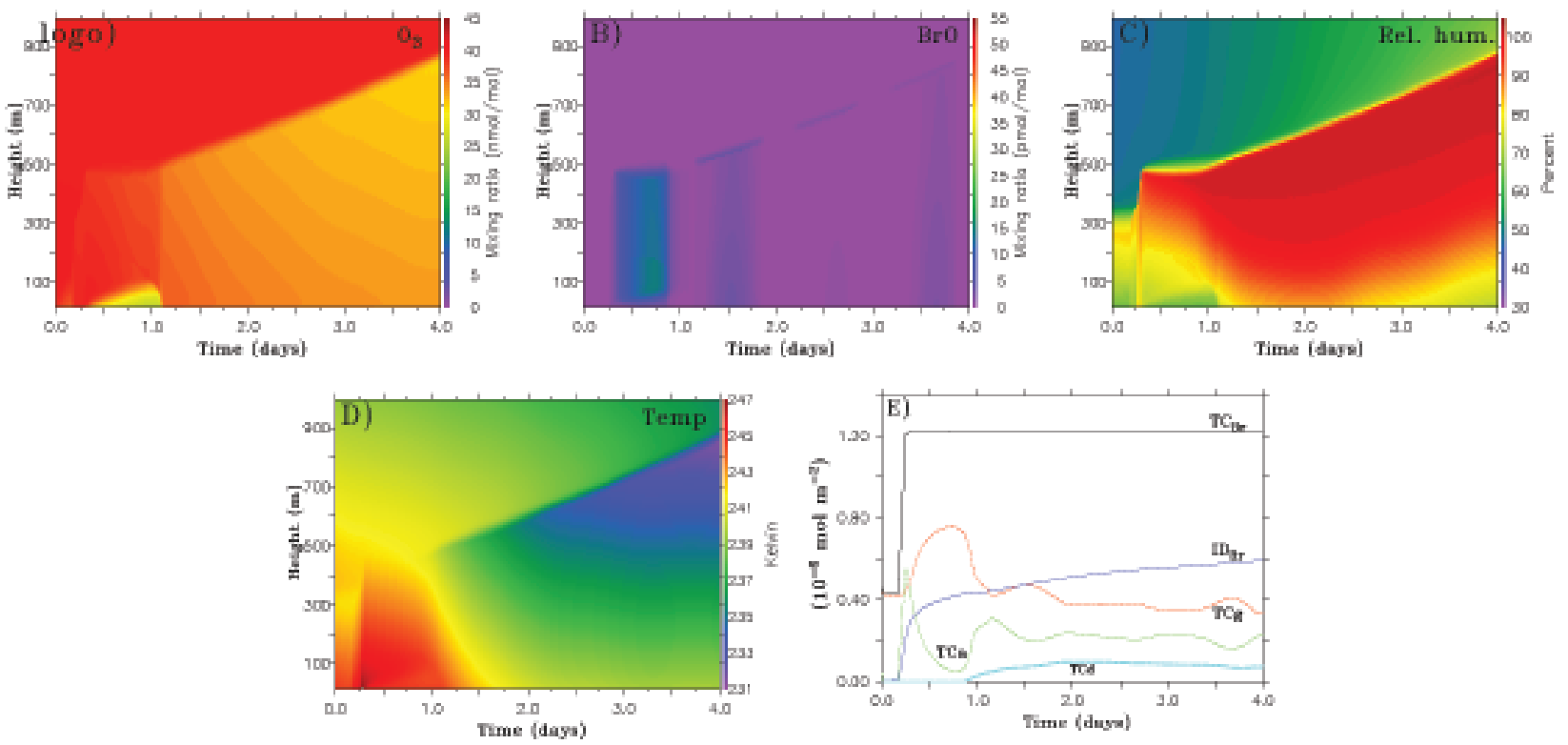

Fig. 4. Run OL-1 h-noR with 1 h of open lead and no recycling on snow considered. (A) and (B) Mixing ratios of $\mathrm{O}_{3}$ and $\mathrm{BrO}$, resp., (C) relative humidity, (D) air temperature $T,(\mathbf{E})$ total bromine budget.

deposited bromine on snow, only showed a greater sink of aerosol bromide due to greater particle mass with eventual ozone mixing ratio $\left(24.5 \mathrm{nmol} \mathrm{mol}^{-1}\right)$ also above the PODE threshold. Hence, the presence of the 10-min open lead does not drive the ozone destruction.

In order to assess the effects of the lead extension, we did a model run with a $1-\mathrm{h}$ OL (equivalent to $18 \mathrm{~km}$, called OL1h-noR, Fig. 4). As already mentioned, the presence of open water induces an increase in the humidity of the overlying airmass. The presence of this large lead affects the BL height which grows from 300 to $500 \mathrm{~m}$ within a couple of hours (see Fig. 4-C). This fast increase in the BL height after the OL is in good agreement with observations from dropsonde data made by Hartmann et al. (1997) and Hartmann et al. (1999).

On day 0 at 18:00, a cloud starts to form in the model at the top of the PBL. LWC reaches a maximum of $7.7 \times 10^{-2} \mathrm{~g} \mathrm{~m}^{-3}$ compared to $2.1 \times 10^{-4} \mathrm{~g} \mathrm{~m}^{-3}$ for the base run. The radiative cooling induces an important temperature decrease (up to $9 \mathrm{~K}$ ) within the cloud (Fig. 4-D). The cloud depth increases to $400 \mathrm{~m}$ within 3.5 days (Fig. 4-C). The observation of low-layer Arctic clouds have demonstrated the interactions between radiative fluxes, sensible, and latent heat fluxes and the BL structure. Herman and Goody (1976) described the radiative and turbulent processes producing Arctic stratus clouds. Radiative cooling and diffusive cooling are in majority responsible for the turbulence below the cloud base and may contribute to the propagation of turbulence in our model. From her measurements, Curry (1986) found that the radiative cooling contributes to mixed-layer convection via turbulence generation. Altogether, these observations highlight the air motions from clouds which might significantly contribute to entrainment of air from aloft.

In the model, the turbulence generated by the presence of the cloud leads to an effective downward transport. The turbulence is efficient, reaching the surface within a couple of hours. The vertical mixing related to the presence of such a turbulence can inhibit the development of an ODE: shallow low-ozone layers are mixed with ozone-enriched air from above. Thus, this dynamical phenomenon is likely to have an influence on the termination of an ODE (also see other possible mechanisms such as topography-induced disturbances, Morin et al., 2005). Chemical observations associated with detailed description of the cloud presence are greatly needed to confirm this ODE dissipation by vertical air mixing.

Due to their growth in the more humid air and therefore increased sedimentation, the concentration of FF aerosols is rapidly reduced leading to a large amount of deposited bromide. The deposition of FF aerosols is nearly complete 36 hours earlier than in the base case. TCa, sum of integrated bromide concentration in sulfate and FF aerosols, remains high due to increased bromide concentration in sulfate aerosols. When no recycling on snow is considered, deposited bromide from FF aerosols (50\% of the total amount of FF aerosols after $3 \mathrm{~h}$ ) is irreversibly lost on snow (blue line in Fig. 4-E). This results in small amounts of bromine in the air: $\mathrm{BrO}$ mixing ratios do not exceed $15 \mathrm{pmol} \mathrm{mol}^{-1}$ on day 0 (Fig. 4-B). On this day, the decrease in ozone down to $26.5 \mathrm{nmol} \mathrm{mol}^{-1}$ near the surface (Fig. 4-A) is $60 \%$ due to deposition on snow. In this particular case, the smaller turbulent mixing close to the surface reduces the ozone vertical mixing and therefore accelerates the chemical destruction of ozone by about $2 \mathrm{nmol} \mathrm{mol}{ }^{-1}$. 
Furthermore, cloud droplets have a larger uptake capacity than dry aerosols as the exchange with the gas phase depends on the LWC. In Fig. 4-E, TCd (light blue line) shows the strong uptake of bromine to droplets after the cloud formation. Similarly, the uptake capacity of aerosols increases as well (higher water content): the rise in TCa starting on day 0 at 19:00 is largely (more than 75\%) due to uptake in sulfate aerosols. A clear shift in gas-particle partitioning of bromine occurs (see also the strong decrease of gas phase $\mathrm{BrO}$ after the first day in Fig. 4-B). This shift in bromine partitioning is similar to model results from von Glasow et al. (2002a). On day 2, 00:00 local time, the ratio $\mathrm{TC}_{a}: \mathrm{TC}_{g}=0.6$ whereas it is only about 0.06 before the cloud development. That means that, due to cloud formation, a major part of the gas phase bromine ( $\mathrm{TCg}$ ) is shifted to the particulate phase, leading to less $\mathrm{O}_{3}$ destruction in the PBL.

In addition, formaldehyde is taken up by droplets (see Lelieveld and Crutzen, 1990) and decreases in our case by $20 \mathrm{pmol} \mathrm{mol}^{-1}$ in cloud layers. This uptake reduces the production of $\mathrm{HOBr}$ via several ways: $90 \%$ of the $\mathrm{HOBr}$ reduction is due to less production of $\mathrm{HO}_{\mathrm{x}}$ (mostly due to less photolysed $\mathrm{HCHO}$ or reaction with $\mathrm{OH}$ and halogen radicals) and $10 \%$ due to the reduced reaction rate of the following reaction:

$\mathrm{BrO}+\mathrm{HCHO} \stackrel{\mathrm{O}_{2}}{\longrightarrow} \mathrm{HOBr}+\mathrm{CO}+\mathrm{HO}_{2}$

We note, however, that the rate coefficient used in our model is rather an upper limit based on work from Hansen et al. (1999) (see more recent studies by Orlando et al., 2000).

In summary, the combination of bromide loss due to deposition, uptake of bromine and other species (e.g., HCHO) to cloud droplets and aerosols, and mixing with ozone-rich air from above prevents the development of an ODE (except for the first day, $\xi_{\mathrm{O}_{3}}$ stays above $32 \mathrm{nmol} \mathrm{mol}{ }^{-1}$ up to the end of the run).

In run 5 (not shown) the model run also traverses a 1-hour open lead but recycling of deposited bromine on snow is included. All deposited matter is instantaneously re-emitted with the same recycling ratio $\nu_{\text {snow }}(75 \%)$ as in the base case. Here, the re-emission contributes to an efficient conversion of diverse brominated compounds into $\mathrm{Br}_{2}$ and $\mathrm{BrCl}$. Several hours after the start of the FF aerosol production, ozone drops to $13 \mathrm{nmol} \mathrm{mol}^{-1}$ (equivalent to a PODE1) with a maximum ozone destruction rate of $2.3 \mathrm{nmol} \mathrm{mol}{ }^{-1} \mathrm{~h}^{-1}$. Therefore, as long as no cloud layer forms in the BL the association of open water with recycling from snow releases more reactive bromine in the air than without $\mathrm{OL}$ and depletes more $\mathrm{O}_{3}$ molecules. As soon as the cloud develops (starting on day 0 , 18:00, same as in run 4), the induced strong mixing ends the PODE.

The presented results of runs 2 to 4 indicate that the ODE as modeled in our base case requires the bromine re-emission from the snowpack. Moreover, as mentioned in Sect. 2.3, studies on snow surfaces and interstitial air have demon-

\section{«separated-FF» run}

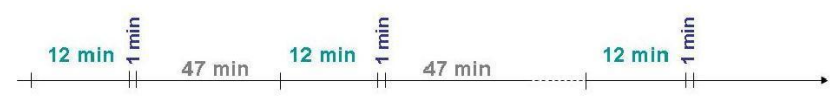

\begin{tabular}{|c|c|c|c|c|c|}
\hline \multicolumn{2}{|c|}{$\mathrm{OL}$} & \multicolumn{2}{|c|}{$\mathrm{OL}$} & \multicolumn{2}{|c|}{$\mathrm{OL}$} \\
\hline FF & Snow & FF & Snow & FF & Snow \\
\hline
\end{tabular}

Day 0, 04:00

Time axis

Day 0, 13:13

Fig. 5. Schematic description of the FF and OL settings for the separated-FF case.

strated the importance of the snowpack for chemical exchanges with the atmosphere, including the conversion of deposited bromine into photolabile reactive species. All subsequent runs will include this process in the form of a $\mathrm{Br}_{2} / \mathrm{BrCl}$ outgassing as described in Sect. 2.3.

These model studies showed that, first, recycling on the snowpack is an important process for the development of an ODE, and second, an ODE can quickly vanish due to vertical mixing induced by the presence of a cloud. The formation of clouds in the PBL may be a significant termination process for ODEs. Third, open leads increase the deposition/reemission process on snow but their presence for an ozone depletion does not seem to be necessary.

In order to further investigate the impact of OL, we examine in run 6 the effects of a 10-min open lead prior to the field of FFs (OLFFS: Open Lead - Frost Flowers - Snow; not shown). Under such OL/FF configuration no brominated matter from the FF field is irreversibly deposited on sea water as the FF aerosol production starts only subsequent to the OL passage. In this run the relative humidity at the start of the FF aerosol production is 6-8\% higher than in the base run. Aerosols released from the FF field grow more rapidly in size in the humid air and consequently deposit more rapidly. The amount of deposited bromine, which is dominated by particulate bromide, is about $20 \%$ higher than in the base case for the first $3 \mathrm{~h}$ after the FF field. In our simple parameterization, deposited bromine is immediately re-released into the gas phase. As a result, TCgOLFFS increased by $4 \%$ compared to $\mathrm{TCg}_{\text {base case }}$ at the end of the run. Therefore, in our model run, the increase in deposition leads to a speed-up in activation of bromine, i.e. the conversion of bromide from $\mathrm{FF}$ aerosols to reactive bromine gases. In run OLFFS this results in a lower minimum in $\mathrm{O}_{3}$ mixing ratio with a MODE reached $20 \mathrm{~h}$ earlier than in the base case (equivalent to $12 \%$ increase in ozone destruction rate). This result underlines the importance of different spatial FF/OL combinations for aerosol compositions and deposition velocities.

As already mentioned, frost flowers are found close to irregular cracks, which can be as small as several meters. 

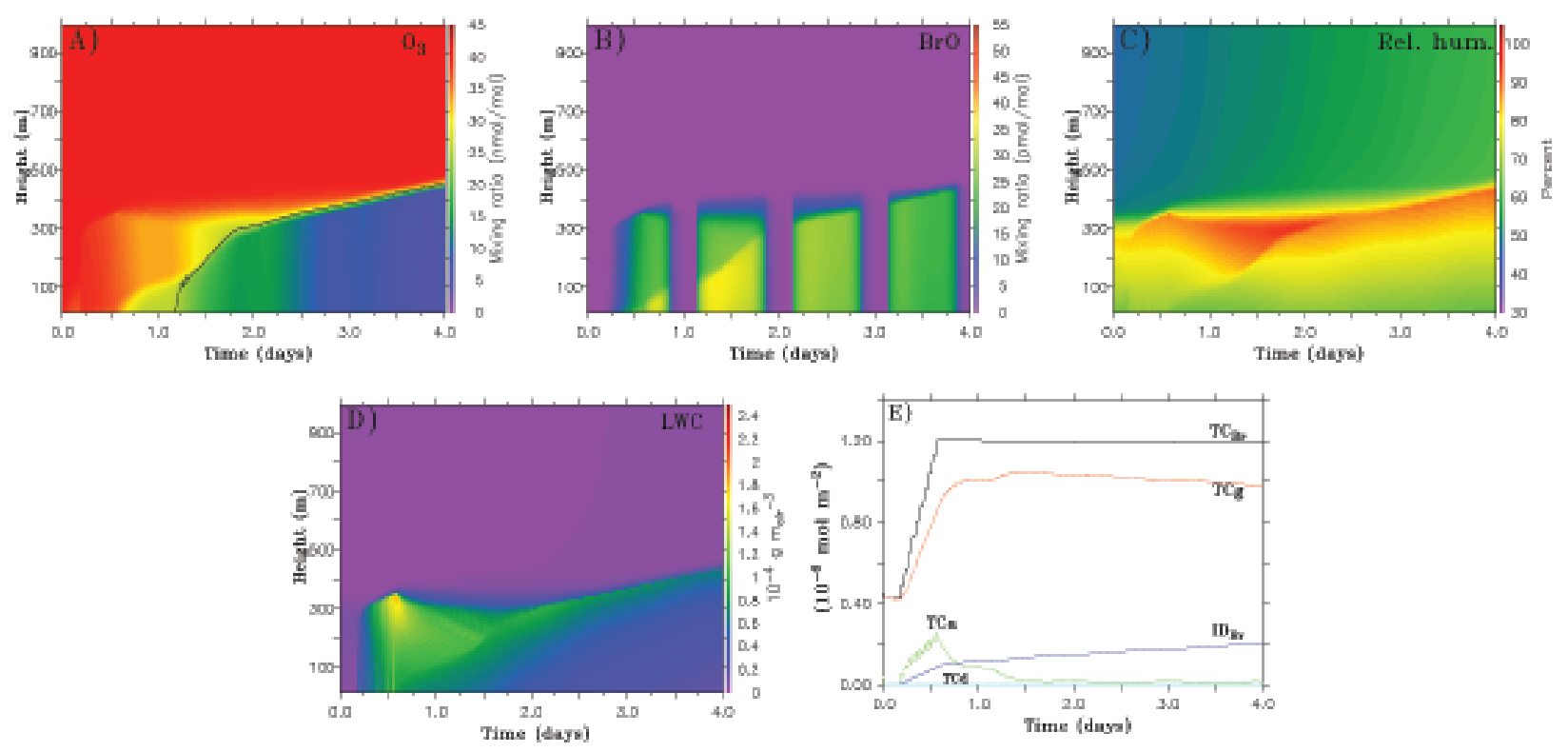

Fig. 6. Run 7 (separated-FF). (A) and (B) gas phase $\mathrm{O}_{3}$ and $\mathrm{BrO},(\mathbf{C})$ relative humidity, (D) LWC, (E) total bromine budget.

These regions of cracks can extend over large areas. In order to simulate such an area but still ensuring that the total time that the model column spends over FF fields (two hours) and open leads $(10 \mathrm{~min})$ is the same as in the other model runs, we did a run where ten FF fields (12 min each, $3.6 \mathrm{~km}$ ) are each followed by an open lead $(1 \mathrm{~min}, 300 \mathrm{~m})$ and a region covered with snow (47 min, $14.1 \mathrm{~km})$. This simulation is called "separated-FF" (run 7, see Fig. 5). The presence of small OLs among the field of FFs sporadically injects humidity in the model over a longer time period of $10 \mathrm{~h}$ (Fig. 6-C). The induced convection is weaker than in the base case, with a lower $\mathrm{LWC}_{\max }$ of $1.8 \times 10^{-4} \mathrm{~g} \mathrm{~m}^{-3}$ (Fig. 6-D). The emissions from FFs produce the same amount of aerosols (see black line in Fig. 6-E) but within $10 \mathrm{~h}$ instead of $2 \mathrm{~h}$.

The initial development of the ODE is slower and maximum $\mathrm{BrO}$ mixing ratios, with only $38 \mathrm{pmol} \mathrm{mol}^{-1}$ (Fig. 6$\mathrm{B})$, are closer to observed numbers than in the base case. The final total deposition $\mathrm{ID}_{\mathrm{Br}}$ is $5 \%$ lower in this case. This run can be categorized as a MODE4 with a minimum of $4 \mathrm{nmol} \mathrm{mol}^{-1}$ of ozone at the end of the four simulated days (Fig. 6-A), compared to $3 \mathrm{nmol} \mathrm{mol}^{-1}$ for the base case. These results show that in a model run with this FF representation as much ozone can be depleted as one unique/large FF area.

Finally, we investigated the changes caused by the emission of aerosols at night instead of at daytime as in previous runs. In these runs the model column passes the FF field on day 0, from 00:00 to 02:00 local time. Particulate bromide mostly remains in FF aerosols as long as no photochemical reactions take place. At night, as no halogen radical forms in the air, neither gas phase $\mathrm{HOBr}$ nor $\mathrm{XONO}_{2}$ (with $\mathrm{X}, \mathrm{Y}=\mathrm{Br}$, $\mathrm{Cl}$ ) can build up. $\mathrm{HOBr}$ is then the limiting factor for Re- action (14). Similarly, the heterogeneous Reaction (18) and (19) cannot proceed efficiently.

Aerosol debromination cannot take place if neither $\mathrm{HOBr}$ nor $\mathrm{XONO}_{2}$ is present. Therefore, the sedimentation of bromine at night is almost entirely bromide-controlled (about 99\%). We investigated two different scenarios, one where $\mathrm{Br}_{2}$ and $\mathrm{BrCl}$ are produced from deposited bromine also in the absence of light (run 8) and another without recycling at night (run 9). In run $8 \mathrm{Br}_{2}$ (Fig. 7-B) and $\mathrm{BrCl}$ get vertically well mixed at night so that the bromine explosion mechanism starts over the whole depth of the $\mathrm{BL}$ at sunrise and $\mathrm{O}_{3}$ gets destroyed rapidly (Fig. 7-A). In this run the threshold for a MODE4 is reached approximately $18 \mathrm{~h}$ more rapidly than in the case where FFs are prescribed during daytime. $\xi_{\mathrm{BrO}}$ has a maximum value of $57 \mathrm{pmol} \mathrm{mol}^{-1}$ in the lowest $150 \mathrm{~m}$ (Fig. 7-C), corresponding to an increase of $17 \%$ compared to the base case.

If no re-release of bromine takes place from snow at night, the presence of FFs under these conditions leads to a large deposition of aerosols without affecting the gas phase concentrations at night (run 9, see right hand side of Fig. 7). At sunrise, $24 \%$ of $\mathrm{TC}_{\mathrm{Br}}$ is constituted by $\mathrm{ID}_{\mathrm{Br}}$ (Fig. 7-D*) compared to $8 \%$ for the run with re-emission at night (run 8). Ozone mixing ratios do not fall below $14 \mathrm{nmol} \mathrm{mol}^{-1}$ (Fig. 7$\mathrm{A}^{*}$ ) and $\mathrm{Br}_{2}$ remains low, below $23 \mathrm{pmol} \mathrm{mol}^{-1}$ (Fig. 7-C $\mathrm{C}^{*}$.

In both cases the presence of FFs at night has considerable consequences for the bromine concentration in the individual phases: depending on the capability of snow to recycle deposited matter at night, deposited bromide is either converted to gas phase bromine (recycling at night) or stored in/on snow (no recycling at night). However, it is important to note that recycling at night compared to daylight recycling is 

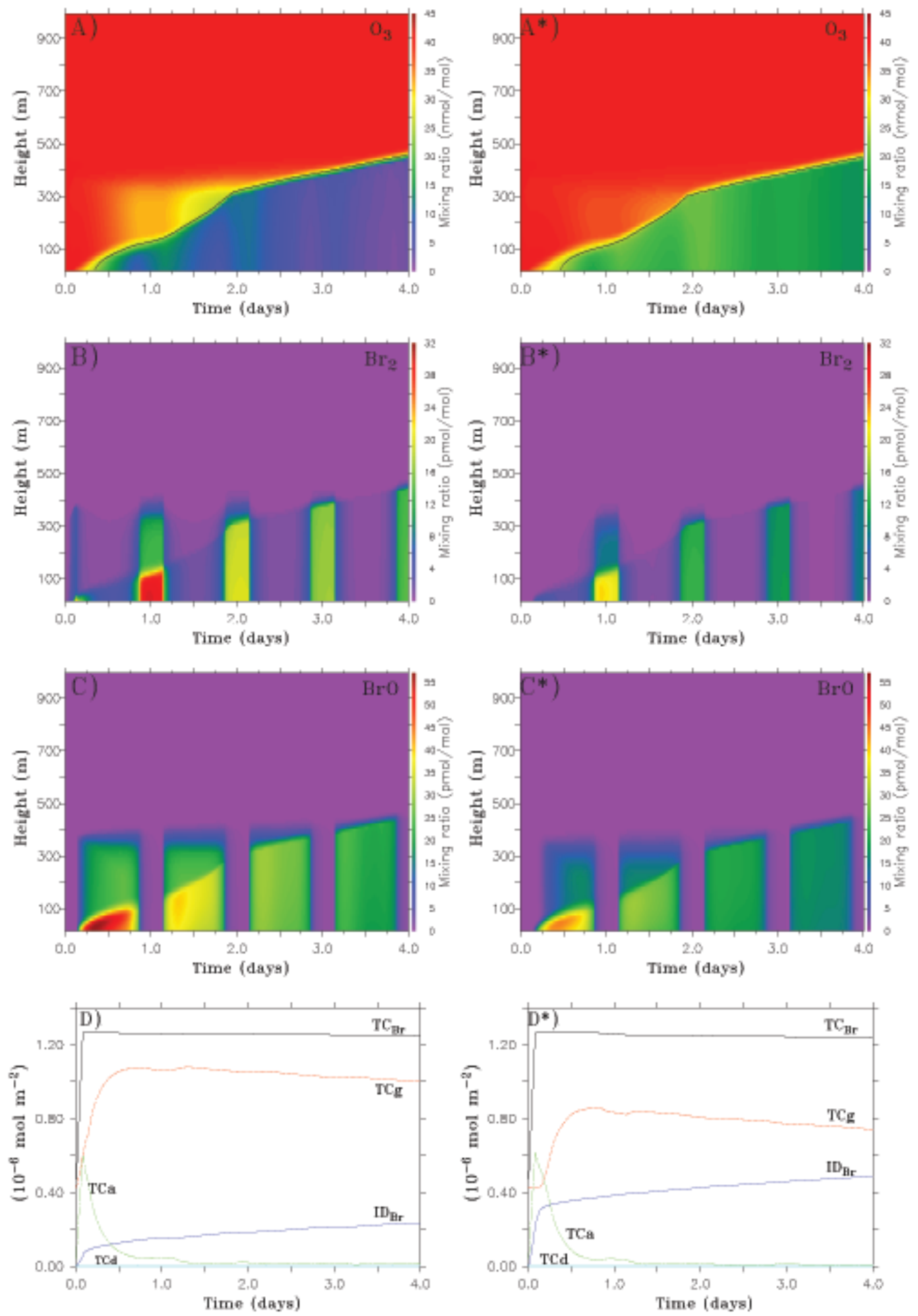

Fig. 7. Frost flowers at night (aerosols released the first day, 00:00 local time). Left (run 8): recycling of deposited bromine from the snow at night; right (run 9): no recycling at night. (A) $\mathrm{O}_{3}$, (B) $\mathrm{Br}_{2}$, (C) $\mathrm{BrO}$, (D) total bromine budget. 

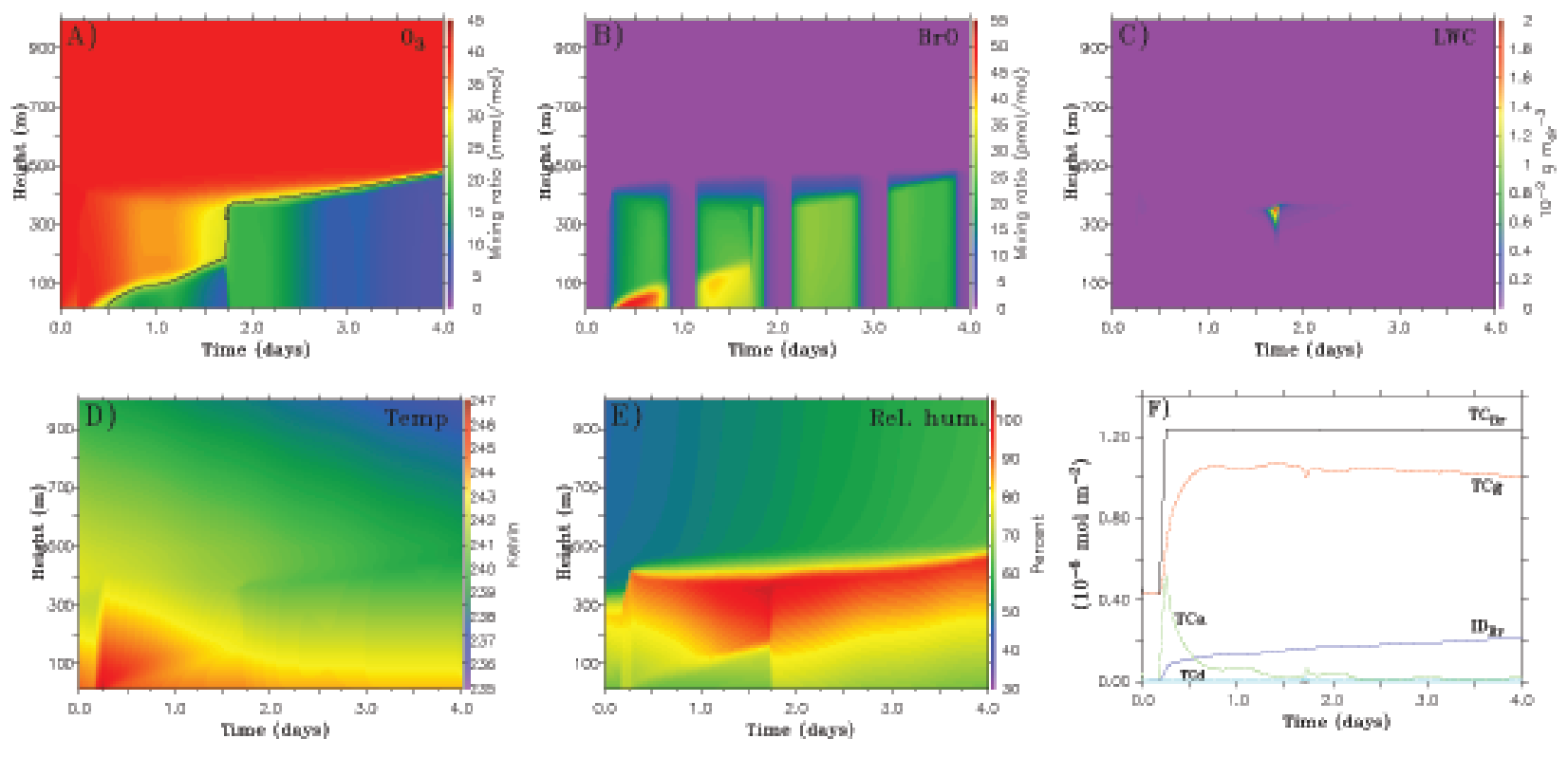

Fig. 8. Run 10. Frost flower temperature increased by $5 \mathrm{~K}$ compared to the base case. (A) $\mathrm{O}_{3},(\mathbf{B}) \mathrm{BrO}$, (C) aerosol LWC, (D) air temperature $T,(\mathbf{E})$ relative humidity, $(\mathbf{F})$ total bromine budget.

rather unimportant (see observations from Foster et al., 2001; Spicer et al., 2002). Laboratory studies have shown that dark reactions on salty ice may release gas phase bromine (Oum et al., 1998). However, their quantitative importance remains to be evaluated. As our model runs are Lagrangian runs the bromine stored in the snow is not taken into account as additional bromine source in the model (see also Sect. 3.6 where we compare our results to field measurements). We therefore encourage experimentalists monitoring the concentration of halogenated species near a frost flower area during day-tonight and night-to-day transitions in order to better understand the effects of FFs during nighttime. The results in this section showed us that multiple surface conditions can influence the ozone level in the BL. In order to better characterize these ODEs, laboratory and field studies with accurate Arctic surface descriptions are needed to understand the criteria leading to a major ODE.

\subsection{Meteorological parameters}

\subsubsection{Temperature}

The mean temperature of frost flowers is subject to horizontal/vertical temperature gradients (in particular due to the presence of open water). By specifying the area of FFs five degrees warmer than our standard value for the surface of $255 \mathrm{~K}$ (run 10), the specific humidity at the surface increases by about $40 \%$. When the model column crosses the FFs, the rise in relative humidity in the overlying air (Fig. 8-E) compared to the base case leads to particle growth, faster deposition (Fig. 8-F) and consequently to an increase in the recycling of bromine from the surface. On the first day, the greater concentration of $\mathrm{Br}$ atoms at lower altitudes $(0-$ $150 \mathrm{~m}$ ) leads to more ozone molecules destroyed via the catalytic cycles mentioned in Sect. 1 . There, $\xi_{\mathrm{BrO}}$ reaches values up to $49 \mathrm{pmol} \mathrm{mol}^{-1}$ (Fig. 8-B). $\mathrm{O}_{3}$ mixing ratios approach a minimum of $8 \mathrm{nmol} \mathrm{mol}^{-1}$ before the formation of a cloud in the afternoon of day 1, 15:00 local time (Fig. 8-A). The presence of cloud droplets lasts for only $5 \mathrm{~h}$ (Fig. 8-C). The induced air mixing caused by the variation in radiative and heat fluxes affects the whole BL within three hours. Ozone at lower altitudes is replenished with ozone-rich air from above. Overall in this model run we note a stronger ODE (equivalent to a PODE) in the vicinity of the surface than in the base case, caused by the change in recycling on snow before the afternoon of day 1. After dispersion of the cloud, ozone mixing ratios decrease again and reach a minimum of about $4 \mathrm{nmol} \mathrm{mol}{ }^{-1}$ (MODE) at the end of the model run.

In conclusion, the prescribed change in temperature associated to the FF area appears to be important in our model results: it modifies the particle deposition velocity and therefore the amount of available bromine radicals released via the snow. Thermal characteristics of frost flowers must be carefully considered to better understand their potential importance.

In addition to the studies above, we also ran the model under colder ambient conditions (Fig. 9 - run 11). By adequately cooling the surface temperature during the spin-up, we obtained a BL with approximately $1 \mathrm{~K}$ colder compared to the base run. Using this colder initial spin-up, we tested the effects of such an airmass on chemistry. In this run we kept the temperature and specific humidity profiles constant 

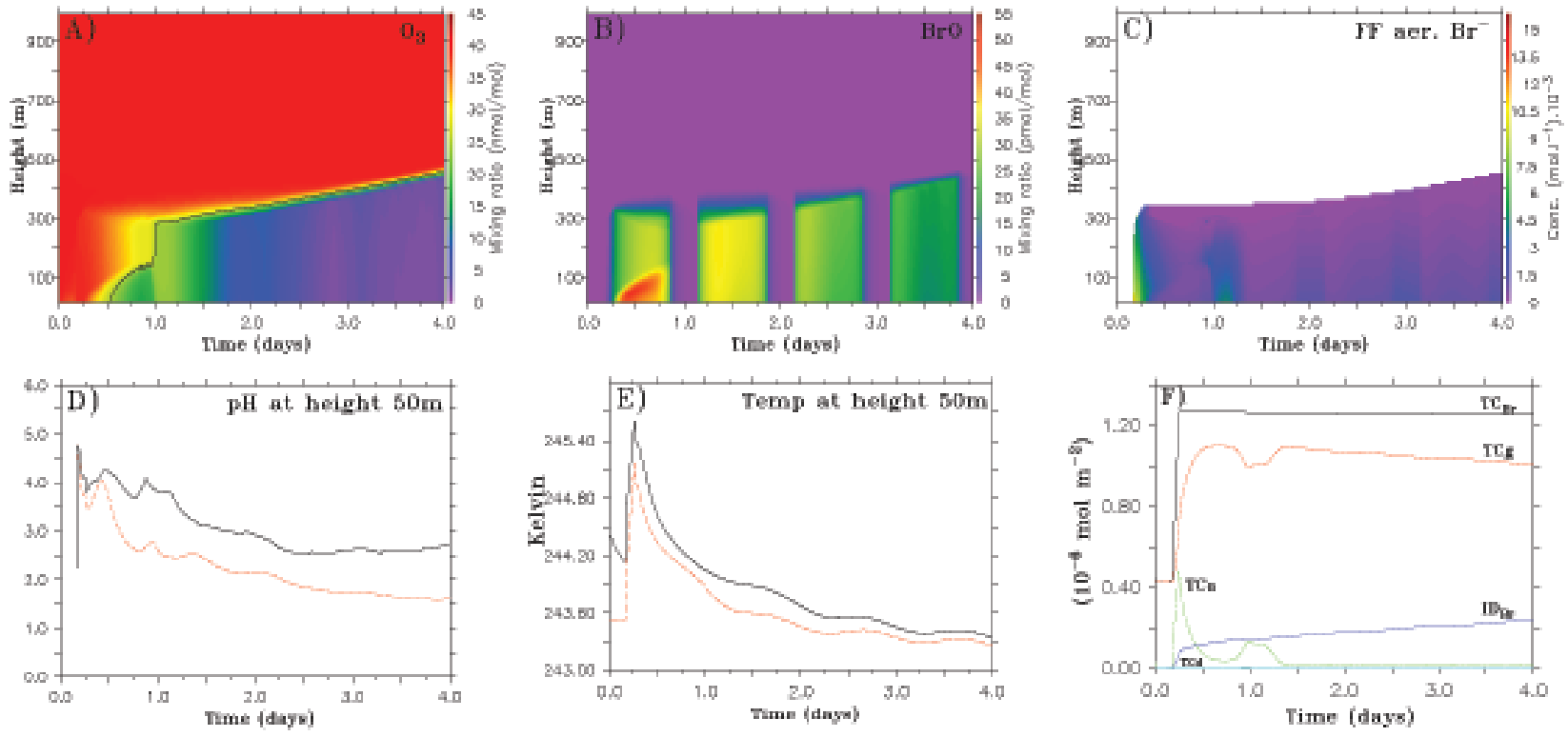

Fig. 9. Run 11. Airmass $1 \mathrm{~K}$ colder than the base run. (A) and (B) gas phase $\mathrm{O}_{3}$ and $\mathrm{BrO}$, (C) $\mathrm{FF}$ aerosol bromide, (D) $\mathrm{FF}$ aerosol $\mathrm{pH}$ at an altitude of $50 \mathrm{~m}$. Solid black line: base run; dashed red line: run 11. (E) same as (D) for air temperature. (F) total bromine budget.

to conserve the airmass characteristics up to the presence of FFs at 04:00 local time, day 0 (Fig. 9-E). Snowpack, frost flowers and open lead temperatures remain unvaried ( $245 \mathrm{~K}$, $255 \mathrm{~K}$ and $271 \mathrm{~K}$ resp.). Due to a lower water vapor saturation pressure under colder conditions, the relative humidity rises by about $7 \%$ in the model. Particles grow more rapidly in the humid air. The accomodation coefficients $(\alpha)$ and the Henry's constants are, for a large variety of chemical species in MISTRA, according to the literature values directly a function of temperature: for a decrease of $1 \mathrm{~K}, \alpha$ increases by about $3-5 \%$ (largest increase for $\mathrm{HBr}, \mathrm{ROOH}$, $\mathrm{HCl}$ ), while Henry's constants rise up to $15 \%$ with highest values for acids $\left(\mathrm{HBr}, \mathrm{HCl}, \mathrm{HNO}_{3}\right)$.

These changes lead to an increase in uptake of acids affecting the $\mathrm{pH}$ of particles. Fig. 9-D shows the FF aerosol pH at an altitude of $50 \mathrm{~m}$ for the base run (solid black line) and for run 11 (dashed red line). In this case, after the aerosol release and equilibrium with the ambient air, the $\mathrm{pH}$ of $\mathrm{FF}$ aerosols decreases from 4.8 to 1.5 within four days, whereas it only decreases to a minimum of 2.5 in the base run. Note the $\mathrm{pH}$ increase after day 0, 06:00 local time due to rise in humidity after the OL. The bromine explosion cycle is more efficient in more acidic particles: FF aerosols are debrominated earlier than in the base run. On day 0, 22:00, the short formation of cloud droplets temporarily modifies the bromine concentration in the gas and particulate phases (see Fig. 9-C and F).

The total amount of bromine $\mathrm{TC}_{\mathrm{Br}}$ is here higher than in the base run due to the increase of temperature-related fluxes at the snow surface. It is also important to note that the rise in humidity is small. The deposition $\mathrm{ID}_{\mathrm{Br}}$ increases by less than $10 \%$. Thus, the acceleration in the bromine explosion is essentially caused by the change in particle $\mathrm{pH}$, not by the modification of the re-emission from the ground. Importantly (Fig. 9-C), this acceleration in the liberation of aerosol bromide to gas phase bromine occurs in the whole BL: on the first day, $\mathrm{BrO}$ in the upper part of the BL exhibits mixing ratios up to $33 \mathrm{pmol} \mathrm{mol}^{-1}$ compared to 25 for the base run (Fig. 9-B). As a consequence, $\mathrm{O}_{3}$ molecules are destroyed more rapidly and more uniformly within the BL. In this run the ODE corresponds to a MODE3.

These results are in good agreement with observations of air depleted in ozone simultaneously with low temperatures (Bottenheim et al., 1990; Beine et al., 1997). However, we have to stress that these unexpectedly large differences are based on estimates of the temperature dependencies of $\alpha$ and the Henry's constants which might not be valid for those low temperatures. As the potential impact is very large, as shown, the temperature dependencies should be revisited in laboratory.

\subsubsection{Wind speed}

To assess the potential effects on the chemistry due to a change in wind speed, we performed a model run with $u=7 \mathrm{~m} \mathrm{~s}^{-1}$ (run 12 in Table 4), instead of $5 \mathrm{~m} \mathrm{~s}^{-1}$ as in the base case. The increase in wind speed leads (with our assumption for the FF source function) to an unrealistically high atmospheric bromine loading with a complete destruction of $\mathrm{O}_{3}$ in the PBL within minutes. A reduction of the scaling factor $\mu$ (see Sect. 2.1) from the standard value of 90 to 45 leads to realistic loadings. The mean ozone loss rate was $0.4 \mathrm{nmol} \mathrm{mol}^{-1} \mathrm{~h}^{-1}$, inducing a MODE4 (Fig. 10-A). 

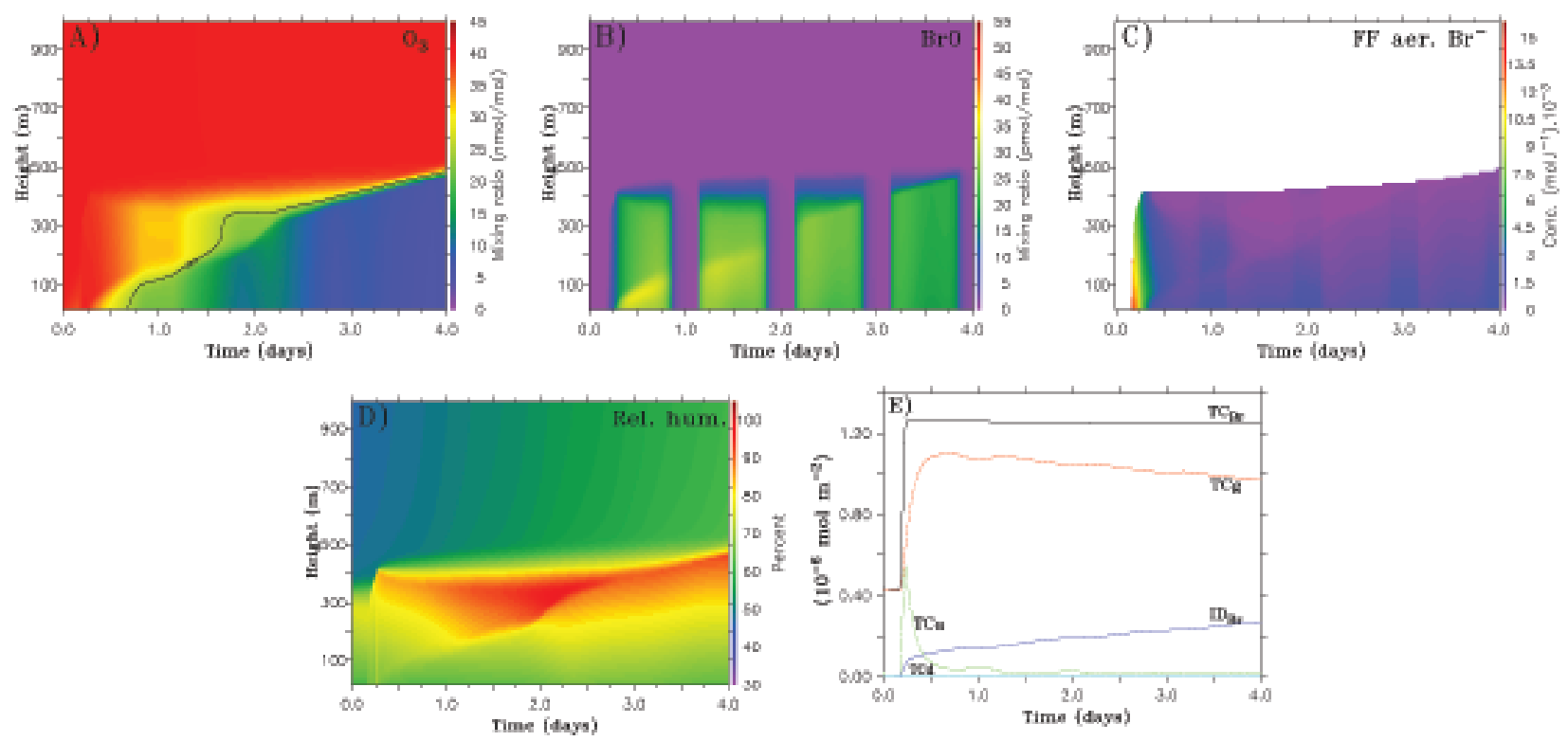

Fig. 10. Run 12. Scaling factor $\mu=45$, wind speed $=7 \mathrm{~m} \mathrm{~s}^{-1}$. (A) $\mathrm{O}_{3}$, (B) $\mathrm{BrO}$, (C) FF aerosol bromide, (D) relative humidity, (E) total bromine budget.

At night, between day 0 and $1, \xi_{\mathrm{Br}_{2}}$ reaches a maximum of $20 \mathrm{pmol} \mathrm{mol}^{-1}$. In our model the higher wind speed increases wind shear which contributes to an extension of the BL up to $475 \mathrm{~m}$ until the end of day 3 (see Fig. 10D). This extension leads to a reduction of the $\mathrm{LWC}_{\max }$ to $1.6 \times 10^{-4} \mathrm{~g} \mathrm{~m}^{-3}$. As a consequence, less entrained air from aloft enters the $\mathrm{BL}$ in the morning of day 2 than in the base case. $\mathrm{BrO}$ mixing ratios reach a maximum of $36 \mathrm{pmol} \mathrm{mol}^{-1}$ on day 0 (Fig. 10-B). The change in dynamics related to an increase of the wind speed to $7 \mathrm{~m} \mathrm{~s}^{-1}$ induced no major change in the chemistry. A PODE4 can be reproduced with a scaling factor $\mu=25$.

Contrarily, under calm conditions ( $u=1 \mathrm{~m} \mathrm{~s}^{-1}$, not shown) the aerosol production is very weak in the model (for $\mu=90$ ). The amount of released FF aerosols is small, and no ODE develops. Ozone in the BL does not decrease below $26 \mathrm{nmol} \mathrm{mol}^{-1}$ after 4 days of simulation. A decline in wind speed might therefore significantly contribute to the cessation of aerosol production from the FFs.

We are well aware that the aerosol source function and its dependence on wind speed used in our model is only a rough approximation. Nevertheless, it is likely that the FF aerosol production in the Arctic presents at least a qualitatively similar wind speed dependence. Based on the results shown in this section, we speculate that the wind speed might be an important parameter affecting the amount of bromine in the atmosphere and thus the ozone depletion.

As the source of FF aerosols and its dependence on wind speed are so uncertain, we greatly encourage fieldwork and lab studies providing a parameterization for the source function of frost flower aerosols.

\subsection{Carbonate precipitation}

In previous model runs, we have assumed that bicarbonate from the brine precipitates completely. For detailed calculations of $\mathrm{HCO}_{3}^{-}$precipitation, see Sander et al. (2006). We discuss here the effects of the precipitation of only $50 \%$ of the $\mathrm{HCO}_{3}^{-}$(see Anderson and Jones, 1985) from the source of FF aerosols (run 13). The results are shown in Fig. 11. In contrast to the base run, the $\mathrm{pH}$ of particles emitted from FFs are buffered to a $\mathrm{pH}$ close to 8 . Acidification of particles is slowed down and requires 18 more hours to reach a $\mathrm{pH}$ of 4-4.5, compared to the base run. The bromine explosion cycle for the first day is strongly reduced, especially in the upper part of the BL (Fig. 11-C). There, mixing ratios of $\mathrm{BrO}$ do not exceed $4 \mathrm{pmol} \mathrm{mol}^{-1}$ (Fig. 11-B). The chemistry in the lowest layers is, as explain before, mainly influenced by the deposition/re-emission from snow. On day 0 , a large fraction of bromide remains in aerosols (see TCa in Fig. 11-D). In this scenario, the re-emission of $\mathrm{Br}_{2} / \mathrm{BrCl}$ from deposited $\mathrm{Br}^{-}$represents the only efficient pathway for the activation of particulate bromide. Therefore, most of the gas phase bromine is directly related to the aerosol deposition rate and is concentrated near the surface. BrO has a maximum of $56 \mathrm{pmol} \mathrm{mol}^{-1}$ in the lowest $100 \mathrm{~m}$ of the BL (Fig. 11-B). After one simulated day $\mathrm{ID}_{\mathrm{Br}}$ increased by $56 \%$ compared to the base run. During this first day, ozone decreases to $15.5 \mathrm{nmol} \mathrm{mol}^{-1}$ (Fig. 11-A).

The strongest bromine explosion takes place where $\xi_{\mathrm{BrO}}$ and $\xi_{\mathrm{HOBr}}$ are maximum, at altitudes below $100 \mathrm{~m}$ in the afternoon of day 0 (see decrease in $\mathrm{Br}^{-}$concentration, Fig. 11C). However, it is weaker than in the base run due to the 

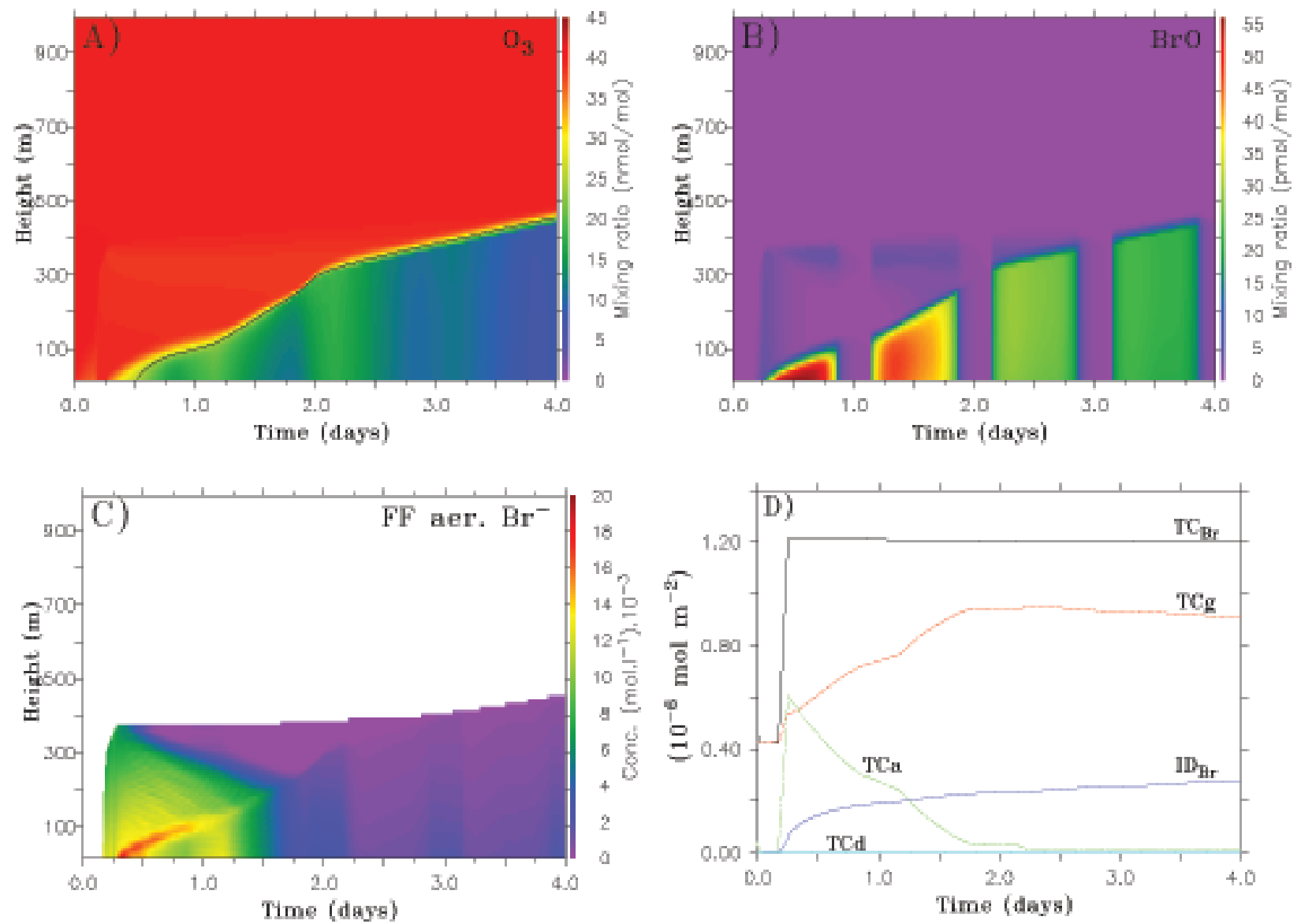

Fig. 11. Run 13. Only $50 \%$ of bicarbonate precipitated. (A) $\mathrm{O}_{3}$, (B) $\mathrm{BrO}$, (C) FF aerosol bromide, (D) total bromine budget.

presence of buffering $\mathrm{HCO}_{3}^{-}$. We calculated an approximate delay of $24 \mathrm{~h}$ for the complete aerosol debromination compared to the base case.

After the second simulated night (between day 1 and 2), most of the aerosol bromide is either deposited or has been liberated into the gas phase. Then, the ozone depletion process remains substantial until the end of the model run (Fig. 11-A). After four days of simulation, ozone decreased to a minimum of $7 \mathrm{nmol} \mathrm{mol}^{-1}$ which is close to our predefined MODE threshold. The eventual mixing ratio of ozone is only $4 \mathrm{nmol} \mathrm{mol}^{-1}$ higher than in the base case. Accumulated deposition at the end of the run is $32 \%$ higher than in the base case (Fig. 11-D).

The precipitation of only $50 \%$ of $\mathrm{HCO}_{3}^{-}$leads to a delay toward several hundreds of kilometers downwind for the completion of the aerosol debromination. The release of bromine to the gas phase is weaker than in the base case when considering the whole PBL. Due to the efficient re-release of deposited bromine in the model the $\mathrm{BrO}$ mixing ratios near the surface are actually higher than in the base case. There is a significant $\mathrm{O}_{3}$ destruction but again weaker than in the base run. It is important to note that, without re-release from

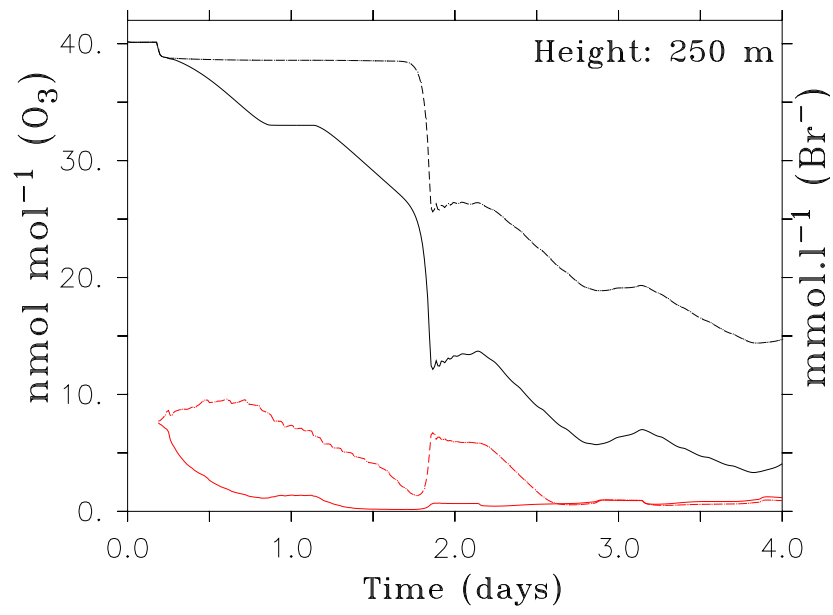

Fig. 12. Values displayed for an altitude of $250 \mathrm{~m}$. Black: $\mathrm{O}_{3}$ (nmol mol$\left.{ }^{-1}\right)$; Red: FF aer. $\mathrm{Br}^{-}\left(\mathrm{mmol} \mathrm{l}^{-1}\right)$. Solid lines: base run. Dashed lines: no bicarbonate precipitated (run 14). 
snow, the bromine explosion in the lowest $100 \mathrm{~m}$ of the BL would hardly initiate.

If no precipitation of calcium carbonate occurs in the brine or on FFs (Fig. 12, run 14), the released FF aerosols hardly liberate bromide (see dashed red line). At altitudes where the chemistry is not influenced by the recycling on snow (up to day 1, 18:00 local time), the bromine explosion is almost absent, and ozone mixing ratios remain constant. At low altitudes, deposited aerosols are recycled as gas phase $\mathrm{Br}_{2} / \mathrm{BrCl}$. Shortly before day 2 we note a strong rebromination of aerosols as the air is now influenced by the surface and as the bromine explosion remains weak. At the end of the simulation ozone reaches a minimum value of $15 \mathrm{nmol} \mathrm{mol}^{-1}$ (see dashed black line) for the whole PBL.

In summary, due to the bromine recycling from snow releasing $\mathrm{Br}_{2} / \mathrm{BrCl}$, ozone keeps being destroyed in layers chemically influenced by the emissions from the snow. However, this study on the $\mathrm{CaCO}_{3}$ precipitation clearly showed that the bromine explosion in $\mathrm{FF}$ aerosols is strongly reduced by the presence of particulate $\mathrm{HCO}_{3}^{-}$.

\subsection{Arctic Haze conditions}

Arctic Haze in spring has been extensively studied (Schnell, 1983; Rasmussen and Khalil, 1984). Polluted airmasses provide acidity in the BL which may play an important role on the ozone/halogen chemistry. In this run (run 15), we assessed the potential importance of a typical haze event on our focused chemistry. This run is initialized with haze aerosols (Table 2) and gas phase mixing ratios typical of a haze event (Table 1). This run is characterized by an increase in aerosol acidity due to the presence of $0.3 \mathrm{nmol} \mathrm{mol}{ }^{-1}$ of sulfur dioxide $\left(\mathrm{SO}_{2}\right)$. This compound is the major source of aqueous phase acidity (as taken up in aerosols and ultimately producing $\mathrm{H}^{+}$ions). As a consequence, the $\mathrm{FF}$ aerosol $\mathrm{pH}$ rapidly decreases (see Fig. 13-D, with $\mathrm{pH} \simeq 1.5-2.5$ at an altitude of $50 \mathrm{~m}$ ). Due to the vertically homogeneous presence of $\mathrm{SO}_{2}$, this particle acidification occurs in the whole $\mathrm{BL}$. The more acidic liquid phase liberates $\mathrm{Br}^{-}$more efficiently and more homogeneously than in the base run. Similarly, as the bromine explosion is now efficient in the upper layers as well, mixing ratios of $\mathrm{BrO}$ reach values up to $5 \mathrm{pmol} \mathrm{mol}^{-1}$ higher than in the base run (Fig. 13-B).

There, we note a maximum decrease in ozone of about $5 \mathrm{nmol} \mathrm{mol}^{-1}$ (Fig. 13-A), a consequence of the stronger debromination (Fig. 13-C). Analogously, near the surface, the larger amount of bromine depletes up to $4 \mathrm{nmol} \mathrm{mol}^{-1}$ of ozone. The MODE4 threshold is reached 6 hours earlier than in the base run. According to our results, Arctic Haze intensifies the ODE via acidification of salt-containing particles and provision of numerous sulfate particles for the bromine recycling. These results are in good agreement with observations from Bottenheim et al. (2002b).

An analysis of the individual processes involved in the modeled ODEs indicated that gas phase $\mathrm{SO}_{2}$ is the key factor in this case, controlling the aerosol acidity. $\mathrm{SO}_{2}$ accelerates the bromine explosion cycle. The analysis of the role of haze aerosols showed that they provide an effective medium for recycling low-reactive bromine species. Without the presence of haze aerosols the cycles converting $\mathrm{HBr}, \mathrm{BrONO}_{2}$, and $\mathrm{HOBr}$ slow down drastically. These compounds eventually become a sink for reactive bromine and deposit on snow. Together, both $\mathrm{SO}_{2}$ and numerous haze particles were found important in the acceleration of the ODE.

We completed our analysis by performing a run containing haze but without assuming $\mathrm{HCO}_{3}^{-}$to have precipitated out of the brine/FFs. The results of this run (not shown) are very similar to that of run 1 (base run). This indicates that the presence of anthropogenic pollution has the same net effect as that of carbonate precipitation on the acidity of the salt particles, the resulting release of bromine, and the development of the ODE. In contrast to ODEs in the Antarctic, it is likely that Arctic ODEs are influenced, in frequency and intensity, by the periodic presence of haze.

\subsection{Recycling of deposited bromine on snow}

Snow has been shown to have a major influence on the atmospheric chemical composition (Grannas et al., 2007). We have shown above that in our model runs, recycling of deposited bromine from the snow plays an important role for the development of an ODE. Even though the release of $\mathrm{Br}_{2}$ and $\mathrm{BrCl}$ from the snow has been measured at Alert, Canada (Foster et al., 2001; Spicer et al., 2002), the relative amount of bromine in the snow that can be recycled is unconstrained.

In all previous model runs we have assumed a recycling efficiency of $v_{\text {snow }}=75 \%$ for deposited bromine and will in this section discuss additional runs with $v_{\text {snow }}=0 \%, 25 \%$ and $50 \%$. The efficiency of bromine recycling probably varies strongly depending on the situation but for simplicity we assume it to be constant with time. Fig. 14 shows the total columns $\mathrm{TCg}$, $\mathrm{TCa}$, and $\mathrm{ID}_{\mathrm{Br}}$. A very clear shift from $\mathrm{ID}_{\mathrm{Br}}$ to $\mathrm{TCg}$ occurs with increasing recycling efficiency on snow whereas particulate $\mathrm{Br}$ (both sulfate and FF aerosols) is not strongly affected. The initial deposition of bromine is dominated by particulate $\mathrm{Br}$ (95\% in the first three hours) in all four runs, but only in the run with $v_{\text {snow }}=0 \%$ (run 3 ) it is irreversibly lost for the atmosphere. In this run $\mathrm{ID}_{\mathrm{Br}}$ contributes about $59 \%$ to $\mathrm{TC}_{\mathrm{Br}}$ at the end of the model run, whereas this is only $47 \%, 33 \%$, and $18 \%$ in runs $16\left(v_{\text {snow }}=25 \%\right)$, run $17\left(v_{\text {snow }}=50 \%\right)$, and run $1\left(v_{\text {snow }}=75 \%\right)$, respectively. As previously mentioned, without recycling on snow no ODE can be induced in the model within four days. A value of $v_{\text {snow }}=25 \%$ induces a PODE 4 , and $v_{\text {snow }}=50 \%$ a PODE 2 . The minimum $\mathrm{O}_{3}$ mixing ratio in run 3 is $23.5 \mathrm{nmol} \mathrm{mol}^{-1}$, whereas it is $18.5,11$, and $3 \mathrm{nmol} \mathrm{mol}^{-1}$ in runs 16 , run 17 , and run 1 , respectively. Correspondingly, $\xi_{\mathrm{BrO}}$ maxima increase with increasing $v_{\text {snow }}$ values with $\xi_{\mathrm{BrO}}$ max $=17,25$, and $37 \mathrm{pmol} \mathrm{mol}^{-1}$ for $v_{\text {snow }}=0 \%, 25 \%$, and $50 \%$, respectively. 
t]
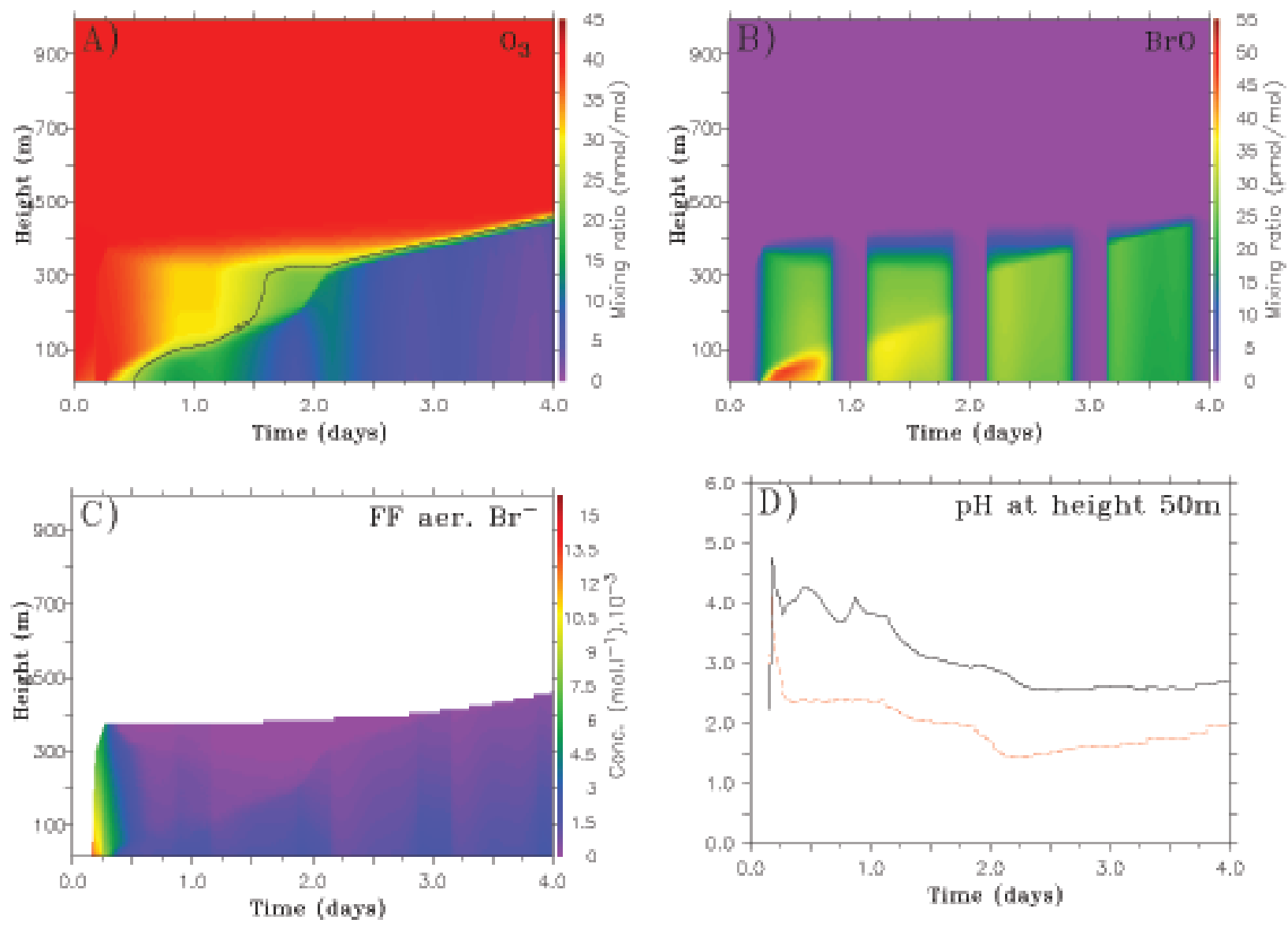

Fig. 13. Arctic Haze conditions (run 15). (A) $\mathrm{O}_{3}$, (B) $\mathrm{BrO}$, (C) FF aerosol bromide, (D) FF aerosol $\mathrm{pH}$ at an altitude of $50 \mathrm{~m}$. Solid black line: base run; dashed red line: run 15 .

As also mentioned above, our assumption of re-release of deposited bromine not only increases the amount of reactive gas phase bromine but it also allows the bromine to be transported farther downwind of the original source. Repetitive deposition and re-release ("leap-frogging") would also provide an explanation for the observations of Simpson et al. (2005) who found $\mathrm{Br}^{-}$in snow a lot farther inland than $\mathrm{Na}^{+}$. We have compared the modeled $\mathrm{ID}_{\mathrm{Br}}$ with their measurements, assuming no snowfall contribution in our calculations. For this purpose, we have calculated the bromine deposition fluxes in the model in mol m $\mathrm{m}^{-2} \mathrm{~s}^{-1}$ and estimated roughly the time period necessary to reproduce the observed concentrations of $\mathrm{Br}^{-}$in snow. As no recycling on snow $\left(v_{\text {snow }}=0 \%\right)$ is inconsistent with observations of $\mathrm{Br}_{2}$ production from the snow and as $v_{\text {snow }}=25 \%$ leads to a too drastic deposition, we did not compare these runs with Simpson et al. (2005). In the case of $v_{\text {snow }}=50 \%$ deposition would have to continue for about 8 days and for $v_{\text {snow }}=75 \%$ approximately 24 days to roughly reproduce the observed values (see Fig. 15). These time spans are in accordance with the desertic nature of polar regions with a mean precipitation as low as $3 \mathrm{~mm} / \mathrm{month}$ at Barrow in spring (Serreze and Barry, 2005). In addition, we compared modeled concentrations of $\mathrm{Na}^{+}$in aerosols as well as in snow with observations. The modeled concentrations in aerosols were found at $2.0-10.0 \mu \mathrm{g} \mathrm{m}^{-3}$ which is relatively higher than observations $\left(0.5-3.0 \mu \mathrm{g} \mathrm{m}^{-3}\right.$, see Hoff and Trivett, 1984; Li and Winchester, 1990). It is important to note, however, that the history and conditions of sampled air may significantly differ from the air simulated in our model. The modeled $\mathrm{Na}^{+}$concentration in snow was found to be in good agreement with observations from Simpson et al. (2005) (not shown).

These comparisons are somewhat problematic as we do not know the history of deposition for the measurements and as we assumed homogeneous meteorological conditions in our model for upscaling the modeled deposition rates. Nevertheless, these comparisons show that our model results are at least semi-quantitatively in agreement with measurements. The results of the comparison of bromide and the suggestions from Peterson and Honrath (2001) that bromine species de- 

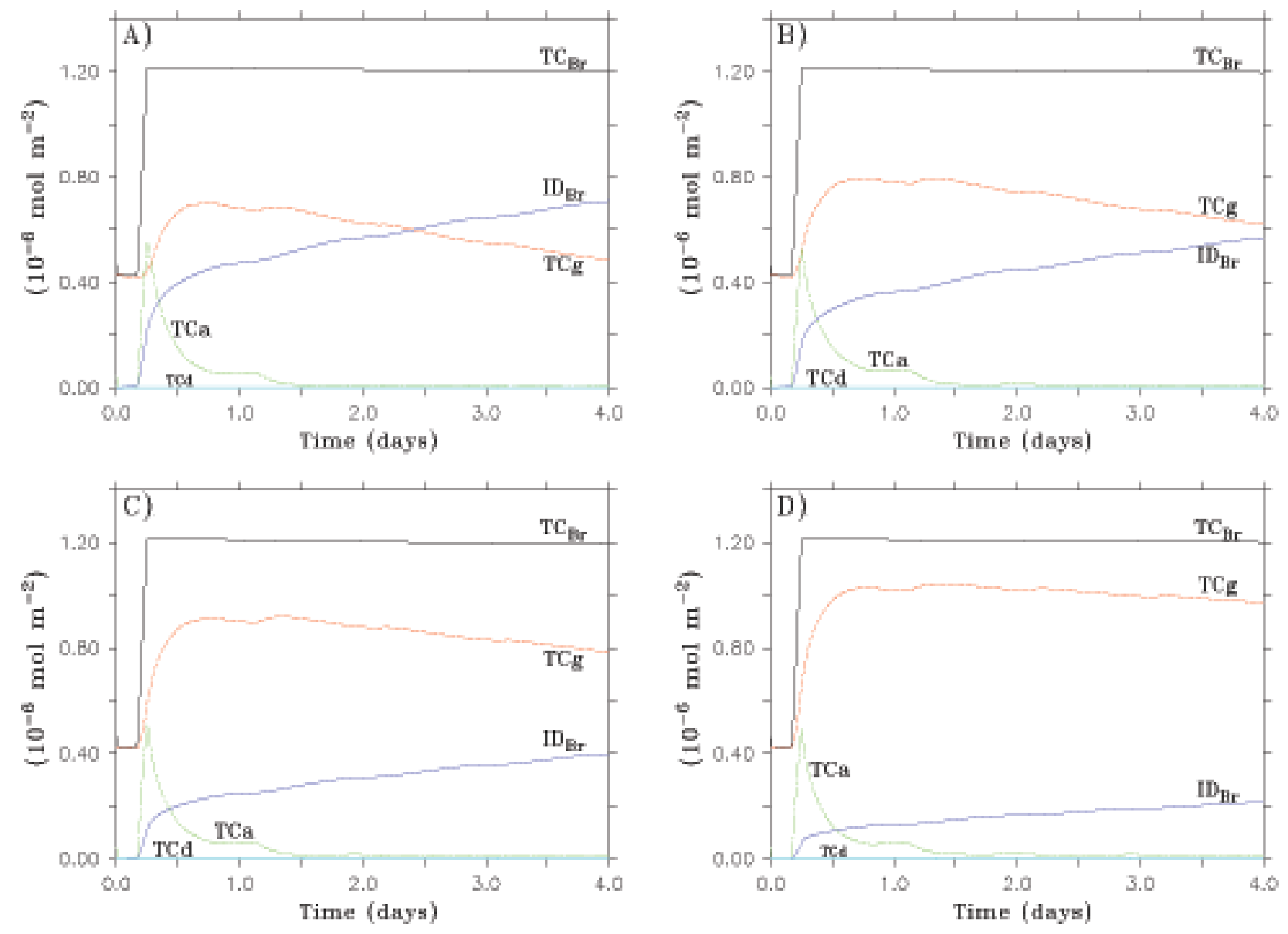

Fig. 14. Total bromine budget. (A) $v_{\text {snow }}=0 \%$ (run 3); (B) $v_{\text {snow }}=25 \%$ (run 16); (C) $v_{\text {snow }}=50 \%$ (run 17); (D) $v_{\text {snow }}=75 \%$ (run 1$)$.

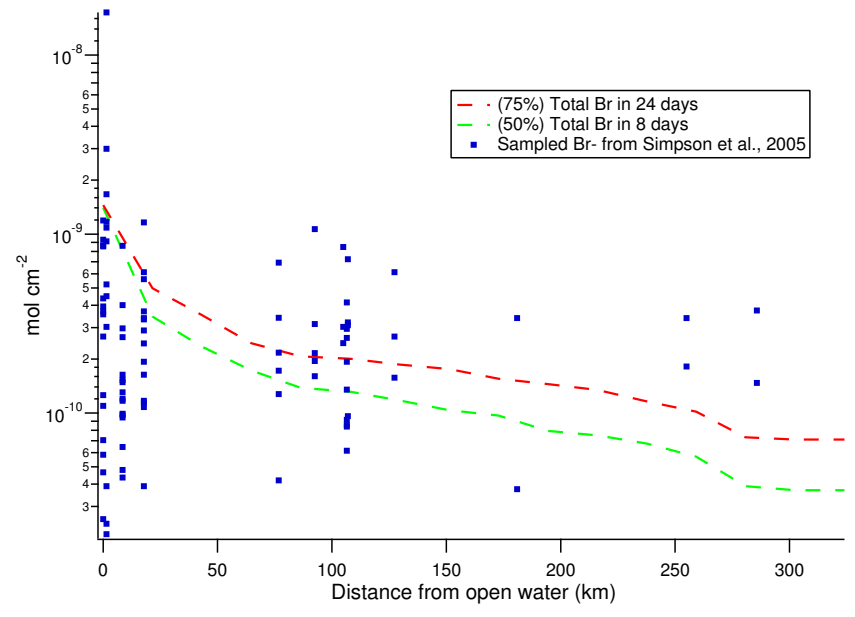

Fig. 15. Comparison between the bromide concentration in snow sampled at Point Barrow by Simpson et al. (2005) (blue dots) and modeled deposition of total bromine compounds (dashed lines). Red dashed line: $v_{\text {snow }}=75 \%$, green dashed line: $v_{\text {snow }}=50 \%$. posited to the snowpack are rapidly recycled are the rationale for our choice of $v_{\text {snow }}=75 \%$ as the most appropriate recycling ratio from the snowpack in our base case.

\subsection{Effect of fluxes from snow}

To conclude our studies on the snowpack effects, we investigated the influence of non-halogen gases that are released from the snow on the atmospheric chemistry. Fluxes of NO, $\mathrm{NO}_{2}, \mathrm{H}_{2} \mathrm{O}_{2}, \mathrm{HCHO}, \mathrm{C}_{2} \mathrm{H}_{4}$, and $\mathrm{HONO}$ were determined as mentioned in Sect. 2.3 and are listed in Table 3. We performed model studies assessing the influence of these fluxes from the snow. To do so, single fluxes are switched off in the model and the results are compared to the base run (more detailed studies will be addressed in a forthcoming paper). Our results showed that only the nitrous acid flux $\left(F_{\mathrm{HONO}}=5.0 \times 10^{8}\right.$ molec $\left.\mathrm{cm}^{-2} \mathrm{~s}^{-1}\right)$ had a substantial influence on the ozone/halogen chemistry. Indeed, field and laboratory measurements highlighted the importance of $\mathrm{HONO}$ exchange between the snowpack and ambient air ( $\mathrm{Li}, 1994$; Zhou et al., 2001; Jacobi et al., 2004). HONO molecules break down by photodissociation to yield the two highly reactive radicals, $\mathrm{OH}$ and $\mathrm{NO}$. 

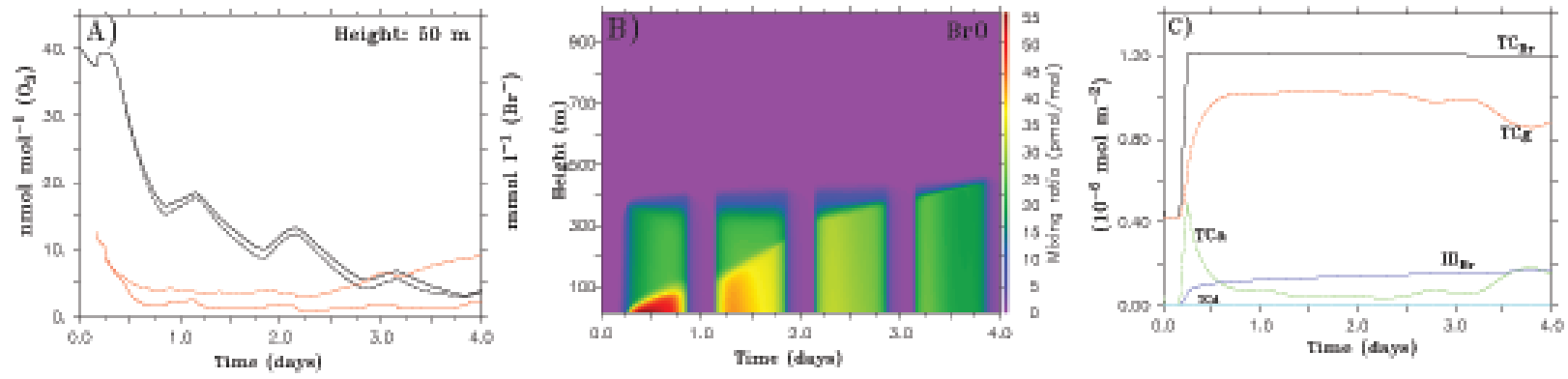

Fig. 16. Run 18 (no-HONO). (A) Comparison between run 18 (dashed lines) and the base run (solid lines) for gas phase $\mathrm{O}_{3}$ (black lines in nmol mol ${ }^{-1}$ ) and $\mathrm{FF}$ aerosol bromide (red lines in $\mathrm{mmol}^{-1}$ ) at an altitude of $50 \mathrm{~m}$. (B) BrO in run 18, (C) total bromine budget for run 18 .

In a run without flux of $\mathrm{HONO}$ (Fig. 16 - run 18) as well as in the base case, for the first simulated hours, most of the gas phase bromine is produced by re-emission of deposited $\mathrm{Br}^{-}$ from the snowpack. Additionally, a small fraction of bromide is activated by halogen nitrate reaction on salt aerosols and the bromine explosion mechanism involving $\mathrm{HOBr}$. The absence of a HONO flux from the snow leads to a reduction of $\mathrm{HO}_{2}$ and $\mathrm{HCHO}$ mixing ratios. As a result, $\mathrm{HOBr}$ mixing ratios are reduced by up to $65 \%$ and $\mathrm{HBr}$ by up to $45 \%$, respectively. Similarly, the decrease in NO concentration, and therefore $\mathrm{NO}_{2}$, reduces the formation of $\mathrm{XONO}_{2}$ and $\mathrm{XNO}_{2}$ molecules via Reactions (15) and (16). This results in a redistribution from gas phase $\mathrm{HOBr}, \mathrm{HBr}, \mathrm{XONO}_{2}$, and $\mathrm{XNO}_{2}$ to $\mathrm{Br}$ and $\mathrm{BrO}$. Shortly after crossing the frost flowers, $\mathrm{BrO}$ increases by more than $15 \%$ compared to the base run (Fig. 16-B), with a maximum value of $56 \mathrm{pmol} \mathrm{mol}^{-1}$. Fig. 16-A shows the comparison between this run (dashed lines) and the base case (solid lines) for $\mathrm{O}_{3}$ (black lines) and $\mathrm{Br}^{-}$from FF aerosols (red lines) at an altitude of $50 \mathrm{~m}$. This figure shows that $\xi_{\mathrm{O}_{3}}$ is reduced by about $2 \mathrm{nmol} \mathrm{mol}^{-1} \mathrm{com}$ pared to the base run, starting on day 0, 12:00.

Besides, as $\mathrm{HOBr}$, and (to a lesser extent) $\mathrm{BrONO}_{2}$ mixing ratios are reduced in this model run, the bromine explosion is also reduced. The dashed red line in Fig. 16-A shows substantial amounts of bromide remaining in FF aerosols until the end of the run. The incomplete debromination reduces the concentration of total gas phase bromine. In terms of ozone depletion, this inversely competes with the acceleration of the $\mathrm{BrO}$ self-reaction.

On day 3, the $\mathrm{BrO}$ self-reaction diminishes due to less $\mathrm{O}_{3}$ molecules present in the PBL. The produced gas phase $\mathrm{HBr}$ and $\mathrm{HOBr}$ induce a stronger bromine uptake in aerosols (less TCg). Our model results show the bromination of sulfate aerosols and the incomplete debromination of the FF aerosols. The bromine uptake in sulfate aerosols contributes $60 \%$ to the increase of TCa, and in FF aerosols $40 \%$, respectively. At the end of the run, the competition between $\mathrm{BrO}$ self-reaction and the weak bromine explosion cycle leads to a decrease in the ozone destruction rate (also see $\mathrm{O}_{3}$ mixing ratio on day 3, in Fig. 16-A). Eventual ozone concentrations in this run are nearly identical to the base case.

It is important to notice that HONO has different repercussions on $\mathrm{O}_{3}$ depending on the bromide concentration in aerosols. If the concentration of aerosol $\mathrm{Br}^{-}$is high, it leads to the chemistry explained above in this section. If its concentration is low, HONO plays mostly a role in the gas phase by transforming $\mathrm{Br}$ radicals (potentially depleting ozone molecules) to less reactive brominated species $\left(\mathrm{HOBr}, \mathrm{BrONO}_{2}, \mathrm{BrNO}_{2}\right)$ as explained in this section. In this case the ozone destruction rate decreases.

Overall, the analysis of these non-halogen fluxes measured in the field highlights the importance of HONO release for the development of an ozone depletion process. This study, however, showed only a moderate influence of HONO on the ozone chemistry. We encourage fieldworks recording HONO in particular, routinely in parallel with ozone mixing ratios and aerosol composition.

\subsection{Frost flower aerosols versus direct surface reaction}

It has been proposed that bromide accumulated on snow during the polar night may react heterogeneously at polar sunrise by photo-induced conversion to activate bromine (McConnell et al., 1992). Furthermore, laboratory (Ghosal et al., 2000, 2005) and molecular modeling studies of aqueous solutions (Jungwirth and Tobias, 2002) showed surface enrichment of $\mathrm{Br}^{-}$on frozen $\mathrm{NaCl}-\mathrm{NaBr}$ solutions and aqueous solutions. This effect might allow the direct release of $\mathrm{Br}_{2}$ and $\mathrm{BrCl}$ from FFs via Reactions (14), (18), or (19). Laboratory studies showed that the release of halogens can occur on frozen salts without the need of acidification (Adams et al., 2002). Contrarily, analysed FF samples showed no $\mathrm{Br}^{-}$fractionation over time in comparison with $\mathrm{Na}^{+}$(Simpson et al., 2005).

In order to test the effects of direct release of $\mathrm{Br}_{2}$ from FFs, we made an additional model run (run 19 - see Fig. 17) where we prescribe a flux of $\mathrm{Br}_{2}$ from the field of FFs (independent of the FF composition) but do not include the production of FF aerosols. The only source of sea salt aerosols in 

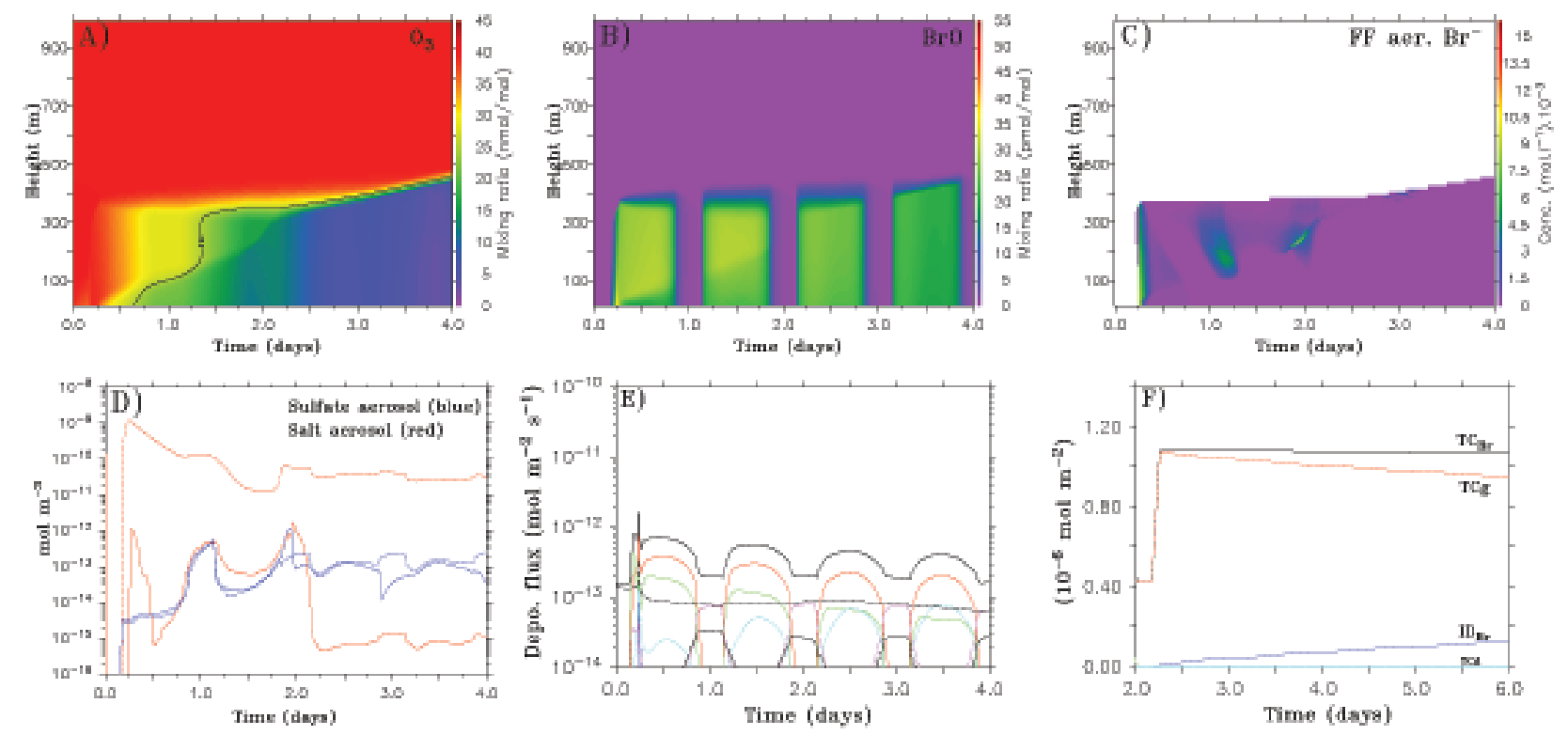

Fig. 17. Run 19. Direct release of $\mathrm{Br}_{2}$ instead of $\mathrm{FF}$ aerosol production. (A) and (B) gas phase $\mathrm{O}_{3}$ and $\mathrm{BrO},(\mathbf{C}) \mathrm{Br}^{-}$in sea salt aerosols, (D) comparison of $\mathrm{Br}^{-}$concentrations at an altitude of $250 \mathrm{~m}$, between this run (solid lines) and the base run (dashed lines) for both sulfate (blue) and sea salt (red) aerosols, (E) same as Fig. 2-K, (F) total bromine budget.

the model is from the open lead, which is passed for $10 \mathrm{~min}$ after the FF field (see Fig. 1).

In order to release enough bromine into the air to induce a MODE4 we had to prescribe a rather large flux of $\mathrm{Br}_{2}$ of $2.7 \times 10^{9}$ molec $\mathrm{cm}^{-2} \mathrm{~s}^{-1}$. Gas phase bromine rapidly spreads into the BL due to the convection over FFs and the open lead. Consequently, ozone (Fig. 17-A) is more homogeneously destroyed within the $\mathrm{BL}$ than in the base run. $\mathrm{BrO}$ mixing ratios have mean values of $20-30 \mathrm{pmol} \mathrm{mol}^{-1}$ during day (Fig. 17-B). We show a comparison of bromide concentration between this run (solid lines) and the base run (dashed lines) for both sulfate (blue lines) and sea salt (red lines) aerosols for a chosen altitude of $250 \mathrm{~m}$ in Fig. 17-D. It reveals equivalent concentrations of $\mathrm{Br}^{-}$in sulfate aerosols but a great difference in sea salt particles of two to five orders of magnitude compared to the base case: the bromine explosion occurring in freshly emitted sea salt particles provides only $0.1 \mathrm{pmol} \mathrm{mol}^{-1}$ of bromine atoms in the air (Fig. 17C). In the previous model runs the deposition/re-emission on snow represented an effective pathway for the liberation of bromide. In this configuration deposited bromide is negligible, so that deposition on snow mainly becomes a sink for bromine (see Fig. 17-B where the lowest layers are less concentrated in $\mathrm{BrO}$ than the upper layers).

$\mathrm{HOBr}$ governs the deposition during daytime without significant $\mathrm{Br}^{-}$sedimentation taking place (Fig. 17-E). $\mathrm{Br}_{2}$ and $\mathrm{CHBr}_{3}$ are the dominant deposited species at night. As these gaseous compounds have a much smaller deposition velocity than particulate $\mathrm{Br}^{-}$, the increase in $\mathrm{ID}_{\mathrm{Br}}$ is small and quasilinear (Fig. 17-F). $\mathrm{ID}_{\mathrm{Br}}$, is only a third of the corresponding value in the base run (see Fig. 2-L) $24 \mathrm{~h}$ after model start. Such a small deposition flux would require a 72-day constant accumulation on snow, without burial, to amount to the concentrations measured by Simpson et al. (2005), which is very unlikely.

This investigation demonstrates that emissions of $\mathrm{Br}_{2}$ in absence of sea salt particles can deplete ozone down to few nmol mol ${ }^{-1}$, but deposition on snow and aerosol chemical composition and mass concentration in this model run do not correspond to measurements made in the Arctic (Lehrer et al., 1997; Wagenbach et al., 1998). These results support the conclusions from Dominé et al. (2005), Simpson et al. (2005) and Kalnajs and Avallone (2006) that activation of bromide ions is unlikely to occur directly on frost flower crystals.

In an additional run, we simulated a direct release of $\mathrm{Br}_{2}$ from the frost flowers, but under oceanic influence (i.e. in the presence of sea salt particles - not shown). $\mathrm{The} \mathrm{Br}_{2}$ flux that is required to reproduce a MODE4 is $1.6 \times 10^{9}$ molec $\mathrm{cm}^{-2} \mathrm{~s}^{-1}$. Due to the rapid photodissociation of $\mathrm{Br}_{2}$ molecules, $\mathrm{Br}$ radicals are quickly available for reaction with ozone and for the bromine explosion cycle via production of $\mathrm{HOBr}$ and $\mathrm{BrONO}_{2}$. $\xi_{\mathrm{BrO}}$ has maximum values of $36 \mathrm{pmol} \mathrm{mol}^{-1}$. Note that, in this case, sea salt particles were emitted during the two days of spin-up and are therefore well mixed over the $\mathrm{BL}$ at the start of this run. $\mathrm{ID}_{\mathrm{Br}}$ is then weakly affected by the deposition of bromide contained in sea salt aerosols. Particles are completely debrominated within 36 hours. In this run, $\mathrm{ID}_{\mathrm{Br}}$ remains very similar to the deposition from run 19 , with the same problems when 
compared to the measurements of Simpson et al. (2005). However, direct reactions producing $\mathrm{Br}_{2}$ from FFs cannot be excluded on the sole basis of these model results and the suggestion from Simpson et al. (2005). Depending on the airmass chemical composition, they might take place and speed up the bromine explosion, but no measurement could yet confirm the presence of high bromine concentrations in the air over a FF field.

\section{Conclusions}

The impact of frost flowers, recycling on snow, and open leads on the chemistry of ozone in the Arctic was investigated. We used the one-dimensional model MISTRA in a Lagrangian mode with frost flower aerosols released to the air being the source of halogens. Again, we want to mention that any other source of salt aerosols produced from the brine in frost flower fields would have the same effects.

Our model studies on the influence of FFs on ozone in the PBL show the best agreement with observations if the recycling of halogens on snow is considered. Recycling on snow was found to be the most important process to sustain high bromine levels in the air in our model. A semiquantitative comparison with $\mathrm{Br}^{-}$in snow samples suggests that approximately $75 \%$ of deposited bromine may be reemitted into the gas phase as $\mathrm{Br}_{2} / \mathrm{BrCl}$. Additional studies on the role and the efficiency of the snowpack for the cycling of deposited bromine are needed to replace our assumption of a constant re-emission ratio with a description of the real physico-chemical processes.

Our model calculations showed that the precipitation of calcium carbonate out of the brine under background conditions is a key process which allows the more rapid acidification of aerosols originating from the FF/brine system. In our model runs, the bromine explosion in aerosols with complete $\mathrm{HCO}_{3}^{-}$precipitation leads to an ozone depletion consistent (in time) with field observations. However, the precipitation of only half of the $\mathrm{HCO}_{3}^{-}$as $\mathrm{CaCO}_{3}$ also showed an efficient ODE: the depletion process slowed down but ozone still decreased close to the MODE threshold. A stronger vertical gradient in $\mathrm{O}_{3}$ concentration was obtained in this case between air influenced by the snow $(0-100 \mathrm{~m})$ and air from above. Under conditions of no $\mathrm{HCO}_{3}^{-}$precipitation the particles not influenced by the surface do not undergo a debromination.

Under Arctic Haze conditions we noticed two important modifications: aerosols are substantially more acidic due to high mixing ratio of $\mathrm{SO}_{2}$; the increased total aerosol number concentration reinforces the bromine recycling through the aqueous phase. Our model results also showed that the presence of haze with $\mathrm{FF}$ aerosols containing $\mathrm{HCO}_{3}^{-}$leads to a similar ozone depletion as in the base run. Therefore, ODEs in the Arctic may not necessarily require the precipitation of
$\mathrm{HCO}_{3}^{-}$to take place. They may appear more frequently and more severe with haze events.

Assessing the influence of fluxes of non-halogen gases from the snow, our model simulations showed that only HONO contributed to a change in ozone/halogen chemistry. The model run without HONO flux from the snow showed the initiation of two opposing processes influencing the ozone depletion due to the reduction of mostly $\mathrm{HOBr}$ and $\mathrm{BrONO}_{2}$ concentrations. The aerosol debromination is less efficient, but the gas phase bromine (mostly re-emitted by the snow) speciation is shifted toward $\mathrm{Br}$ and $\mathrm{BrO}$, increasing the importance of the $\mathrm{BrO}$ self-reaction. The competition between the two processes enhances the ozone depletion during most of the run. During the last modeled day, the aerosol re-bromination leads to a slight slow-down of the ODE.

The consequences of changes in OL/FF combination were in general minor. The main noticeable modifications affected the aerosol compositions and deposition velocities. First, the presence of an open lead prior to the FF field induces an increase of the bromide deposition to the snow compared to the case where the OL is located after the FF field. Second, when FF aerosols are produced at night, the deposition of these aerosols corresponds to a shift from particulate bromine to either gas phase bromine (with recycling on snow) or to $\mathrm{ID}_{\mathrm{Br}}$ (without recycling). Note that, in the Lagrangian mode of our model studies, bromine is permanently lost to the snow if the model column passes the snow at nighttime and no recycling is assumed. In reality, of course, bromine deposited at night (and in the days and nights before) could be recycled on the next day after sunrise. Third, the extension from 2 to 10 hours for the presence of FFs (with patchy FF/OL/snow combinations - see Fig. 5) showed a comparable ozone depletion as in the base run, approaching a MODE4, while $\xi_{\mathrm{BrO}}$ did not exceed $38 \mathrm{pmol} \mathrm{mol}^{-1}$, compared to $48 \mathrm{pmol} \mathrm{mol}^{-1}$ for the base run.

Due to the humidity fluxes from the OL, the maximum aerosol liquid water content increases in our simulations with increasing OL size. If this increase is strong enough so that it leads to the formation of a cloud, the resulting increase in turbulence leads to the entrainment of $\mathrm{O}_{3}$ from the free troposphere into the boundary layer and stronger mixing within the BL. This mixing ends the ODE. However, this phenomenon has not yet been reported during field campaigns. In order to facilitate the interpretation of field data on ODEs, details on the presence and development of clouds should be reported.

Studies on the change of air temperature and FF temperature revealed that this meteorological parameter has an important impact on the aerosol composition and its deposition rate: a relatively warm FF field ( $260 \mathrm{~K}$, compared to $255 \mathrm{~K}$ for the base run) induces an increase in relative humidity, and therefore in the deposition/re-emission process. Consequently, more ozone is depleted. Under cold airmass conditions (air cooled by $1 \mathrm{~K}$ ), the aerosol uptake capacity substantially increases with a noticeable uptake of acids from the gas 
phase. Our model run showed an acceleration of the bromine explosion (thus, a decrease in $\mathrm{O}_{3}$ mixing ratios). We have to stress that the temperature dependencies of the uptake parameters that lead to these differences are estimates as found in the literature. They should be experimentally tested.

Our studies on the potential release of photolabile bromine directly from the frost flower crystals (instead of from FF aerosols) showed unrealistic results in comparison to field data: the $\mathrm{Br}_{2}$ flux from the FFs as unique source of bromine leads to too small deposition rates on snow and too small aerosol $\mathrm{Br}^{-}$content and therefore appears unlikely. This conclusion did not change when additionally considering sea salt aerosols in the PBL at the start of the run.

The parameterization of the FF aerosol source function presented in this work is probably the most important uncertainty in our model simulations, but it is based on the very likely assumption of a wind speed dependence and it is based on a comparison with field data for the resulting atmospheric bromine loadings. Without doubt, it has to be improved, based on laboratory experiments which should provide a source function for the FF aerosol production as a function of wind speed and particle size. Similarly, the thermodynamical behavior of ions from the brine migrating through the QLL of frost flowers is poorly known: the understanding of the precise multi-dimensional composition of frost flowers should be improved. In this paper we have assumed that aerosols produced from the FFs are liquid. However, solid (or partly solid) microbranches from those crystals may also break off under wind stress and be released in the air. For the source of concentrated aerosols, the differentiation between the brine layer on first-year sea ice and frost flowers should also be accurately investigated in future studies.

A snow sub-model will be developed in the near future in order to study the detailed interactions between snowpack and atmosphere.

Acknowledgements. We would like to thank B. Simpson for helpful discussions and for kindly providing us his data (Fig. 15). We especially thank S. Pechtl for proof reading. Also, thanks to D. Wagenbach, H.-W. Jacobi and F. Dominé for further discussions. This work was funded by the Deutsche Forschungsgemeinschaft (DFG) (Emmy Noether Junior Research group Marhal GL353/1,2).

Edited by: F. J. Dentener

\section{References}

Adams, J. W., Holmes, N. S., and Crowley, J. N.: Uptake and Reaction of $\mathrm{HOBr}$ on Frozen and dry Salt Surfaces, Atmos. Chem. Phys., 2, 79-91, 2002,

http://www.atmos-chem-phys.net/2/79/2002/.

Anderson, L. G. and Jones, E. P.: Measurements of total alkalinity, calcium and sulphate in natural sea ice, J. Geophys. Res., 90, 9194-9198, 1985.

Anlauf, K. G., Mickle, R. E., and Trivett, N. B. A.: Measurement of ozone during Polar Sunrise Experiment 1992, J. Geophys. Res., 99(D12), 25 345-25 354, doi:10.1029/94JD01312, 1994.

Argentini, S., Viola, A. P., Mastrantonio, G., Maurizi, A., Georgiadis, T., and Nardino, M.: Characteristics of the boundary layer at Ny-Ålesund in the Arctic during the ARTIST field experiment, Annals Geoph., 46, 185-195, 2003.

Barrie, L. A. and Hoff, R. M.: The oxidation rate and residence time of sulphur dioxide in the arctic atmosphere, Atmos. Environ., 18(12), 2711-2722, 1984.

Barrie, L. A., Bottenheim, J. W., Schnell, R. C., Crutzen, P. J., and Rasmussen, R. A.: Ozone destruction and photochemical reactions at polar sunrise in the lower Arctic atmosphere, Nature, 334, 138-141, doi:10.1038/334138a0, 1988.

Barrie, L. A., den Hartog, G., Bottenheim, J. W., and Landsberger, S.: Anthropogenic aerosols and gases in the lower troposphere at Alert, Canada in April 1986, J. Atmos. Chem., 9(1-3), 101-127, doi:10.1007/BF00052 827, 1989.

Barrie, L. A., Bottenheim, J. W., and Hart, W. R.: Polar Sunrise Experiment 1992 (PSE 1992): Preface, J. Geophys. Res., 99(D12), 25 313-25 314, doi:10.1029/94JD01 929, 1994.

Beine, J., Jaffe, D. A., Stordal, F., Engardt, M., Solberg, S., Schmidbauer, N., and Holmen, $\mathrm{K} .: \mathrm{NO}_{\mathrm{x}}$ during ozone depletion events in the arctic troposphere at $\mathrm{Ny}$-Ålesund, Svalbard, Tellus, 49B(5), 556-565, 1997.

Bischoff, J. L., Fitzpatrick, J. A., and Rosenbauer, R. J.: The solubility and stabilization of ikaite $\left(\mathrm{CaCO}_{3} \cdot 6 \mathrm{H}_{2} \mathrm{O}\right)$ from $0^{\circ}$ to $25^{\circ} \mathrm{C}$ : Environmental and paleoclimatic implications for thinolite tufa, J. Geol., 101, 21-33, 1993.

Bottenheim, J. W., Gallant, A. J., and Brice, K. A.: Measurements of $\mathrm{NO}_{y}$ species and $\mathrm{O}_{3}$ at $82^{\circ} \mathrm{N}$ latitude, Geophys. Res. Lett., 13(2), 113-116, 1986.

Bottenheim, J. W., Barrie, L. A., Atlas, E., Heidt, L. E., Niki, H., Rasmussen, R. A., and Shepson, P. B.: Depletion of lower tropospheric ozone during Arctic spring: The polar sunrise experiment 1988, J. Geophys. Res., 95, 18 555-18 568, 1990.

Bottenheim, J. W., Dibb, J. E., Honrath, R. E., and Shepson, P. B.: An introduction to the Alert 2000 and Summit 2000 Arctic research studies, Atmos. Environ., 36(15), 2467-2469, doi:10.1016/S1352-2310(02)00 135-8, 2002a.

Bottenheim, J. W., Fuentes, J. D., Tarasick, D. W., and Anlauf, K. G.: Ozone in the Arctic Lower Troposphere During Winter and Spring 2000 (ALERT2000), Atmos. Environ., 36, 25352544, $2002 b$.

Cho, H., Shepson, P. B., Barrie, L. A., Cowin, J. P., and Zaveri, R.: NMR investigation of the Quasi-Brine Layer in Ice/Brine Mixtures, J. Phys. Chem. B, 106, 11226-11232, doi:10.1021/jp020 449, 2002.

Cicerone, R. J., Heidt, L. E., and Pollack, W. H.: Measurements of atmospheric methyl-bromide and bromoform, J. Geophys. Res., 93(D4), 3745-3749, 1988. 
Covert, D. S. and Heintzenberg, J.: Size distributions and chemical properties of aerosol at Ny-Ålesund, Svalbard, Atmos. Environ., 27A(17/18), 2989-2997, 1993.

Curry, J. A.: Interactions among Turbulence, Radiation and Microphysics in Arctic Stratus Clouds, J. Atmos. Sci., 43(1), 90-106, 1986.

de Serves, C.: Gas phase formaldehyde and peroxide measurements in the Arctic atmosphere, J. Geophys. Res., 99(D12), 2539125 398, doi:10.1029/94JD00 547, 1994.

Dethleff, D.: Polynyas as a possible source for enigmatic Bennett Island atmospheric plumes, American Geophysical Union, Geophysical Monograph 85, 1994.

Dominé, F., Taillandier, A. S., Simpson, W. R., and Severin, K.: Specific surface area, density and microstructure of frost flowers, Geophys. Res. Lett., 32, L13502, doi:10.1029/2005GL023 245, 2005.

Drinkwater, M. R. and Crocker, G. B.: Modelling changes in the dielectric and scattering properties of young snow-covered sea ice at GHz frequencies, J. Glaciol., 34, 274-282, 1988.

Eigen, M. and Kustin, K.: The kinetics of halogen hydrolysis, J. Am. Chem. Soc., 84, 1355 - 1361, 1962.

Evans, M. J., Jacob, D. J., Atlas, E., Cantrell, C. A., Eisele, F., Flocke, F., Fried, A., Mauldin, R. L., Ridley, B. A., Wert, B., Walega, J., Weinheimer, A., Blake, D., Heikes, B., Snow, J., Talbot, R., and Dibb, J.: Coupled evolution of $\mathrm{BrO}_{\mathrm{x}}-\mathrm{ClO}_{\mathrm{X}}{ }^{-}$ $\mathrm{HO}_{\mathrm{x}}-\mathrm{NO}_{\mathrm{x}}$, chemistry during bromine-catalyzed ozone depletion events in the arctic boundary layer, J. Geophys. Res., 108(D4), doi:10.1029/2002JD002 732, 2003.

Fan, S.-M. and Jacob, D. J.: Surface ozone depletion in Arctic spring sustained by bromine reactions on aerosols, Nature, 359, 522-524, doi:10.1038/359522a0, 1992.

Fickert, S., Adams, J. W., and Crowley, J. N.: Activation of $\mathrm{Br}_{2}$ and $\mathrm{BrCl}$ via uptake of $\mathrm{HOBr}$ onto aqueous salt solutions, J. Geophys. Res., 104(D19), 23 719-23 727, doi:10.1029/1999JD900 359, 1999.

Foster, K. L., Plastridge, R. A., Bottenheim, J. W., Shepson, P. B., Finlayson-Pitts, B. J., and Spicer, C. W.: The Role of $\mathrm{Br}_{2}$ and $\mathrm{BrCl}$ in Surface Ozone Destruction at Polar Sunrise, Science, 291, 471-474, doi:10.1126/science.291.5503.471, 2001.

Frieß, U., Hollwedel, J., König-Langlo, G., Wagner, T., and Platt, U.: Dynamics and chemistry of tropospheric bromine explosion events in the Antarctic coastal region, J. Geophys. Res., 109, D06305, doi:10.1029/2003JD004 133, 2004.

Fuhrer, K., Hutterli, M., and McConnell, J. R.: Overview of recent field experiments for the study of the air-snow transfer of $\mathrm{H}_{2} \mathrm{O}_{2}$ and $\mathrm{HCHO}$, in: Chemical Exchange Between the Atmosphere and Polar Snow, edited by Springer-Verlag, N. Y., NATO ASI Series, Vol. 43, 1996.

Georgiadis, T., Bonafé, U., Calzolari, F., Nardino, M., Orsini, A., Pirazzini, R., Ravegnani, F., Sozzi, R., Trivellone, G., and Argentini, S.: Study of the surface energy balance at Ny-Ålesund, Svalbard, Conference Proceedings-Italian Physical Society, 69, 163-174, 2000.

Ghosal, S., Shbeeb, A., and Hemminger, J. C.: Surface Segregation of Bromine doped $\mathrm{NaCl}$ : Implications for the Seasonal Variations in Arctic Ozone, Geophys. Res. Lett., 27(13), 1879-1882, 2000.

Ghosal, S., Hemminger, J. C., Bluhm, H., Mun, B. S., Hebenstreit, E. L. D., Ketteler, G., Ogletree, D. F., Requejo, F. G., and
Salmeron, M.: Electron Spectroscopy of Aqueous Solution Interfaces Reveals Surface Enhancement of Halides, Science, 307, 563-566, 2005.

Gloersen, P. and Campbell, W. J.: Recent variations in Arctic and Antarctic sea-ice covers, Nature, 352, 33-36, doi:10.1038/352033a0, 1991.

Grannas, A. M., Jones, A. E., Dibb, J., Amman, M., Anastasio, C., Ariya, P., Beine, H. J., Bergin, M., Bottenheim, J., Boxe, C. S., Carver, G., Chen, G., Crawford, J. H., Dominé, F., Frey, M. M., Guzmán, M. I., Heard, D. E., Helmig, D., Hoffmann, M. R., Honrath, R. E., Huey, L. G., Hutterli, M., Jacobi, H.-W., Klán, P., McConnell, J., Sander, R., Savarino, J., Shepson, P. B., Simpson, W. R., Sodeau, J. R., von Glasow, R., Weller, R., Wolff, E., and Zhu, T.: An overview of snow photochemistry: evidence, mechanisms and impacts, Atmos. Chem. Phys., 7, 4329-4373, 2007, http://www.atmos-chem-phys.net/7/4329/2007/.

Hafskjold, B., Ikeshojit, T., and Ratkjes, S. K.: On the molecular mechanism of thermal diffusion in liquids, Mol. Phys., 80(6), 1389-1412, 1993.

Hansen, J. C., Li, Y., Francisco, J. S., and Li, Z.: On the Mechanism of the $\mathrm{BrO}+\mathrm{CH}_{2} \mathrm{O}$ Reaction, J. Phys. Chem. A, 103, 8543-8546, 1999.

Hartmann, J., Kottmeier, C., and Raasch, S.: Roll Vortices and Boundary Layer Development during a Cold Air Outbreak, Boundary-Layer Meteorology, 84(1), 45-65, doi:10.1023/A:1000392931 768, 1997.

Hartmann, J., Albers, F., Argentini, S., Borchert, A., Bonafé, U., Cohrs, W., Conidi, A., Freese, D., Georgiadis, T., Ippoliti, A., Kaleschke, L., Lüpkes, C., Maixner, U., Mastrantonio, G., Ravegnani, F., Reuter, A., Trivellone, G., and Viola, A.: Reports on Polar Research. Arctic Radiation and Turbulence Interaction Study (ARTIST), Alfred-Wegener-Institute for Polar and Marine Res., Bremerhaven, Germany, 1999.

Hausmann, M. and Platt, U.: Spectroscopic measurement of bromine oxide and ozone in the high Arctic during Polar Sunrise Experiment 1992, J. Geophys. Res., 99(D12), 25 399-25413, 10.1029/94JD01 314, 1994.

Herman, G. and Goody, R.: Formation and Persistence of Summertime Arctic Stratus Clouds, J. Atmos. Sci., 33, 1537-1553, 1976.

Hoff, R. M. and Trivett, N. B. A.: Ground-based measurements of Arctic haze made at Alert, N.W.T., Canada, during the Arctic Gas and Aerosol Sampling Project (AGASP), Geophys. Res. Lett., 11, 389-392, 1984.

Hoff, R. M., Leaitch, W. R., Fellin, P., and Barrie, L. A.: Mass Size Distributions of Chemical Constituents of the Winter Arctic Aerosol, J. Geophys. Res., 88, 10 947-10 956, 1983.

Hollwedel, J., Wenig, M., Beirle, S., Kraus, S., Kühl, S., WilmsGrabe, W., Platt, U., and Wagner, T.: Year-to-Year Variability of Polar Tropospheric BrO as seen by GOME, Adv. Space Res., 34, 804-808, 2004.

Hollwedel, J. C.: Observations of Tropospheric and Stratospheric Bromine Monoxide from Satellite, Ph.D. thesis, Universität Heidelberg, 2005.

Hönninger, G. and Platt, U.: Observations of BrO and its vertical distribution during surface ozone depletion at Alert, Atmos. Environ., 36, 2481-2489, 2002.

Hönninger, G., Leser, H., Sebastián, O., and Platt, U.: Groundbased measurements of halogen oxides at the Hudson Bay by 
longpath DOAS and passive MAX-DOAS, Geophys. Res. Lett., 31, L04111, doi:10.1029/2003GL018982, 2004.

Honrath, R. E., Peterson, M. C., Guo, S., Dibb, J. E., Shepson, P. B., and Campbell, B.: Evidence of $\mathrm{NO}_{\mathrm{x}}$ Production Within or Upon Ice Particles in the Greenland Snowpack, Geophys. Res. Lett., 26(6), 695-698, doi:10.1029/1999GL900077, 1999.

Honrath, R. E., Guo, S., Peterson, M. C., Dziobak, M. P., Dibb, J. E., and Arsenault, M. A.: Photochemical production of gas phase $\mathrm{NO}_{\mathrm{x}}$ from ice crystal $\mathrm{NO}_{3}^{-}$, J. Geophys. Res., 105(D19), 24 183-24 190, doi:10.1029/2000JD900361, 2000a.

Honrath, R. E., Peterson, M. C., Dziobak, M. P., Dibb, J. E., Arsenault, M. A., and Green, S. A.: Release of $\mathrm{NO}_{\mathrm{x}}$ from Sunlightirradiated Midlatitude Snow, Geophys. Res. Lett., 27(15), 22372240, doi:10.1029/1999GL011286, 2000b.

Hopper, J. F. and Hart, W.: Meteorological aspects of the 1992 Polar Sunrise Experiment, J. Geophys. Res., 99(D12), 25 315-25 328, doi:10.1029/94JD02400, 1994.

Hopper, J. F., Peters, B., Yokouchi, Y., Niki, H., Jobson, B. T., Shepson, P. B., and Muthuramu, K.: Chemical and meteorological observations at ice camp SWAN during Polar Sunrise Experiment 1992, J. Geophys. Res., 99 (D12), 25 489-25 498, doi:10.1029/94JD02 303, 1994.

Hopper, J. F., Barrie, L. A., Silis, A., Hart, W., Gallant, A. J., and Dryfhout, H.: Ozone and meteorology during the 1994 Polar Sunrise Experiment, J. Geophys. Res., 103(D1), 1481-1492, doi:10.1029/97JD02 888, 1998.

Hutterli, M. A., Röthlisberger, R., and Bales, R. C.: Atmosphereto-snow-to-firn transfer studies of HCHO at Summit, Greenland, Geophys. Res. Lett., 26, 1691-1694, 1999.

Hutterli, M. A., Connell, J. R. M., Stewart, R. W., Jacobi, H.-W., and Bales, R. C.: Impact of temperature-driven cycling of hydrogen peroxide $\left(\mathrm{H}_{2} \mathrm{O}_{2}\right)$ between air and snow on the planetary boundary layer, J. Geophys. Res., 106(D14), 15393-15 404, doi:10.1029/2001JD900 102, 2001.

Jacobi, H.-W., Frey, M. M., Hutterli, M. A., Bales, R. C., Schrems, O., Cullen, N. J., Steffen, K., and Koehler, C.: Measurements of hydrogen peroxide and formaldehyde exchange between the atmosphere and surface snow at Summit, Greenland, Atmos. Environ., 36, 2619-2628, doi:10.1016/S1352-2310(02)001061, 2002.

Jacobi, H.-W., Bales, R. C., Honrath, R. E., Peterson, M. C., Dibb, J. E., Swanson, A. L., and Albert, M. R.: Reactive trace gases measured in the interstitial air of surface snow at Summit, Greenland, Atmos. Environ., 38, 1687-1697, doi:10.1016/j.atmosenv.2004.01.004, 2004.

Jacobi, H.-W., Kaleschke, L., Richter, A., Rozanov, A., and Burrows, J. P.: Observation of a Fast Ozone Loss in the Marginal Ice Zone of the Arctic Ocean, J. Geophys. Res., 111, D15 309, doi:10.1029/2005JD006715, 2006.

Jobson, B. T., Niki, H., Yokouchi, Y., Bottenheim, J., Hopper, F., and Leaitch, R.: Measurements of $\mathrm{C}_{2}-\mathrm{C}_{6}$ hydrocarbons during the Polar Sunrise 1992 Experiment: Evidence for $\mathrm{Cl}$ atom and Br atom chemistry, J. Geophys. Res., 99(D12), 25 355-25 368, doi:10.1029/94JD01243, 1994.

Jones, A. E., Weller, R., Wolff, E. W., and Jacobi, H.-W.: Speciation and Rate of Photochemical $\mathrm{NO}$ and $\mathrm{NO}_{2}$ Production in Antarctic Snow, Geophys. Res. Lett., 27, 345-348, 2000.

Jones, A. E., Weller, R., Anderson, P. S., Jacobi, H.-W., Wolff, E. W., Schrems, O., and Miller, H.: Measurements of $\mathrm{NO}_{\mathrm{x}}$ emis- sions from the Antarctic snowpack, Geophys. Res. Lett., 28, 1499-1502, 2001.

Jungwirth, P. and Tobias, D. J.: Ions at the Air/Water Interface, J. Phys. Chem. B, 106, 6361-6373, 2002.

Kaleschke, L., Richter, A., Burrows, J., Afe, O., Heygster, G., Notholt, J., Rankin, A. M., Roscoe, H. K., Hollwedel, J., Wagner, T., and Jacobi, H.-W.: Frost flowers on sea ice as a source of sea salt and their influence on tropospheric halogen chemistry, Geophys. Res. Lett., 31, L16114, doi:10.1029/2004GL020655, 2004.

Kalnajs, L. E. and Avallone, L. M.: Frost flower influence on springtime boundary-layer ozone depletion events and atmospheric bromine levels, Geophys. Res. Lett., 33, L10810, doi:10.1029/2006GL025809, 2006.

Kempers, L. J. T. M.: A thermodynamic theory of the Soret effect in a multicomponent liquid, J. Chem. Phys., 90(11), 6541-6548, 1989.

Khalil, M. A. K. and Rasmussen, R. A.: Statistical analysis of trace gases in Arctic haze, Geophys. Res. Lett., 11(5), 437-440, 1984.

Kieser, B. N., Bottenheim, J. W., Sideris, T., and Niki, H.: Spring 1989 observations of lower tropospheric chemistry in the canadian high arctic, Atmos. Environ., 27A(17/18), 2979-2988, 1993.

King, J. C. and Turner, J.: Antarctic Meteorology and Climatology, Cambridge University Press, 1997.

Kirchner, U., Benter, T., and Schindler, R. N.: Experimental verification of gas phase bromine enrichment in reactions of $\mathrm{HOBr}$ with sea salt doped ice surfaces, Ber. Bunsenges. Phys. Chem., 101, 975-977, 1997.

Koop, T., Kapilashrami, A., Molina, L. T., and Molina, M. J.: Phase transitions of sea-salt/water mixtures at low temperatures: Implications for ozone chemistry in the polar marine boundary layer, J. Geophys. Res., 105(D21), 26393-26402, doi:10.1029/2000JD900 413, 2000.

Kreher, K., Johnston, P. V., Wood, S. W., Nardi, B., and Platt, U.: Ground-based measurements of tropospheric and stratospheric BrO at Arrival Heights, Antarctica, Geophys. Res. Lett., 24, 3021 - 3024, 1997.

Landgraf, J. and Crutzen, P.: An Efficient Method for 'On-Line' Calculations of Photolysis and Heating Rates, J. Atmos. Sci., 55, 863-878, 1998.

Langendörfer, U., Lehrer, E., Wagenbach, D., and Platt, U.: Observation of filterable bromine variabilities during Arctic tropospheric ozone depletion events in high (1 hour) time resolution, J. Atmos. Chem., 34, 39-54, 1999.

Le Bras, G. and Platt, U.: A possible mechanism for combined chlorine and bromine catalyzed destruction of tropospheric ozone in the Arctic, Geophys. Res. Lett., 22 (5), 599-602, 1995.

Leaitch, W. R., Barrie, L. A., Bottenheim, J. W., and Li, S. M.: Airborne observations related to ozone depletion at polar sunrise, J. Geophys. Res., 99(D12), 25 499-25 517, doi:10.1029/94JD02750, 1994.

Legagneux, L., Cabanes, A., and Dominé, F.: Measurement of the specific surface area of 176 snow samples using methane adsorption at 77K, J. Geophys. Res., 107(D17), 4335, doi:10.1029/2001JD001016, 2002.

Lehrer, E., Wagenbach, D., and Platt, U.: Aerosol chemical composition during tropospheric ozone depletion at Ny-Ålesund/Svalbard, Tellus, 49B(5), 486-495, 
doi:10.1034/j.1600-0889.49, 1997.

Lehrer, E., Hönninger, G., and Platt, U.: A one dimensional model study of the mechanism of halogen liberation and vertical transport in the polar troposphere, Atmos. Chem. Phys., 4, 24272440, 2004, http://www.atmos-chem-phys.net/4/2427/2004/.

Lelieveld, J. and Crutzen, P. J.: Influences of cloud photochemical processes on tropospheric ozone, Nature, 343, 227-233, 1990.

Li, S.-H. and Winchester, J. W.: Haze and Other Aerosol Components in Late Winter Arctic Alaska, 1986, J. Geophys. Res., 95(D2), 1797-1810, 1990.

Li, S.-M.: Equilibrium of particle nitrite with gas phase HONO: Tropospheric measurements in the high Arctic during polar sunrise, J. Geophys. Res., 99(D12), 25 469-25 478, 1994.

MacDowall, J.: Some observations at Halley Bay in seismology, glaciology and meteorology, Proc. Roy. Soc., 256, 149-192, 1960.

Marion, G. M.: Carbonate mineral solubility at low temperatures in the Na-K-Mg-Ca-H-Cl-SO $-\mathrm{OH}-\mathrm{HCO}_{3}-\mathrm{CO}_{3}-\mathrm{CO}_{2}-\mathrm{H}_{2} \mathrm{O}$ system, Geochim. Cosmochim. Acta, 65, 1883-1896, 2001.

Martin, S., Drucker, R., and Fort, M.: A laboratory study of frost flower growth on the surface of young sea-ice, J. Geophys. Res., 100 (C4), 7027-7036, doi:10.1029/94JC03 243, 1995.

Martinez, M., Arnold, T., and Perner, D.: The role of bromine and chlorine chemistry for arctic ozone depletion events in $\mathrm{Ny}$ Ålesund and comparison with model calculations, Ann. Geoph., 17, 941-956, 1999.

McConnell, J. C., Henderson, G. S., Barrie, L., Bottenheim, J., Niki, H., Langford, C. H., and Templeton, E. M. J.: Photochemical bromine production implicated in Arctic boundary-layer ozone depletion, Nature, 355, 150-152, 1992.

Michalowski, B. A., Francisco, J. S., Li, S.-M., Barrie, L. A., Bottenheim, J. W., and Shepson, P. B.: A computer model study of multiphase chemistry in the Arctic boundary layer during polar sunrise, J. Geophys. Res., 105(D12), 15 131-15 145, doi:10.1029/2000JD900004, 2000.

Mickle, R. E., Bottenheim, J. W., Leaitch, W. R., and Evans, W.: Boundary layer ozone depletion during AGASP-II, Atmos. Environ., 23(11), 2443-2449, 1989.

Mitchell, J. M. J.: Visual range in the polar regions with particular reference to the alaskan Arctic, J. Atm. Terr. Phys., Spec. Suppl., 1, 195-211, 1957.

Monahan, E. C., Spiel, D. E., and Davidson, K. L.: A model of marine aerosol generation via whitecaps and wave disruption, in: Oceanic Whitecaps, edited by: Monahan, E. C. and Niocaill, G. M., 167-174, D. Reidel, Norwell, Mass, 1986.

Moortgat, G. K., Meller, R., and Schneider, W.: Temperature dependence $(256-296 \mathrm{~K})$ of the absorption cross sections of bromoform in the wavelength range $285-360 \mathrm{~nm}$, in: Tropospheric Chemistry of Ozone in Polar Regions, NATO ASI Ser, Subser 1: Global Environmental Change, edited by Niki, H. and Becker, K. H., pp. 359-370, Springer Verlag, New York, 1993.

Morales Maqueda, M. A., Willmott, A. J., and Biggs, N. R. T.: Polynyas dynamics: A review of observations and modeling, Review of Geophysics, 42, 1-37, 2004.

Morin, S., Hoenninger, G., Staebler, R. M., and Bottenheim, J.: A high time resolution study of boundary layer ozone chemistry and dynamics over the Arctic ocean near Alert, Nunavut, Geophys. Res. Lett., 32, L08809, doi:10.1029/GL2004022098, 2005.
Mozurkewich, M.: Mechanisms for the release of halogens from sea-salt particles by free radical reactions, J. Geophys. Res., 100(D7), 14 199-14 207, doi:10.1029/94JD00358, 1995.

Oltmans, S. J.: Surface ozone measurements in clean air, J. Geophys. Res., 86, 1174-1180, 1981.

Oltmans, S. J. and Komhyr, W.: Surface ozone distributions and variations from 1973 - 1984 measurements at the NOAA Geophysical Monitoring for Climate Change Baseline observatories, J. Geophys. Res., 91(D4), 5229-5236, 1986.

Orlando, J. J., Ramacher, B., and Tyndall, G. S.: Upper Limits for the Rate Coefficients for Reactions of $\mathrm{BrO}$ with Formaldehyde and HBr, Geophys. Res. Lett., 27, 2633-2636, doi:10.1029/2000GL011725, 2000.

Oum, K. W., Lakin, M. J., and Finlayson-Pitts, B. J.: Bromine activation in the troposphere by the dark reaction of $\mathrm{O}_{3}$ with seawater ice, Geophys. Res. Lett., 25(21), 3923-3926, 1998.

Papadimitriou, S., Kennedy, H., Kattner, G., Dieckmann, G. S., and Thomas, D. N.: Experimental evidence for carbonate precipitation and $\mathrm{CO}_{2}$ degassing during sea ice formation, Geochim. Cosmochim. Acta, 68, 1749-1761, 2003.

Perovitch, D. K. and Richter-Menge, J. A.: Surface characteristics of lead ice, J. Geophys. Res., 99, 16341-16350, 1994.

Peterson, M. C. and Honrath, R. E.: Observations of Rapid Photochemical Destruction of Ozone in Snowpack Interstitial Air, Geophys. Res. Lett., 28(3), 511-514, doi:10.1029/2000GL012 129, 2001.

Platt, U.: DOAS-measurements during the ARCTOC campaigns 1995 and 1996 in Ny Ålesund/Svalbard, ARCTOC final report, 1997.

Platt, U. and Lehrer, E.: Arctic Tropospheric Ozone Chemistry, Tech. Rep. NO. EV5V-CT93-0318, ARCTOC, Final Report of the EU-Project, Heidelberg, 1996.

Pruppacher, H. R. and Klett, J. D.: Microphysics of Clouds and Precipitation, Kluwer Academic Pub., Dordrecht/Boston/London, 1997.

Ramacher, B., Rudolph, J., and Koppmann, R.: Hydrocarbon measurements during tropospheric ozone depletion events: Evidence for halogen atom chemistry, J. Geophys. Res., 104(C3), 36333653, doi:10.1029/1998JD100061, 1999.

Rankin, A. M., Auld, V., and Wolff, E. W.: Frost flowers as a source of fractionated sea salt aerosol in the polar regions, Geophys. Res. Lett., 27(21), 3469-3472, doi:10.1029/2000GL011771, 2000.

Rankin, A. M., Wolff, E. W., and Martin, S.: Frost flowers: Implications for tropospheric chemistry and ice core interpretation, J. Geophys. Res., 107, 4683, doi: 10.1029/2002JD002492, 2002.

Rasmussen, R. A. and Khalil, M. A. K.: Gaseous bromine in the arctic and arctic haze, Geophys. Res. Lett., 11(5), 433-436, 1984.

Richardson, C. and Keller, E. E.: The brine content of sea ice measured with a nuclear magnetic resonance spectrometer, J. Glaciol., 6, 89-100, 1966.

Richter, A., Wittrock, F., Eisinger, M., and Burrows, J. P.: GOME Observations of Tropospheric BrO in Northern Hemispheric Spring and Summer 1997, Geophys. Res. Lett., 25(14), 2683 2686, doi:10.1029/98GL52016, 1998.

Ridley, B. A., Walega, J., Montzka, D., Grahek, F., Atlas, E., Flocke, F., Stroud, V., Deary, J., Gallant, A., Boudries, H., Bottenheim, J., Anlauf, K., Worthy, D., Sumner, A. L., Splawn, B., and Shepson, P.: Is the Arctic Surface Layer a Source and Sink 
of $\mathrm{NO}_{\mathrm{x}}$ in Winter/Spring?, J. Atmos. Chem., 36, 1-22, 2000.

Ridley, B. A., Atlas, E. L., Montzka, D. D., Browell, E. V., Cantrell, C. A., Blake, D. R., Blake, N. J., Cinquini, L., Coffey, M. T., Emmons, L. K., Cohen, R. C., DeYoung, R. J., Dibb, J. E., Eisele, F. L., Flocke, F. M., Fried, A., Grahek, F. E., Grant, W. B., Hair, J. W., Hannigan, J., Heikes, B. J., Lefer, B. L., Mauldin, R. L., Moody, J. L., Shetter, R. E., Snow, J. A., Talbot, R. W., Thornton, J. A., Walega, J. G., Weinheimer, A. J., Wert, B. P., and Wimmers, A. J.: Ozone Depletion Events Observed in the High Latitude Surface Layer During the TOPSE Aircraft Program, J. Geophys. Res., 108(D4), doi:10.1029/2001JD001507, 2003.

Roscoe, H. K. and Roscoe, J.: Polar tropospheric ozone depletion events observed in the International Geophysical Year of 1958, Atmos. Chem. Phys., 6, 3303-3314, 2006,

http://www.atmos-chem-phys.net/6/3303/2006/.

Roscoe, H. K., Kreher, K., and Friess, U.: Ozone loss episodes in the free Antarctic troposphere, suggesting a possible climate feedback, Geophys. Res. Lett., 28, 2911-2914, 2001.

Sander, R., Vogt, R., Harris, G. W., and Crutzen, P. J.: Modeling the chemistry of ozone, halogen compounds, and hydrocarbons in the arctic troposphere during spring, Tellus, 49B(5), 522-532, 1997.

Sander, R., Rudich, Y., von Glasow, R., and Crutzen, P. J.: The role of $\mathrm{BrNO}_{3}$ in marine tropospheric chemistry: A model study, Geophys. Res. Lett., 26(18), 2857-2860, doi:10.1029/1999GL900478, 1999.

Sander, R., Burrows, J., and Kaleschke, L.: Carbonate precipitation in brine - a potential trigger for tropospheric ozone depletion events, Atmos. Chem. Phys., 6, 4653-4658, 2006, http://www.atmos-chem-phys.net/6/4653/2006/.

Saw, G. E.: Microparticle size spectrum of Arctic haze, Geophys. Res. Lett., 11(5), 409-412, 1984.

Schnell, R. C.: Arctic haze and the Arctic Gas and Aerosol Sampling Program (AGASP), Geophys. Res. Lett., 11, 361-364, 1983.

Serreze, M. C. and Barry, R. G.: The Arctic Climate System, Cambridge University Press, 2005.

Simpson, W. R., Alvarez-Aviles, L., Douglas, T. A., Sturm, M., and Dominé, F.: Halogens in the coastal snow pack near Barrow, Alaska: Evidence for active bromine air-snow chemistry during springtime, Geophys. Res. Lett., 32, L04811, doi:10.1029/2004GL021748, 2005.

Simpson, W. R., Carlson, D., Hönninger, G., Douglas, T. A., Sturm, M., Perovich, D., and Platt, U.: First-year sea-ice contact predicts bromine monoxide $(\mathrm{BrO})$ levels at Barrow, Alaska better than potential frost flower contact, Atmos. Chem. Phys., 7, 621-627, 2007a.

Simpson, W. R., von Glasow, R., Riedel, K., Anderson, P., Ariya, P., Bottenheim, J., Burrows, J., Carpenter, L., Frie, U., Goodsite, M. E., Heard, D., Hutterli, M., Jacobi, H.-W., Kaleschke, L., Neff, B., Plane, J., Platt, U., Richter, A., Roscoe, H., Sander, R., Shepson, P., Sodeau, J., Steffen, A., Wagner, T., and Wolff, E.: Halogens and their role in polar boundary-layer ozone depletion, Atmos. Chem. Phys., 7, 4375-4418, 2007b.

Snow, J. A., Heikes, B. G., Merrill, J. T., Wimmers, A. J., Moody, J. L., and Cantrell, C. A.: Winter-spring evolution and variability of $\mathrm{HO}_{\mathrm{x}}$ reservoir species, hydrogen peroxide and methyl hydroperoxide, in the northern mid to high-latitudes, J. Geophys. Res., 108(D4), doi:10.1029/2002JD002172, 2002.
Spicer, C. W., Plastridge, R. A., Foster, K. L., Finlayson-Pitts, B. J., Bottenheim, J. W., Grannas, A. M., and Shepson, P. B.: Molecular halogens before and during ozone depletion events in the Arctic at polar sunrise: concentrations and sources, Atmos. Environ., 36(15-16), 2721-2731, doi:10.1016/S1352-2310(02)00125-5, 2002.

Staebler, R. M., den Hartog, G., Georgi, B., and Düsterdiek, T.: Aerosol size distributions in Arctic haze during the Polar Sunrise Experiment 1992, J. Geophys. Res., 99(D12), 25 429-25 437, 1994.

Stroud, C., Madronich, S., Atlas, E., Ridley, B., Flocke, F., Weinheimer, A., Talbot, B., Fried, A., Wert, B., Shetter, R., Lefer, B., Coffey, M., Heikes, B., and Blake, D.: Photochemistry in the arctic free troposphere: $\mathrm{NO}_{\mathrm{x}}$ budget and the role of odd nitrogen reservoir recycling, Atmos. Environ., 37(24), 3351-3364, doi:10.1016/S1352-2310(03)00353-4, 2003.

Strunin, M. A., Postnov, A. A., and Mezrin, M. Y.: Meteorological potential for contamination of arctic troposphere: Boundary layer structure and turbulent diffusion characteristics, Atmos. Res., 44, 37-51, 1997.

Sturges, W. T., Cota, G. F., and Buckley, P. T.: Bromoform emission from Arctic ice algae, Nature, 358, 660-662, doi:10.1038/358660a0, 1992.

Sumner, A. L. and Shepson, P. B.: Snowpack production of formaldehyde and its effect on the Arctic troposphere, Nature, 398(6724), 230-233, doi:10.1038/18423, 1999.

Swanson, A. L., Blake, N. J., Dibb, J. E., Albert, M. R., Blake, D. R., and Rowland, F. S.: Photochemically induced production of $\mathrm{CH}_{3} \mathrm{Br}, \mathrm{CH}_{3} \mathrm{I}, \mathrm{C}_{2} \mathrm{H}_{5} \mathrm{I}$, ethene, and propene within surface snow at Summit, Greenland, Atmos. Environ., 36(15), 26712682, doi:10.1016/S1352-2310(02)00 127-9, 2002.

Tang, T. and McConnell, J. C.: Autocatalytic release of bromine from Arctic snow pack during polar sunrise, Geophys. Res. Lett., 23(19), 2633-2636, doi:10.1029/96GL02572, 1996.

Tarasick, D. W. and Bottenheim, J. W.: Surface Ozone Depletion Episodes in the Arctic and Antarctic from Historical Ozonesonde Records, Atmos. Chem. Phys., 2(3), 197-205, 2002.

Tuckermann, M., Ackermann, R., Gölz, C., Lorenzen-Schmidt, H., Senne, T., Stutz, J., Trost, B., Unold, W., and Platt, U.: DOAS-observation of halogen radical-catalysed arctic boundary layer ozone destruction during the ARCTOC-campaigns 1995 and 1996 in Ny-Ålesund, Spitsbergen, Tellus, 49B(5), 533-555, doi:10.1034/j.1600-0889.49, 1997.

Vogt, R., Crutzen, P. J., and Sander, R.: A mechanism for halogen release from sea-salt aerosol in the remote marine boundary layer, Nature, 383, 327-330, doi:10.1038/383327a0, 1996.

von Glasow, R. and Crutzen, P. J.: Model study of multiphase DMS oxidation with a focus on halogens, Atmos. Chem. Phys., 4, 589608, 2004,

http://www.atmos-chem-phys.net/4/589/2004/.

von Glasow, R. and Sander, R.: Variation of sea salt aerosol $\mathrm{pH}$ with relative humidity, Geophys. Res. Lett., 28, 247-250, 2001.

von Glasow, R., Sander, R., Bott, A., and Crutzen, P. J.: Modeling halogen chemistry in the marine boundary layer. 2. Interactions with sulfur and cloud-covered MBL, J. Geophys. Res., 107 (D17), 4323, doi:10.1029/2001JD000 943, 2002a.

von Glasow, R., Sander, R., Bott, A., and Crutzen, P. J.: Modeling halogen chemistry in the marine boundary layer 1. Cloud-free MBL, J. Geophys. Res., 107(D17), 4341, 
doi:10.1029/2001JD000942, 2002b.

Wagenbach, D., Ducroz, F., Mulvaney, R., Keck, L., Minikin, A., Legrand, M., Hall, J. S., and Wolff, E. W.: Sea-salt aerosol in coastal Antarctic regions, J. Geophys. Res., 103, 10 961-10 974, 1998.

Wagner, T. and Platt, U.: Observation of Tropospheric BrO from the GOME satellite, Nature, 395, 486-490, 1998.

Wagner, T., Leue, C., Wenig, M., Pfeilsticker, K., and Platt, U.: Spatial and temporal distribution of enhanced boundary layer $\mathrm{BrO}$ concentrations measured by the GOME instrument aboard ERS2, J. Geophys. Res., 106, 24 225-24 235, 2001.

Wolff, E. W., Jones, A. E., Martin, T. J., and Grenfell, T. C.: Modelling photochemical $\mathrm{NO}_{\mathrm{x}}$ production and nitrate loss in the upper snowpack of Antarctica, Geophys. Res. Lett., 29, 1944, doi:10.1029/2002GL015 823,, 2002.
Worthy, D. E. J., Trivett, N. B. A., Hopper, J. F., and Bottenheim, J.: Analysis of long-range transport events at Alert, Northwest Territories, during the Polar Sunrise Experiment, J. Geophys. Res., 99(D12), 25 329-25 344, doi:10.1029/94JD01209, 1994.

Zhang, K. J., Briggs, M. E., Gammon, R. W., and Sengers, J. V.: Optical measurement of the Soret coefficient and the diffusion coefficient of liquid mixtures, J. Chem. Phys., 104(17), 68816892, 1996.

Zhou, X., Beine, H. J., Honrath, R. E., Fuentes, J. D., Simpson, W., Shepson, P. B., and Bottenheim, J. W.: Snowpack Photochemical production of HONO: A Major Source of $\mathrm{OH}$ in the Arctic Boundary Layer in Springtime, Geophys. Res. Lett., 28(21), 4087-4090, doi:10.1029/2001GL013 531, 2001. 